\title{
WestVirginiaUniversity
}

THE RESEARCH REPOSITORY @ WVU

Graduate Theses, Dissertations, and Problem Reports

2003

\section{National survey of psychological practices across rural and urban communities}

Craig M. Helbok

West Virginia University

Follow this and additional works at: https://researchrepository.wvu.edu/etd

\section{Recommended Citation}

Helbok, Craig M., "National survey of psychological practices across rural and urban communities" (2003). Graduate Theses, Dissertations, and Problem Reports. 1922.

https://researchrepository.wvu.edu/etd/1922

This Dissertation is protected by copyright and/or related rights. It has been brought to you by the The Research Repository @WVU with permission from the rights-holder(s). You are free to use this Dissertation in any way that is permitted by the copyright and related rights legislation that applies to your use. For other uses you must obtain permission from the rights-holder(s) directly, unless additional rights are indicated by a Creative Commons license in the record and/ or on the work itself. This Dissertation has been accepted for inclusion in WVU Graduate Theses, Dissertations, and Problem Reports collection by an authorized administrator of The Research Repository @ WVU.

For more information, please contact researchrepository@mail.wvu.edu. 
NATIONAL SURVEY OF PSYCHOLOGICAL PRACTICES

ACROSS RURAL AND URBAN COMMUNITIES

Craig M. Helbok

\author{
Dissertation submitted to \\ the College of Human Resources and Education \\ at West Virginia University \\ in partial fulfillment of the requirements for the degree of \\ Doctor of Philosophy \\ in \\ Counseling Psychology
}

Robert P. Marinelli, Ed.D., Chairperson

Donald E. Eggerth, Ph.D.

David J. Srebalus, Ed.D.

Roy H. Tunick, Ed.D.

Richard T. Walls, Ph.D.

Department of Counseling, Rehabilitation Counseling, and Counseling Psychology

Morgantown, West Virginia

2003

Keywords: Rural, National Survey, Ethics, Psychological Practices

Copyright 2004 Craig M. Helbok 


\section{ABSTRACT \\ National Survey of Psychological Practices \\ Across Rural and Urban Communities}

Craig M. Helbok

The purpose of this study was to examine potential differences in the practice of psychology across urban and rural communities. The review of the rural literature suggests that psychologists in rural areas are likely to encounter numerous ethical dilemmas and problems that are related specifically to the characteristics of such communities. To date, however, much of this literature has been based on theory and the individual experiences of practitioners. This study sought to quantify any differences in the practice of psychology across communities for such ethical issues as multiple relationships, competency, burnout, confidentiality, and visibility in the community. A survey instrument was created based on previous surveys of ethical practices. A national sample of 1000 psychologists, stratified into urban and non-urban practitioners, was obtained from the American Psychological Association. After several mailings 447 usable surveys were returned. Data analysis revealed significant differences between urban/suburban and small town/rural groups, particularly for the dependent variables of multiple relationships and visibility. Significant differences were found across gender such that male psychologists are more likely than female psychologists to engage in a range of multiple relationship behaviors, and female psychologists are significantly more likely to make use of support from supervisors, colleagues, family and friends. Psychologists in private practice are significantly more likely than those in institutional settings to engage in multiple relationships, to find their work satisfying and rewarding, and to have control over their work environment; whereas practitioners in institutional settings are more likely to have support from colleagues and supervisors, and to work when too distressed to be effective. Psychologists with more experience are significantly more likely to engage in multiple relationship behaviors than those with less experience. Psychologists with a psychodynamic orientation are more likely to make use of supervision and to discuss case work with colleagues than other orientations. The most common concern listed, across community type and gender, is a lack of alternative referral sources. Results from this survey are compared to previous surveys of ethical practices. Qualitative results are categorized and discussed. Suggestions are made for future research based on these findings. 
This work is lovingly dedicated to my parents,

Ronald Roland and Eleanor Marie Helbok;

and to my children,

Allora Michelle and Sebastian Christopher. 


\section{ACKNOWLEDGEMENTS}

I am grateful to my advisor, Robert P. Marinelli, Ed.D. for his guidance in organizing the final document. I am also indebted to Dr. Marinelli for his advice, editing, and support throughout the entire development of this project. I would like to thank Richard T. Walls for his guidance and editing particularly with the research design and data analysis. I am grateful to Donald E.

Eggerth, Ph.D., for his service as a committee member, and his mentoring and support over the course of my graduate studies. I am thankful to David J. Srebalus, Ed.D. and Roy H. Tunick, Ed.D., for their feedback and service as committee members on this project. I would also like to thank Dr. Parke and my survey methods classmates for their timely feedback in the development of the survey instrument. I am thankful to those who took the time to serve as expert/respondents by taking this survey and offering feedback during its development. I appreciate the psychologists who participated in this survey for their investment of time, the sharing of their personal experiences, and the words of encouragement. 


\section{TABLE OF CONTENTS}

Abstract

ii

Dedication

iii

Acknowledgements

iv

Table of Contents

.. $\mathrm{V}$

List of Tables

viii

\section{CHAPTER I}

Introduction and Review of the Literature............................................. 1

Defining Ethical Dilemmas and Problems....................................1

Nonsexual Dual Relationships ..................................................

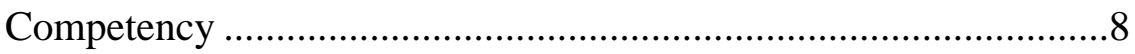

Burnout .......................................................................... 14

Confidentiality ................................................................ 19

Surveys of Ethical Practices..........................................................22

Review of the Literature in Rural Ethics ............................................29

Characteristics of Rural Communities .....................................29

Multiple Relationships ........................................................33

The core ethical issues ..................................................33

Decision-making models to resolve multiple relationship ethical dilemmas .........................................35

Confidentiality ................................................................ 40

Competency …...............................................................43

Visibility ...................................................................... 47

Statement of the Problem..................................................................51 


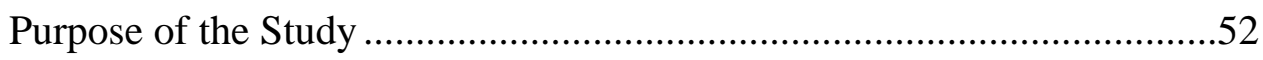

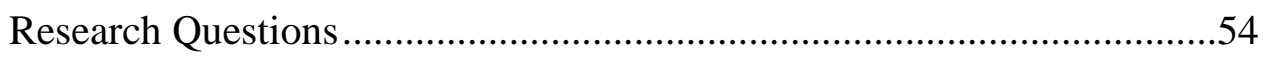

\section{CHAPTER II}

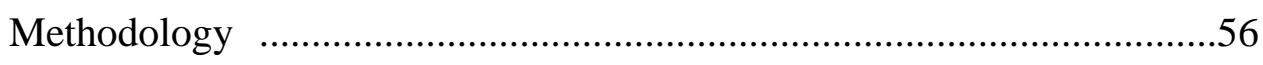

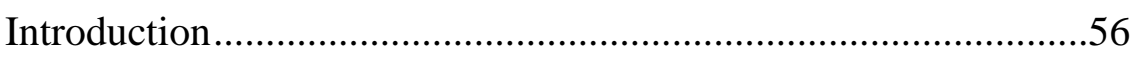

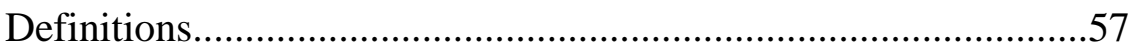

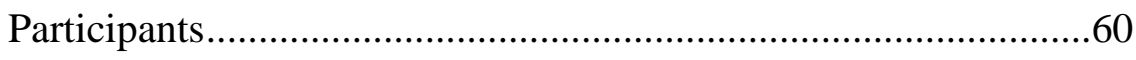

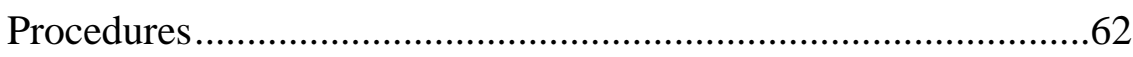

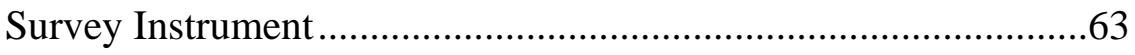

Research Design and Analysis.......................................................67

\section{CHAPTER III}

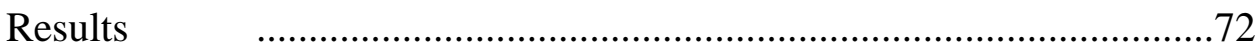

Sample Characteristics..................................................................72

Reliability Checks .........................................................................

Primary Research Questions ..........................................................79

Type of Community ...........................................................89

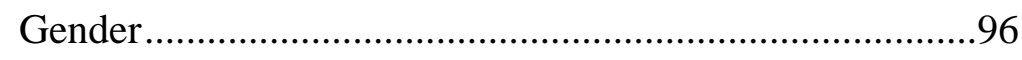

Work Setting .......................................................................100

Years of Experience ..........................................................106

Theoretical Orientation .....................................................109

CHAPTER IV

Summary, Discussion, and Limitations of the study …………................119

Summary of the Study ................................................................119 
Review of the literature........................................................119

Research methodology and questions ...............................124

Discussion and Implications of Research Findings ......................126

Research question \#1 …......................................................126

Research question \#2 ………...........................................131

Research question \#3 …………………………………....133

Research question \#4 …………………............................137

Research question \#5 …………………………………....138

Comparisons of this Survey with Previous Surveys and Emerging Patterns ..............................................................139

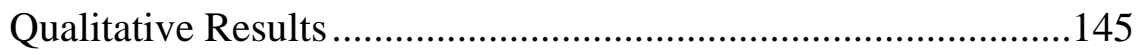

Comments on the survey.......................................................145

Multiple relationships ......................................................148

Competency issues...........................................................151

Defining rural communities and communities

within communities...........................................................152

Miscellaneous comments ..................................................154

Clarifications of questions and responses .........................155

Limitations and Future Research ...................................................156

Concluding Remark ........................................................164

REFERENCES

APPENDIX A

APPENDIX B 


\section{LIST OF TABLES}

Table 1 - Demographic Data by Urban/Suburban and

Small town/Rural Categories - Personal Data..................................75

Table 2 - Demographic Data by Urban/Suburban and

Small town/Rural Categories - Work/Education..............................76

Table 3 - Percentage of Responses for Each Survey Question

Across Urban and Small Town Categories.

Table 4 - Community - Significantly Different ANOVA Results

for Multiple Relationship Questions....

Table 5 - Community - Significantly Different ANOVA Results

for Visibility Questions.

Table 6 - Community - Remainder of Significantly Different ANOVA

Results for Questions by Category

Table 7 - Gender - Significantly Different ANOVA Results for

Multiple Relationship Questions

Table 8 - Gender - Significantly Different ANOVA Results for

Burnout Questions

Table 9 - Work Setting - Significantly Different ANOVA Results for Multiple Relationship Questions

Table 10 - Work Setting - Significantly Different ANOVA Results for Competency Questions

Table 11 - Work Setting - Significantly Different ANOVA Results for Burnout Questions

Table 12 - Years Experience - Significantly Different ANOVA Results for Multiple Relationship Questions....

Table 13 - Highest Rated Concerns by Community - Urban/Suburban

Table 14 - Highest Rated Concerns by Community - Small town/Rural .115

Table 15 - Highest Rated Concerns by Gender - Female

Table 16 - Highest Rated Concerns by Gender - Male 


\section{CHAPTER I}

Introduction and Review of the Literature

\section{Defining Ethical Dilemmas and Problems}

The purpose of this study is to examine potential differences in ethical practices across rural and urban areas. The study of ethics has generally been under the domain of philosophy and deals with the evaluation of moral behaviors and judgements. Ethics change over time and contexts, though some may be considered universal. In this paper we will be concerned with ethical practices of psychologists as they relate to the current ethical codes (APA, 1992, 2002). Ethical codes were not initially written to guide the day-to-day behavior of psychologists, they were written as lofty aspirations to guide personal and professional growth (Gottlieb, 1994). We will see throughout this review that there is still a great deal of debate about what should constitute an ethical standard, a moral behavior, or simply be considered good practice. Generally the standards of good practice are much higher than basic ethical standards (Pope, Tabachnick, and Keith-Speigel, 1988). Some behaviors may be considered poor practice by many, but not necessarily unethical. This study will examine whether there are differences between ethical ideals and actual practice and try to identify barriers to achieving ideals.

Ethical codes and standards are constantly evolving documents. Psychologists need to study actual ethical behaviors to inform the ongoing development of ethical codes, as well as inform the training of new psychologists. Examples of practices that have been considered unethical at one time, then ethical, include certain multiple relationships and bartering. We need to examine those "gray" areas of ethical standards and practice in order to create honest discussion of what behaviors should be prohibited in the ethical codes. In this time of litigation, malpractice suits, and license revocations it is important that the field reach some consensus in defining the ethical 
practice of psychology. Additionally, some psychologists are coming to believe that ethical decision-making and clinical judgements are closely related and influence each other, such that the study of ethical practices should also inform clinical practices (Gottlieb, 1994). Finally, some have argued that ethical codes are no longer living up to their purpose of promoting client welfare, but rather have become more concerned with protecting psychologists, and hence more rigid and possibly too conservative in their proscriptions (Tubbs \& Pomerantz, 2001)

This study will not examine all aspects of ethical practices of urban and rural psychologists. Instead, the author has chosen those areas that are cited most often in the literature by psychologists as their primary ethical concerns. These areas include multiple relationships, competency, burnout, and confidentiality. Gross and Robinson (1987) identify core ethical practices for counselors when considering client welfare which include: avoiding dual relationships that might impair professional judgement; being cognizant of situations in which conflicts of interest can jeopardize client welfare; insuring confidentiality and informed choice; and making financial arrangements in accord with professional standards. Although this was addressed to counselors, these seem to be the same core ethical principles about which psychologists are concerned. The authors also point out that it is not just client welfare we need to consider in ethical decision-making, but also society, the agencies for which we work, referral agencies, colleagues and other professionals, state statutes, professional boards and other institutions. A secondary goal of this study is to validate the complexity of ethical decisionmaking for individual clinicians as well as inform the process of creating ethical codes.

The first section of chapter one is an introduction to general ethical issues and definitions of specific problems and dilemmas. Each of the aforementioned areas will be defined, and recent research pertinent to that area discussed. A review of other survey-based research concerning 
ethics is discussed next. The second section is devoted to a review of the literature specific to the practice of psychology in rural areas, and the ensuing ethical dilemmas. The statement of the problem and purpose of the study, including research hypotheses follow the review of rural literature. The study itself addresses the main question of whether practicing psychology in rural areas leads to more, or unique, ethical dilemmas that distinguish it from urban-based psychological practice. The second chapter describes the methods, population, and survey instrument. The third chapter presents the results with some discussion. The fourth chapter contains the comparison with previous surveys, the qualitative results, a summary and implications of the study, along with limitations and suggestions for future research. Nonsexual Dual Relationships

A nonsexual dual relationship (NSDR, or 'multiple relationship') is one in which the therapist becomes involved in another relationship with his or her client that is different than the therapeutic relationship. The second relationship may be social, professional, or financial. The therapeutic and secondary relationships may be concurrent or consecutive (Pope, 1991; Smith \& Fitzpatrick, 1995; Sonne, 1994). Pope and Vetter (1992) found that dual relationships are the second most troubling ethical problem reported by psychologists. The current study will focus only on nonsexual relationships as there appears to be adequate research demonstrating the harmful effects of sexual relationships, as well as general agreement that sexual relationships with clients should be avoided. Additionally, Epstein and Simon (1990) state that "less extreme forms of exploitation, such as excessive familiarity, seductiveness, nonclinical business dealings and breaches of confidentiality are much more common than overt sexual activitiy” (p. 450). In addition to relationships outside of the therapy session, NSDR's may include hugging the client, 
disclosing personal feelings to the client, lending books to clients, and other in session behaviors (Williams, 1997).

In the area of NSDR there is still much ambiguity in the ethical codes, and debate among clinicians as to which behaviors constitute a dual relationship. The ethical codes fail to specify the conditions in which relationships and contacts outside of the therapeutic relationship are harmful, benign, or actually beneficial (Smith \& Fitzpatrick, 1995). It does appear that a NSDR will risk impairment of the therapist's objectivity and possibly lead to exploitation of the client. Borys and Pope (1989) found that dual relationships form the major basis of financial losses in malpractice suits and ethics complaints against psychologists. However, there may be times when dual relationships cannot be avoided. It appears that psychologists may be afraid to discuss those cases where dual relationships are hard to avoid for fear of censure by their peers. Anderson and Kitchner (1996) point out that little, if any, systematic research has been conducted on the impact and prevalence of NSDR. Their critical incident research revealed eight general categories of NSDR that psychologists engage in along with the therapeutic relationship, including personal/friendship, social interactions/events, business, collegial/professional, supervisory, religious involvement, collegial and social, and workplace relationships.

A dual or multiple relationship does not appear to be a discrete entity, but rather a continuum of behaviors. Psychologist beliefs about these behaviors also fall along a continuum. At one extreme of the continuum are those that feel any self-disclosure on the part of the therapist constitutes a dual relationship. Others may argue that self-disclosure is beneficial at times, and puts the therapeutic relationship on a more even footing. Regardless of their beliefs about the ethics of self-disclosure, surveys do show that most psychologists tend to use self-disclosure 
with some clients (Pope, Tabachnick, \& Keith-Spiegel, 1987)). At the other end of the continuum, some may argue that going with a client to dinner contributes to therapeutic progress (Lazarus, 1994) although few psychologists are likely to engage in this activity.

One way of conceptualizing what constitutes a dual relationship is in terms of the therapeutic frame and boundaries. Gordon (1993) defines the therapeutic frame in terms of the rule of neutrality (guarding against the therapists own feelings coming into the relationship) and the rule of abstinence (the therapist refraining from inappropriately using the therapeutic relationship to gratify their own, or the client's, needs). The frame is seen as vital to the client being able to work through problems and have trust in the relationship. From this perspective, self-disclosure is seen as rarely helpful, and frequently more harmful than most therapists believe (Gordon, 1993). Smith and Fitzpatrick (1995) define the therapeutic frame in terms of the roles of client and therapist. The roles are further defined in terms of structural elements (time, place, money), and content elements (the process of therapy), though other authors define the frame with different characteristics of these roles. Defining these roles and “establishing clear boundaries about what is and is not acceptable within the therapeutic context sets a standard for unambiguous communication between therapist and client” (p. 500). However, these same authors also point out that even clearly delineated boundaries are regularly transgressed by very competent therapists.

Borys (1994) states that the therapeutic frame is important because of the emotional issues that are manifested and worked through in the therapeutic relationship. She states that clear consistent boundaries provide a safety and structure for clients that may be curative in itself. Any alterations or departure from the therapist-client roles may lead to a range of possible negative reactions by the client, as well as lead to therapist actions that are based on self- 
gratification rather than client well-being. Johnston and Farber (1996) list as consequences of poor boundary management the communication of therapist's conflicts to the patient, contamination of the transference, dissolution of the therapeutic holding environment (or frame), and the possibility of inappropriate gratification from the contertransference. Several authors point out that maintaining clear boundaries does not imply that the therapist must be cold and distant, that a secure frame can include a therapist who is warm, empathic, and sincere (Borys, 1994; Gutheil, 1994).

Gutheil and Gabbard (1993) distinguish between boundary crossings and boundary violations. A boundary crossing is when the therapist has a contact with the client that crosses the acceptable standard of a therapeutic boundary or practice. For example, self-disclosure may be a boundary crossing, but the therapist may have a legitimate rationale to make that crossing. This conceptualization recognizes that not all boundary crossings are harmful to the client, and may in fact be beneficial to the client. An incidental encounter such as meeting in the community would also be considered a boundary crossing. For some clients such a meeting may have negligible effects, for others it may involve role reversal and role strain (seeing the idealized therapist in another role) and will need to be processed in the therapeutic relationship (Pope \& Vetter, 1992; Sharkin \& Birky, 1992). A boundary violation, on the other hand, involves a boundary crossing that places the client at risk. The issue is complicated by the fact that psychologists differ as to what they think will place a client at risk, and what constitutes a violation. For example, a therapist trained in the 1970's within a humanistic orientation may believe that hugging a client is appropriate, while a psychodynamic therapist may believe it is unethical, poor practice, or a dual relationship for the patient and therapist to address each other by their first names. 
Johnston and Farber (1996) point out that therapy often requires a partial dissolution of the separation between the therapist and patient, and that this boundary crossing can be threatening to both participants. They cite research to show that clients consider incidents where the therapist stepped outside of their role, and therapeutic frame, by expressing spontaneous care or concern, to be the most critical aspect of the therapy. The results of their survey also suggest that therapists are much more flexible in relation to the establishment and maintenance of therapeutic boundaries than is generally assumed in the literature. Gordon (1993) asserts that some boundary crossings are beneficial for the client, though it is important for the therapist to be aware of their decision-making process, and their own values, needs, beliefs, and limitations. Williams (1997) argues we may be too defensive in our risk management, that such a defensive position ignores all those who may be helped by boundary crossings such as self-disclosure, and that therapists may become less human, and less effective, by avoiding any behavior that hints at a dual relationship. Lazarus (1994), who tends toward the liberal extreme in allowing dual relationships, states that therapists who are too rigid and inflexible will "offend, or at the very least, fail to help people who might otherwise have benefited from their ministrations” (p. 257). McRay, McMinn and Meek (1998) question the 'slippery slope’ stating that boundary crossings do not inevitably lead to client harm, and that inflexible positions regarding dual relationships may alienate people who desperately need services, particularly in small towns. Ethical decision-making in relation to multiple relationships will be addressed in more depth in the review of the rural literature.

Recent research reveals that psychologists do in fact disagree about what constitutes a dual relationship, and that theoretical orientation affects beliefs about the ethics of certain dual relationship behaviors (Anderson \& Kitchner, 1996; Baer \& Murdock, 1995). Psychodynamic 
therapists are less likely to report engaging in dual relationships and other associated behaviors such as self-disclosure (Baer \& Murdock 1995; Borys \& Pope, 1989). Borys and Pope (1989) found that close to 40 percent of those surveyed (psychiatrists, psychologists, and social workers) disclosed details of a personal stressor to a client, and about 35 percent accepted a client's invitation to a special occasion. Pope, Tabachnick and Keith-Spiegel (1987) in a survey of psychologists found that close to 70 percent of those surveyed used self-disclosure as a therapeutic technique "sometimes" or more often, and 35 percent had asked favors from clients, if only rarely. Close to 30 percent of those surveyed provided therapy to a friend. This study also found that male respondents were significantly more likely to report engaging in social and financial dual relationships with clients than female therapists. Borys and Pope (1989) reported that practioners who live and work in the same small town are more likely to engage in dual relationships. Baer and Murdock (1995) found that male therapists are more likely to endorse NSDR behaviors as ethical, and that low differentiated therapists had difficulties maintaining boundaries. Differentiation was theoretically based on Bowen’s family systems theory, indicating the degree of individuation from the family of origin, and measured by the Personal Authority in the Family System questionnaire. They also found that theoretical orientation was significantly related to endorsing multiple relationships, with psychodynamic/analytic significantly less likely to endorse multiple relationship behaviors as ethical than the other orientations.

\section{Competency}

The ethical standards, general principles, and general guidelines state that psychologists need to practice within their boundaries of competence. Gross and Robinson (1987) list the following aspects of competence: accurate representation of credentials, professional growth through 
continuing education, provision of only those services for which one is qualified, maintenance of accurate knowledge and expertise in specialized areas, and obtaining assistance in solving personal issues which impede effectiveness.

However defining competence, deciding who is competent and who is not, and implementing controls to ensure that therapists practice within the boundaries of competence, may all be quite difficult. Additionally, there may be times when the psychologist deems it necessary to practice outside her or his areas of competence. Clayton and Bongar (1994) state that competency consists of appropriate training, supervision and consultation, that it is important to consult with peers and continue one's education. Several authors define competence in terms of domains or components such as the knowledge domain (knowing what to do), the skill domain (being able to do it), and the affective domain (attitudes, values, beliefs) (Berven \& Scofield, 1987; Haas, 1993; Koocher \& Keith-Spiegel, 1998). The General Guidelines state that psychologists need to limit their practice to demonstrated areas of professional competence, and to maintain current knowledge of scientific and professional developments (APA, 1987). Haas (1993) relates that competence does consist of knowledge, training, and continuing education, but that it also involves a "willingness to subject decisions to peer review, openness to criticism by colleagues, willingness to confess ignorance or error when appropriate, and concentrated and sustained efforts to deepen one's clinical craftmanship" (p. 255). Several authors note that knowing and admitting one's limits is an essential aspect of competence (Haas, 1993; Koocher, 1979; Koocher \& Keith-Spiegel, 1998).

Peterson and Bry (1980) assert that competence is a construct much like intelligence or personality, and that we can only summarize and measure characteristics of the performance of competence. Their study attempted to develop a definition of competence inductively by asking 
supervisors of graduate students what they thought were the most salient characteristics of competent students. Over the course of two studies they combined these characteristics into four factors. The first factor is responsibility, including integrity, psychological soundness and conscientiousness. The second is warmth, such as interpersonal skills, compassion and openness. The third is intelligence, and the fourth factor is experience leading to technical skills, maturity, and self-assurance.

Koocher (1979) points out the difficulty in identifying how much competence a psychologist has because it is difficult to define what a psychologist is and does. He states that psychologists may be highly competent in some areas, but have no skills or abilities in other areas. Although the profession of psychology has come a long way in defining skills and abilities necessary to be a psychologist, we still have difficulty identifying and certifying competence. Does competence mean a psychologist has reached a minimum or superior level of ability, or does it simply mean they are not likely to do too much harm to patients? Koocher (1979) identifies three levels of credentialing. The primary credential generally includes longitudinal samples of psychologist behavior, including person to person supervision and direct observation of practice, such as a graduate training program. A secondary credential stipulates the primary credential as a minimum requirement, and then includes a cross-sectional sample of behavior, such as an exam and submitting samples of behavior. An example of a secondary credential would be a state issued license to practice psychology. A tertiary credential generally does not involve close scrutiny or behavioral samples, such as those offered by professional organizations. The problem with these credentials is that, though it is the best we have to date, there is evidence that even primary credentials do not predict very accurately how well a psychologist will do in the practice of psychology (Berven \& Scofield, 1987; Hutt, 1981). In addition to the difficulty in 
defining what constitutes competency, there are few standards in place to monitor or detect incompetence or to adjudicate when psychologists are shown to be incompetent (Claiborn, 1982; Koocher, 1979; Peterson \& Bry 1980).

Several studies find that there is low consensus concerning what constitutes the boundaries of competence, and that psychologists are concerned about their own and their colleagues levels of competence (Hass, Malouf, \& Mayerson, 1986). Psychologists are concerned that other therapists are treating psychiatric conditions and using techniques for which they have no training or supervised practice (Golden \& Schmidt, 1998). Pope \& Vetter (1992) found that respondents in small towns were especially concerned about colleagues practicing beyond their training and competence level, and without adequate supervision. Pope (1991) points to several national surveys that indicate at least twenty percent of psychologists render clinical services for which, by their own judgement, they were clearly incompetent. Koocher (1979) states that incompetence itself is not unethical because it is a matter of relative judgement along a continuum. There may be several reasons psychologists practice outside their areas of competence, including, as already discussed, not being aware of one's limitations and not seeing other alternatives due to being in a small town.

Another reason is that in order to learn, and grow, as practioners it is only natural that at times we will practice beyond our current abilities. Pope (1991) and Wood, Rogers, McCarthy, and Lewine (1994) point out that as psychologists enter into new domains of practice, such as public hospital practice, they may be called upon to work with new populations, and to practice outside of previously established boundaries of competence because few standards had been developed for that particular area. The general guidelines for service providers encourage psychologists to develop, apply, and evaluate innovative theories and procedures, which by definition requires us 
to stretch our limits of competence (APA, 1987). Weiner (1989) points out that it is rare for competent psychodiagnosticians to not have to grapple with the gray areas of ethicality by having to stretch their limits of competency and sometimes having to work in areas that have not yet been codified into standards of practice. Ideally psychologists will seek supervision and consultation as they do seek to expand their current areas of competence.

Some areas of competence are hard to operationalize and document. Whyte (1994) asks how do we define the ability to listen well and care, the ability to contain chaos and distress, how do we measure the quality of receptiveness? Haas (1993) identifies several virtues that would be ideal to have in a psychologist, but may be hard to define, such as perseverance, courage, integrity, humility, hope, and the determination to seek intellectual and emotional growth.

Obtaining competency and maintaining competency are two different issues as well. Pope and Vetter (1992) found in their survey some concern that practicing therapists who were trained many years ago have not kept up their skills or knowledge base, and thus were no longer competent. This may be particularly true today as the scientific base for psychology grows at a rapid pace, adding new treatments while making others obsolete, as evidenced by the case of empirically validated treatments. Writers have discussed the half-life of knowledge in engineering, which has declined from 20 years to about 5 years over the last several decades, and drawn the same analogy for the field of psychology (Berven \& Scofield, 1987; Haas, 1993).

Berven and Scofield (1987) describe three methods for staying current and maintaining competency. Instruction involves formal learning, attending classes, inservices, workshops and seminars. Inquiry is less formal, and involves learning from conducting research, giving scholarly and academic presentations, and reading journals. In this case learning is more of a byproduct of a natural curiosity. Performance is the final area, and includes habitual application of 
ideas or skills in day to day activities until it becomes part of the therapist's scope of practice. The authors note that most credentialing organizations only recognize the first method of continuing education, which can cause problems for those who do not have as much access to workshops, supervision, and colleagues. They also identified the affective domain as contributing to the maintenance of competency, though this will be discussed in the next section defining burnout.

Clayton and Bongar (1994) assert that many psychologists fail to use consultation when it is in fact one of the better methods to maintain competency. Pope, Tabachnick, and Keith-Spiegel (1987) found that over 70 percent of survey respondents considered consultation with colleagues to be a good or excellent source of information for maintaining competency in their practice. However, 25 percent admitted to acting unethically by practicing outside the scope of their competence rather than seeking guidance. Clayton and Bongar (1994) relate that consultation with colleagues can provide suggestions about difficult cases, include discussions regarding professional and ethical issues, be a valuable source of continuing education, as well as provide a source of support and community. These authors summarize that:

It is emphasized here that relationships with other professionals (within and outside the field of clinical psychology) combined with current reading and involvement in professional organizations can be an important avenue for maintaining interest in and awareness of the ever growing clinical knowledge base, potential problems with a treatment area, and one's own limitations. (p. 49)

The authors also point out that the greatest threat to quality of care is not from limited training, but from those who fail to recognize the limitations of their own training and experience. 


\section{$\underline{\text { Burnout }}$}

Burnout is a complex construct generally referring to a pattern of exhaustion, a feeling of being worn out, or not having the strength and resources to cope with environmental demands (Ackerly, Burnell, Holder, \& Kurdek,1988; Savicki \& Cooley, 1987). Competency tends to be associated with support in knowledge, skills, and abilities, while burnout tends to be associated with emotional support, though there may be some overlap between these constructs. Lamb (1999) points out the definitional distinctions between impairment and incompetence, that the latter may require additional training, the former treatment. Maslach and Florian (1988) assert that burnout is a syndrome consisting of three different factors, emotional exhaustion, depersonalization, and loss of personal accomplishment. The Maslach Burnout Inventory, a 22item inventory, with each factor as a separate scale, is often used to measure burnout in health professionals (Maslach \& Jackson, 1986). Emotional exhaustion refers to feeling drained, and not being able to give anymore of oneself. Depersonalization refers to negative and cynical feelings directed toward clients and people in need of help, and personal accomplishment entails feeling competent in one's work, and believing that the work is rewarding.

Persons experiencing burnout lose their idealism, energy, and purpose; they experience symptoms such as constant fatigue, insomnia, frustration, and depression (Raquepaw \& Miller, 1989; Skorupa \& Agresti, 1993). Maslach and Florian (1988) state that depersonalization can lead to counselors believing that clients are deserving of their troubles. Burnout is associated with high turnover, poor job performance, and poor health. Skorupa and Agresti (1993) state that psychotherapists are aware of the reality of burnout among their colleagues, and that the prevalence of burnout and impairment raises serious ethical concerns. Pope, Tabachnick, and 
Keith-Spiegel (1987) found that $62 \%$ of Division 29 psychologists admitted to working when too distressed to be effective, even though $85 \%$ thought it was unethical to do so. Street and Rivett (1996) in reviewing the literature on burnout found that many psychotherapists felt that their work left them little time or energy for their own family or personal life.

Researchers have been attempting to identify moderator variables associated with particular aspects of the burnout syndrome. Savicki and Cooley (1987) state that in general, high burnout is associated with lower worker impact on policy and procedure, lack of worker autonomy, and a lack of clarity for work objectives and responsibilities. They developed a series of work environment scales and correlated aspects of the work environment with levels of burnout. They found that low levels of worker burnout are associated with environments where workers are strongly committed to their work, coworker relationships are encouraged, and supervisory relationships are supportive. High burnout was associated with vague job expectations, management imposing extensive rules and regulations, and little encouragement and support for new ideas. Different aspects of the work environment did relate to different factors of burnout. For example, peer cohesion seemed to relate more closely to personal accomplishment, whereas high work pressure and low autonomy related to high levels of emotional exhaustion. The authors also suggest that coworkers can serve as a reference group to judge their own competency, as well as an ongoing supervisory and consulting resource from which to get advice and support.

Ackerly, Burnell, Holder, and Kurdek (1988) examined moderating variables such as demographics, objective work characteristics, types of therapeutic activities, types of therapeutic issues, and factors associated with the work setting. They found that practitioners in private practice tended to have less emotional exhaustion, less depersonalization, and a higher sense of 
personal accomplishment, than practitioners in the public sector. This may be attributed to several factors. For example, it may be that those working in the private sector are more likely to be dealing with growth-oriented issues, rather than chronic mental illness. It may also be that private practitioners perceive more control over their work environment. The researchers did find personal control and overinvolvement to be the factors with the strongest correlations to burnout. A major concern from this research was the finding that close to $40 \%$ of polled psychologists experienced high levels of emotional exhaustion, 35\% depersonalization, and that $21 \%$ would choose another career if they had to do it all over again. Interestingly, they also found that younger psychologists were more likely to have symptoms of burnout; it may be that those who survive longer in the field find a way to conserve their resources, though this needs to be explored in more depth.

Koeske and Kelly (1995) isolated overinvolvement as a moderator variable in their study. They point out there is a fine line between dedication and over-dedication, a line psychologists begin to walk early in their graduate training. Overall they found low rates of overinvolvement and high rates of job satisfaction. They found that overinvolvement was related to burnout, which was then related to intrinsic dissatisfaction. They also report that social support was a buffer against the impact of burnout, which contradicts other studies to be discussed shortly. However, they found this effect mainly for poorly supported workers. This study appears to support the Ackerly et al. (1988) study indicating overinvolvement can lead to burnout and therapists may need to find ways to ameliorate this effect. It may also be that certain therapists, e.g. those with a high need for approval, may be more likely to become overinvolved.

Ross, Altmaier, and Russell (1989) examined social support and social isolation. They used a social provisions scale to measure social support, identifying different levels of social support 
such as: attachment, social integration, reassurance of work, guidance, reliable alliance, and opportunity for nurturing. They also found a higher rate of burnout among younger psychologists and that supervising others is associated with higher burnout. On the other hand, supervisor support does have positive effects on the well-being of the workers. Overall social support does not have a buffering effect, but social integration and supervisor support are associated with lower levels of burnout. Raquepaw and Miller (1989) also found that private practioners had higher levels of personal accomplishment and less emotional exhaustion. They report that the number of clients on the counselor caseload did not predict level of burnout, but the counselor's perception of the caseload did. They conclude it may be the appraisal of the stressor, rather than the stressor itself, that leads to burnout.

Lee and Ashforth (1996) completed a meta-analytic study to examine correlates of burnout and test the conservation of resources theory of stress and burnout. This theory postulates that burnout occurs when certain valued resources are lost or are not adequate to meet demands. They identified demands as role ambiguity, role conflict, stressful events, and heavy workload. The researchers identified resources such as social support and job enhancement opportunities. They found that personal accomplishment does develop independently of emotional exhaustion and depersonalization. The authors hypothesize that individuals may be more sensitive to demands placed on them than they are to the resources received. In other words, persons may perceive stress due to a demand, regardless of whether they have the resources to meet that demand. In this scenario, it may be beneficial to reframe perceived stressors as challenges to be met, much like in the cognitive treatment of depression. They also found that coworkers may provide individuals with a sense of competence through support and serving as a frame of reference to judge their own abilities. Lastly, Dupree and Day (1995) found that private 
practioners reported higher levels of personal satisfaction, and lower levels of burnout. They found gender differences in burnout levels associated with the impact of managed care. Their results suggest that males seem to rate their job satisfaction based on risk and opportunities for advancement, while women tended to associate it with process, social relationships, and the opportunity to be in a helping role.

A final issue to discuss in this area is that of the distressed therapist and therapist wellfunctioning. We know very little about the latter, and counseling psychology continues to fall short of its goals in studying well-functioning, both in the general population and within our own profession. Deutsch (1985) states that the therapist's mental and emotional well being is the foundation of his or her craft, that research shows a correlation between therapist mental health and client outcomes. She conducted an exploratory self-report survey study and found that $82 \%$ of therapists experienced relationship difficulties at one time, and that $47 \%$ sought treatment for relationship problems. Of particular relevance is that $57 \%$ of respondents reported at least one episode of depression in their lives.

Thorenson, Miller, and Krauskopf (1989) found that, overall, psychologists reported being healthy and satisfied with work and interpersonal relationships. They found that about $11 \%$ reported depression (within the past year), 11\% relationship difficulties, and 9\% problems with alcohol use. Of concern is the impact of therapist distress on client outcomes. Distressed therapists may be more likely to cross therapeutic boundaries by inappropriate use of selfdisclosure and changing into a client role during therapy. Thorenson, Miller and Krasukopf (1989) state that "professional distress does indeed exist and that there is substantial resistance to confronting, directing, or reporting an impaired colleague to treatment or licensing boards" (p. 153). Pope and Tabachnick (1994) found that $84 \%$ of their survey respondents had been in 
therapy, and $61 \%$ of those reported at least one episode of depression. More research needs to be done to evaluate psychologist susceptibility to depression and impairment. It may also be that therapists are more sensitive to emotional states than most and more likely to seek treatment for preventive measures. On a positive note, many of those who did seek therapy found it to be helpful (86\%).

Coster and Schwebel (1997) used a questionnaire to find out how psychologists cope with their demanding careers, focusing on well-functioning rather than impairment. The authors did state, from their findings, that it appears impairment is not due to a deficit in professional skills, but rather, a lack of resources to cope with stressors. One of the major findings across their studies is that peer support is very important: "If you do not have a close, cooperative, trusting relationship with one or more colleagues, we advise you to establish one. Such a relationship is a powerful resource in coping with the inescapable practice and management of ethical problems" (p. 10). If such relationships are not readily available, it may be worth the effort to seek out and establish such relationships even if it is with professionals other than psychologists. Self-awareness and self-monitoring were deemed important by those psychologists responding to the survey. Supervision and support from friends and family were important in maintaining well-functioning. Many psychologists asserted the importance of maintaining a balanced life, having time away from their professional role. The authors do validate the fact it is hard, after the unbalanced life of graduate and post-graduate work, to get back into a balanced lifestyle.

\section{Confidentiality}

Confidentiality is generally considered an ethical commitment by the therapist to not reveal anything about a client contact to another person without that client's permission (Spiegel, 1990). This standard of professional conduct is distinct from privileged information which is a legal 
term referring to the client's privilege to keep information to their self or to share it in certain protected relationships. The privilege/confidential debate is beyond the scope of this paper. However, Gross and Robinson (1987) highlight some basic aspects of confidentiality that apply to all counselors, therapists, and psychologists. They state that clinical workers have a primary obligation to safeguard information about individuals obtained in the course of therapy. The client should have the right to decide what information is shared with whom. The therapist also needs to inform clients of the limits of confidentiality, and when the therapist is going to break confidentiality. Generally, most therapists must break confidentiality when the client threatens to harm self or others, in the case of child abuse, and when there is a court order.

However, there are many other times when confidentiality is broken, intentionally and by accident. In group therapy for example, the therapist cannot guarantee confidentiality between clients. There are many state, legal, insurance, and agency rules and regulations that affect whether therapists can keep information confidential. Some argue that confidentiality is a relative term, that psychologists should never guarantee confidentiality, whereas other psychologists believe confidentiality should be absolute, even with the threat of danger to self or others (Baird \& Rupert, 1987; Spiegel, 1990). Debate also concerns whether clients should be informed about breaks in confidentiality. Baird and Rupert (1987) report that $60 \%$ of their respondents felt consulting with a colleague required neither client consent nor client knowledge, though they did not clarify if this would necessarily entail sharing client identifying information. Supervision is another case where therapists often do not get client consent, or let clients know, they will be talking about the case with supervisors (Venier, 1998). Some argue discussing casework is fine as long as the client name, or identifying information is not used, but this may be difficult in small towns and other situations where clients can be identified with minimal 
information. The ethical standards attempt to address this issue, stating that when consulting with colleagues, psychologist do not share confidential information that could identify the client, unless there is prior consent (APA, 1992, 2002).

Maintaining confidentiality may be difficult even when the psychologist intends to keep all information confidential. Pope et. al. (1987) report that $61.9 \%$ of psychologists reported unintentional breaks of confidentiality. Pope (1990) discusses the problems of working in a hospital setting when so many persons have access to treatment records. Furthermore, newer treatment methods include multidisciplinary teams with staff meetings to discuss the case. Patients are often not informed of the fact their case is being discussed with so many different professionals. Informal information sharing often happens between agencies as well. Some agencies and psychologists may feel it is a common courtesy to let referring agents know the clients they referred are coming to treatment and benefiting from treatment. Record keeping, electronic files, faxing of records and information, all present concerns to maintaining confidentiality (Venier, 1998). More research is needed to see how therapists are handling confidentiality in their work, particularly in terms of consultation and supervision.

Maintaining confidentiality can also increase stress for the therapist. Spiegel (1990) writes that "These stresses are more noticeable where therapists and clients encounter each other outside the therapeutic setting: rural communities, colleges, medical centers, EAP or HMO programs" (p. 637). Psychologists may also be concerned that if they inform clients they will be discussing their case with others that clients will not share important information, or that the client will lose confidence in a therapist that needs supervision and consultation (Baird and Rupert, 1987). Golden and Schmidt (1998) report that confidentiality has been a major concern for psychologists for the last two decades. However, in 1979 therapists were concerned about 
breaches due to carelessness, while now they are concerned about breaches due to managed care and the use of technology. This writer believes we need honest discussion about how confidentiality is being managed by psychologists in practice.

\section{Surveys of Ethical Practices}

Researchers have used survey methods to explore ethical beliefs and behaviors for the last several decades. Shore and Golann (1969) used a three question, open format, survey of the division of community psychology to explore ethical concerns for psychologists. The response rate was only $8.2 \%$, though the survey was useful in highlighting some of the major ethical concerns at that time. Their responses were separated into five categories, confidentiality, consultation, competence, professional versus citizen role, and miscellaneous. Psychologists who responded were concerned about sharing information between agencies, formally and informally, about support staff having access to and sharing confidential information, and the effect of diagnostic labeling of clients. Also of concern was working in a small town where keeping confidential information gathered in one role separate from that obtained in another role may be difficult. "Such difficulties become very acute in community work in small communities where professionals are often cast in personal roles as well as professional roles at different times with the same individual, or with people who have contact with that individual" (p. 455). Respondents were also concerned with how to define competence and obtaining ongoing supervision and training, and the blurring of personal and professional roles when psychologists become active in their community. It is interesting to note that almost three decades later psychologists are still reporting very similar ethical concerns and a need for guidance in ethical decision making. 
The classic survey, on which this and many other surveys have been based, is the Pope, Tabachnick, and Keith-Spiegel (1987) survey of ethical beliefs and practices of psychologists. This survey, which has been replicated with several populations, consists of 83 questions regarding ethical behaviors and beliefs, in which respondents reported how much the behavior happened (never, rarely, sometimes, fairly often, often, and N/A), and how ethical they believed the behavior to be (unquestionably not, under rare circumstances, don't know/not sure, under any circumstances, and unquestionably yes). . The researchers assessed the value of several resources for ethical education utilized by participants, as well as collecting demographics. They surveyed 1000 members of Division 29 of the APA, with a response rate of $45.6 \%$. Response percentage rates from $40-50 \%$ appear to be the norm in the type of survey research discussed in this section.

This study was particularly useful for establishing some baselines of ethical beliefs and behaviors. Although this survey is more sophisticated that the Shore and Golann (1969) study, there are still the methodological concerns of a biased sample due to a low response rate, and relying on self-report. We will see that there is a decline in behaviors that may be unethical across the next decade of surveys, which suggests to this writer that psychologists are becoming more ethically savvy. It will be difficult to determine if psychologists have changed their behaviors over the last decade since this survey, or if they are simply giving more socially desirable answers. Therefore, it could be that this particular survey provides a more accurate view of the practices of psychologists, because psychologists were not as aware of ethical issues at this time, and were therefore less likely to give socially desirable responses.

The relevant response percentages from this study have been reported throughout this paper. The authors identified behaviors that are almost universal, those items where $90 \%$ of the respondents reported the behavior at least on rare occasions. For example, using self-disclosure 
as a therapy technique was reported by $93.3 \%$ of the respondents. Other categories included behaviors that are rare (i.e. sexual intimacy, 1.9\%), and difficult judgements (i.e. accepting goods rather than money, 21.3\% reported don't know). As already mentioned, competency and confidentiality are concerns highlighted by this survey, as close to $60 \%$ reported working when too distressed to be effective and $61.9 \%$ reported unintentionally disclosing confidential information. The Pope, Tabachnick, and Keith-Spiegel (1988) study is based on the same data as the previous study with the data analysis focusing on beliefs about specific practices. The major finding from this analysis is that the standards for good practice are held to higher criteria than ethical standards. Psychologists may engage in poor practice, without the behavior necessarily being unethical. The only exception in this survey was altering a diagnosis for insurance reasons, which was generally considered unethical, but not necessarily poor practice.

Haas, Malouf, and Mayerson (1986) used a case vignette format to survey ethical beliefs and practices of psychologists. Participants were presented 10 ethical dilemma vignettes and asked to indicate their preferred resolution and reason for choosing the resolution. Respondents were also asked to indicate the frequency with which they encountered several ethical dilemmas, and to rate the severity of each dilemma. The sample was 600 randomly chosen members of Division 29, with a response rate of 59\% of those that received the survey. The highest rated method of learning about ethics was discussion with colleagues. The authors found high agreement on ethical choices (75\% of respondents agreeing) for only 3 of the 10 cases. The highest area of concern with regard to frequency of encountering the dilemma was for confidentiality. Respondents also rated concern over assessment of their own, and colleagues, competence as very serious, with little consensus about what determines boundaries of 
competence. They report that $45 \%$ of respondents "would discuss their qualifications with the client and, apparently, let the client determine the therapist's competence" (p. 320).

Pope and Vetter (1992) surveyed 1,319 APA members, with a 51\% return rate resulting in a sample of 679 psychologists. This national survey used a critical incident method to explore the types of ethical dilemmas most encountered by psychologists. The most reported ethical dilemmas concerned confidentiality issues. The second most frequently reported issue concerned blurred dual, or conflictual relationships, incidents that involved "maintaining clear, reasonable, and therapeutic boundaries around the professional relationship with a client” (p. 69). The researchers point out the need to define dual relationships more clearly in future ethical codes, when they are therapeutically acceptable, if ever, and how practitioners in small towns and rural communities should cope with dual relationship issues as 41 of the incidents involved such situations. Other incidents involved concerns about psychologists in small towns having to practice beyond their scope of competency, giving assessments and tests one is not trained to give, and several incidents around payment sources.

Borys and Pope (1989) focused more specifically on dual relationships in this survey of psychologists, psychiatrists, and social workers. In order to test if previous surveys examining both beliefs and practices had a priming effect on each other, one-half of the sample received a survey on beliefs, the other half on practices. They found no evidence that having both beliefs and practices on the same questionnaire influenced responses. As stated previously, most therapists reported that dual relationships are unethical, males were more likely to engage in dual relationships than females, and psychodynamically oriented therapists were less likely to engage in, or endorse dual relationship behaviors than therapists from other orientations. Respondents from small towns were more likely to rate dual relationship involvement as ethical than were 
urban or suburban respondents. Overall, there were no major differences across the three professions in ratings of ethical behaviors and practices. The response rate for this study was 49\%. Also of note, $45.7 \%$ of respondents reported being in private practice, which may have changed since that time with the complications of managed care and third party payers.

Gibson and Pope (1993) conducted a national survey of 579 certified counselors (response rate of 59\% from those who received forms). The survey instrument consisted of 88 questions in which respondents rated the behavior as ethical or not, and then gave themselves a confidence rating on their decision. The goal was to identify those areas that counselors had difficulty in making a decision. Seven items were rated as the most tentative, most of which concerned the collection of fees from clients. The most controversial issues, based on those questions in which $40 \%$ reported the behavior was ethical, and $40 \%$ reported unethical, included dual relationships such as going into business with a former client, becoming social friends with a former client, and providing counseling to a student supervisee. In this study, the researchers again found that respondents reported talking with colleagues as the most useful resource for learning about ethical practice.

Several researchers have used survey methods to assess the ethical behaviors of specific populations. Tabachnick, Keith-Spiegel, and Pope (1991) surveyed psychologists on the ethics of teaching. The most difficult areas to evaluate were the blurring of boundaries, particularly when faculty members have power and influence over students but at the same time are encouraged to spend time with students in social contexts. It may be that doctoral level graduate students are close to becoming colleagues, but at the same time are still considered students, which leads to role confusion. Of particular concern from this study was the finding that $79 \%$ of respondents had ignored unethical behavior by colleagues. 
Rae and Worchel (1991) surveyed pediatric psychologists and found considerable variability in responses, with $80 \%$ agreement on only 39 of 101 behaviors. This seems to suggest that there is either a good deal of confusion, or disagreement, as to what constitutes ethical behavior. Tarvydas, Leahy, Saunders, Chan, Thielsen, and Murray (2001) adapted the Gibson and Pope (1993) survey to conduct a national study of Certified Rehabilitation Counselors and their beliefs about ethical behaviors. Again, it was found that dual relationship issues are an area of controversy, as was concern over financial situations. Percival and Striefel (1994) adapted the Pope et al. (1987) survey to examine the beliefs of members of the Association for Applied Psychophysiology and Biofeedback (AAPB). They found similar findings as the above reported surveys, with controversial behaviors including dual relationships (becoming social friends with a former client), accepting goods as fees for services, going into business with a former client and going to a client’s special event. Again, females were less likely to rate dual relationship behaviors as ethical.

Pomerantz, Ross, Gfeller, and Hughes (1998) surveyed 148 mental health professionals in the state of Missouri to determine if there were differences in ethical beliefs across counselors, psychiatrists, psychologists, and social workers. The survey instrument was based on Pope et al. (1987). Overall there was a high degree of consensus across the four professions. There was a significant effect for professional group on 5 behaviors, such as addressing client by first name, utilizing involuntary hospitalization, unintentionally disclosing confidential information, allowing clients to take tests home, and clients addressing therapist by first name. This survey did highlight the importance of working closely with other professionals who may, or may not have similar ethical standards as psychologists. 
Tubbs and Pomerantz (2001) used the Pope et al. (1987) survey to see if any changes occurred since the original survey. Psychologists were less likely to report unethical behaviors in this study, though this could be due to respondents being more aware of the socially desirable responses than they were twenty years ago. Other explanations for the decrease include the sample in the study being limited to 92 licensed psychologists in Illinois, there have been changes in theoretical orientations over time (training cohort effects), and psychologists may fear censure more than they have in the past. Many behaviors around the issue of dual relationships highlight this change over time. For example, in the original Pope et al. (1987), 42.1\% said they never become friends with a former client, while in the Tubbs and Pomerantz (2001) study that particular response rate was $73.9 \%$. Accepting services from a client in lieu of a fee went from $66.9 \%$ rated as never, to $92.4 \%$. The authors conclude by asserting the importance of surveying ethical behaviors and beliefs of psychologists frequently and with some degree of geographic specificity, and assert that "Future research in this area should not only examine the ethical norms in other specific states, but differences between large cities and small towns as well” (p. 399).

Finally, Hines, Ader, Chang and Rundell (1998) surveyed military and civilian psychiatrists to examine differences in dual relationships, boundary crossings, and boundary violations. This survey is particularly relevant because of the similarities between working in a rural area, and working in a military setting. The authors state that "In military settings dual relationships are often unavoidable...work at small installations where they are the only psychiatrist, or one of very few... Military psychiatrists may not have the luxury of referring a patient to another psychiatrist" (p. 826). In addition to the problem of dual relationships, the authors also discussed 
dual agency, which is the division of loyalty among three parties, such as the psychiatrist, the patient and the military.

The final sample consisted 207 military psychiatrists and 600 civilian psychiatrists (response rate was 39.1\%). Civilian psychiatrists were further divided into HMO and non-HMO practitioners, as HMO's also create a type of dual agency. The survey instrument was adapted from Borys and Pope(1989) and other survey questionnaires. The questions were also intended to distinguish between dual relationships, boundary crossings, and boundary violations as discussed early in this paper. They found that the number of boundary crossings correlated significantly with the number of dual relationships. Seventy-two percent of all respondents reported participating in at least one dual relationship in the past year. Again, it was found that male psychiatrists, who were older, in rural practice, in solo practice, and not psychodynamically oriented, were more likely to participate in dual relationships. Their findings, though limited by the self-report nature of the study, support the notion that boundary crossings do not often lead to boundary violations, and that boundary management needs to be considered on a case-by-case basis.

\section{Review of the Literature in Rural Ethics}

\section{Characteristics of Rural Communities}

The purpose of this literature review is to explore current ethical issues in rural communities. Debate continues over the exact definition of rural, and whether such a definition should be based on geography or population (Murray \& Keller, 1991). For this paper we will consider a rural community as one with a population of 10,000 or less, recognizing there are major differences between a community of 500 and one of 10,000 residents. Ethical dilemmas may 
arise due to population density as well as geographical isolation. Rural communities are complex interrelated systems of formal and informal social and political units (Hargrove, 1986). Relationships among community members are interdependent, complex, and may have deep historical, social, political, and familial roots (Hargrove, 1986; Sundet \& Mermelstein, 1983). Members of the community often have multiple roles within the community, tend to rely on each other and kinship ties, and prefer to take care of their own problems rather than place any trust in outsiders (Stockman, 1990). Sterling (1992) points out the need for psychologists to educate themselves about local politics, familial history, and local power structures. To fully appreciate the complexity of these ethical issues it is important to examine some of the characteristics of rural communities.

Rural communities are heterogeneous. However, several authors have related prevalent characteristics of many rural communities. Compared to urban areas these communities tend to have scarce resources, high rates of poverty, lack of access to employment, lack of higher formal education, higher illiteracy rates, inadequate health services, limited insurance coverage, higher rates of disabilities, and fewer mental health resources (Murray \& Keller, 1991; Reed, 1992; Wagenfeld, 1988; Wilcoxon, 1989). Persons who live in these communities tend to have strong family ties, avoid conflict and discussion of feelings, have limited tolerance for diversity, high religious involvement, possess fatalistic and stoic attitudes, and are less likely to seek mental health services due to the stigma and lack of education about such services (Cook, Copans, \& Schetky, 1998; Stockman, 1990).

The myth of the rural resident as being independent, strong, and living a peaceful nonstressful life has lead many to underestimate the need for mental health services in such communities. However, there is considerable evidence that the prevalence of social and health 
problems in rural areas generally exceed those in urban areas (Wagenfeld \& Buffum, 1983).

Persons in rural communities are exposed to considerable stress due to poverty and financial strain, weather, natural disasters, farm crises, and other conditions outside their control.

Research has shown that rural residents experience mood and anxiety disorders, trauma, cognitive, developmental and psychotic disorders, at rates as least as high as urban areas (Roberts, Battaglia, \& Epstein, 1999). Suicide rates in rural areas have been higher than in urban areas for the last 20 years; rural areas have high rates of chronic illness, alcohol abuse, and disability (Roberts, Battaglia, \& Epstein, 1999; Wagenfeld, 1988).

Most psychologists are trained according to an urban model of psychology, with most of their practical experience occurring at universities in urban areas with access to many services. Urban-based practice tends to take for granted services such as day treatment centers, public transportation, community centers, and easy access to self-help groups (Cook, Copans, \& Schetky, 1998). Rural areas generally have limited resources requiring psychologists to be creative and flexible, to make use of existing natural resources such as kin, churches, and other nonprofessional supports (Reed, 1992). Murray and Keller (1991) state "...there has been a consensus in the literature that this urban model of mental health service delivery is inappropriate to meet the special needs of rural communities" (p. 225). These same authors point out the relative dearth in the literature concerned with rural practice. Rural providers often feel that ethics codes, texts, and other literature are so urban biased, or culturally incongruent, that they are not helpful (Roberts, Battaglia, \& Epstein, 1999).

There is very little discussion in the psychology literature about resolving ethical dilemmas and problems inherent in a rural community. Much of the literature for this review comes from psychiatric, social work, and community psychology sources. There is a clear need for 
psychologists to work in rural settings (Hargrove \& Breazeale, 1993; Sladen \& Mozdzierz 1989). Some of the very characteristics mentioned above lead to ongoing difficulty in recruiting and retaining professional staff (Sullivan, Hasler, \& Otis, 1993). However, this review will also consider some of the benefits of working in a rural area, and the data discussed herein may allude to job satisfaction working in rural areas. Psychologists, with their training in areas as diverse as health psychology, behavioral medicine, vocational, counseling, and clinical psychology, and an emphasis on person-environment interactions, can make a valuable contribution to research and training in rural practice and ethics.

The interrelated issues of the practice of psychology, and the aforementioned rural characteristics, tend to intensify ethical dilemmas. An ethical dilemma involves the choice between two apparently correct, and equally appealing, decisions. Four basic dilemmas will be covered: 1) Becoming involved in the community to be accepted and create an effective delivery service, which then leads to multiple relationships and limiting the number of prospective clients. 2) Making use of natural and already existing resources, which may lead to confidentiality concerns. 3) Being a generalist to help the most people with limited resources, which may lead to competency concerns such as scope of practice and burnout. 4) High visibility in the community leading to issues regarding self-disclosure and therapist anonymity. In addition to dilemmas, which involve a choice between two alternative courses of action, this paper will also explore ethical problems, which often involve situations that simply arise and cannot be avoided. Depth will be sacrificed for breadth in order to examine several ethical dilemmas. A final point to emphasize is that even though some ethical considerations may be different in rural areas than urban areas, it does not mean the ethical codes should be abandoned or loosely interpreted. On the contrary, it is because of the fact that multiple relationships are 
inevitable, or anonymity impossible, that the psychologist needs to be even more diligent in working within the ethical codes and principles, closely monitoring each therapeutic, professional, and personal relationship.

Multiple Relationships

The core ethical issues. Jennings (1992) points out relationships in rural communities tend to be created by accessibility, rather than intentionality as is the case in urban areas. In rural communities people tend to take on many roles. For example, the doctor may coach the baseball team, be a deacon in the church, and serve on the volunteer fire department. Murray and Keller (1991) relate that the rural professional needs a strong community orientation, with flexible involvement in the community. In addition, the psychologist will need to establish professional, business, and personal relationships with a limited number of options for such relationships (Faulkner \& Faulkner, 1997; Schank \& Skovholt, 1997). Brownlee (1996) cites some writers who maintain that all non-sexual multiple relationships should be avoided at all costs. Ebert (1997) argues that it was not the intent of the ethics code, or of the majority of writers on ethics, to prohibit all dual relationships, but that "I have often heard psychologists as well as my students conclude that all dual relationships must be avoided” (p. 146). One survey of psychologists demonstrates that there is wide disagreement as to whether nonsexual dual relationships are ethical (Borys \& Pope, 1989).

Faulkner and Faulkner (1997) discuss several cases involving potential dual relationships in which the psychologist should make a referral. However, this begs the question because if referrals were so easy to make, there would be no dilemma. Faulkner and Faulkner (1997) make a very important point that it is not only former and current clients that need to be considered in forming relationships in the community, but also potential clients. The more active a 
psychologist is in the community, the more they are likely to limit the pool of potential clients, as forming a counseling relationship with someone with whom a relationship already exists is also an ethical concern. So the psychologist needs to be visible to build trust, but not too visible to avoid limiting whom they may see for treatment at a future point in time.

The majority of writers seem to recognize that some dual relationships cannot be avoided. In rural areas one will run into clients in the community, be in the PTA with clients, and may even have to purchase goods from clients. The 1992 APA ethics code recognized that "In many communities and situations it may not be feasible or reasonable for a psychologist to avoid social or other nonprofessional contacts with persons such as patients, clients, students, supervisees, or research participants" (APA 1992, p. 1601). The current APA ethics code states that multiple relationships that "would not reasonably be expected to cause impairment or risk exploitation or harm are not unethical” (APA, 2002, p. 1065). Some authors argue that insisting on giving services only to those with whom the psychologist has had no prior contact would be immoral because services may be withheld that are very much needed (Jennings 1992). Urban derived ethical prohibitions against multiple relationships may deprive patients the right to treatment when there are no other accessible alternatives. Cook, Copans, and Schetkey (1998) in discussing whether the psychologist should treat the children of colleagues or friends, state that ideally they should do no more than consult, but, "humanitarian considerations may mitigate against the risks of undertaking clinical responsibility for a colleague, friend, or family member" (p. 678).

Completely avoiding multiple relationships seems to be impossible in the rural community (Campbell \& Gordon, 2003). Gottlieb (1993) asserts that the rule stating mental health professionals avoid dual relationships is aspirational in nature, and it is a rule that cannot always 
be met. However, not all relationships are equivalent, nor are all forms of treatment. There is clearly a difference between running into somebody in the store or serving on the same PTA, and being involved in an intimate friendship. Similarly, treatment relationships may run along a continuum from a prevention or career workshop, psychoeducational counseling, short-term brief therapy, to intensive psychotherapy. Therefore, the psychologist in a rural community needs to constantly assess the specifics of current and potential relationships with members of the community. Psychologists are also faced with several possibilities when confronted with a dual relationship ethical dilemma. They may refer a client when possible, or they may end a social relationship at the start of a therapeutic one, or modify existing and future relationships. It may be necessary to assess the benefits and potential harm when accepting clients with whom psychologists may have existing relationships.

In the counseling relationship roles and expectations are clearly defined. However, when a psychologist has a relationship with a client outside of this therapeutic one, it requires both the psychologist and the client to change roles. Such role changes can cause role confusion, and loss of objectivity in the therapeutic relationship. This would be true even of chance encounters in the community. Sterling (1992) points out the need to discuss these role changes and their impact on the client in the next counseling session. Clearly, clients with higher ego functioning will find it easier to adapt to this situation than would clients with poor ego functioning. Ego functioning would then be an important consideration for the psychologist in the decision making process.

Decision-making models to resolve multiple relationship ethical dilemmas. Kitchner (1988) provides one decision-making model for dealing with multiple relationships. Her model is based on role theory and centers on the role conflicts created in multiple relationships. She recognizes 
that dual relationships cannot always be avoided in rural areas, citing cases from the medical literature. This model lists three guidelines to differentiate between dual relationships that are likely to be problematic, and those that are less likely to lead to conflicts. The first guideline concerns incompatibility of role expectations. As the incompatibility of expectations increases, so does the potential for misunderstanding and harm. For example, a client that has had previous social conversations with a therapist may not understand the therapist remaining remote and less social in the therapeutic relationship. The second guideline states that as the obligations of different roles diverge, the potential for divided loyalties and loss of objectivity increases. An example would be a client and therapist taking different positions on a vote at a town meeting over zoning or some other community issue. The third guideline states that as the power and prestige differential between client and therapist increases so does the potential for exploitation. In this situation clients may experience an inability to objectively make decisions about their own best interests. Kitchner (1988) points out that predicting harm is extremely difficult, and that even when all of these guidelines have been met, the dual relationship may still be unethical.

Gottlieb (1993) asserts that not all dual relationships are inevitably exploitative. The model he presents utilizes three dimensions to assess the potential for harm: power differential, duration of treatment, and termination. As stated earlier, not all therapy involves an intensive relationship between clients and therapist. The third dimension concerns whether or not a client is likely to reenter treatment after termination. Gottlieb (1993) suggests the psychologist assess the current relationship, its nature and intensity, and whether there is likely to be any future therapeutic contacts. Secondly, the psychologist should evaluate the role incompatibility of the multiple relationships, and possible role conflict. Finally, the author emphasizes the importance of seeking consultation at any point in the decision-making process where a problem is apparent. 
Coyle (1999) points out that any intimate knowledge of a client creates a power differential, and that once a therapeutic relationship has begun, they may never be able to return to a social relationship or friendship.

Anderson and Kitchner (1998) propose an ethical decision-making model for posttherapy nonsexual dual relationships. They identified eight different dual relationships psychologists may engage in. These relationships vary from incidental and unavoidable, to intentional relationships formed after the therapeutic contact. This model presents a series of questions around four general themes in making a decision to enter a posttherapy relationship. The first theme concerns the therapeutic contract and parameters of the initial contractual relationship. Questions in this area concern the presenting problem, type of closure, the termination process, and whether additional assistance may be needed. The second area involves the dynamics of the therapeutic bond, how strong the bond was, the power differential, and if a new relationship will undo the work that was done in therapy (e.g., is the patient relying on an internalized representation of the therapist for ego functioning). The third general theme relates to social role issues, as described in Kithcner's (1988) earlier model, with questions pertaining to role expectations in both relationships. The final theme concerns the therapist's motivation for seeking or having a multiple relationship. The authors repeatedly emphasize the primacy of seeking consultation with other mental health professionals in order to examine one's motives, and to help identify potential risks and concerns to which the therapist may be blind.

Ebert (1997) provides a model based on conflict of interest rather than multiple relationships as discussed thus far. Ebert (1997) argues that the construct of a multiple relationship is not very useful, and that it often leads to confusion. He points out that not all multiple-role relationships lead to problems, nor are they always unethical. Hence, it is not the dual-relationship per se, but 
it's potential to harm through conflict of interest that leads to ethical violations. This is not a new idea, and he avers that the intention of the ethical guidelines was based on this conflict of interest. The problem arises in that over the last decade the guidelines began to focus on defining multiple relationships, and the multiple relationship itself, rather than the potential for conflict of interest. The 1992 ethical code did nothing to alleviate this confusion. For example sometimes bartering is unethical, sometimes it is not; socializing with a current, or former, client may or may not be unethical, but a dual relationship with a student and socializing with the student may be encouraged. These gray areas become particularly troublesome in the court system and license board hearings depending on who is testifying as expert witness, when they were trained, and the theoretical model with which they are aligned.

Therefore, Ebert (1997) poses a decision-making model that builds on the models already mentioned, such as Gottlieb (1993), but emphasizes conflict of interest, potential for harm, and attempts to tie ethical guidelines to legal cases and ethics committee decisions. The Analytical Model for Multiple-Role Relationships is very comprehensive, with a series of questions at each step of the decision-making tree. The first set of decisions involve determining if there is a multiple relationship, if that relationship is in the prohibited class, and identifying potential conflicts of interest. The second phase delineates an analysis of the potential for harm, and particular areas where harm can be caused. A series of questions and a flow chart provide guidance along a decision- making path. The model is too comprehensive to go into detail for the purposes of this review; the reader is referred to the original article for more depth. This model, along with the others presented herein, do reflect that progress is being made in recognizing that dual relationships do occur in many contexts, and there is potential for harm in many, but not all, of these relationships. Furthermore, these models can aid in sound and 
informed decision-making, as well as inform the process of deciding ethical complaints. More research is needed to determine how, and if, psychologists approach decision-making when confronted with ethical dilemmas.

Stockman (1990) expands on the Kitchner (1988) model. She stresses the need to be immediately clear with clients about the boundaries of professional relationships and the ways personal interaction could affect the therapeutic relationship. She recognizes the need to be involved in the community, but cautions against taking leadership positions on boards that may lead to divided loyalties. In a rural area the psychologist needs to also be particularly concerned about loyalty issues in marriage and family therapy situations. Stockman (1990) discusses the difficulty in creating strict guidelines due to the uniqueness of each case. Faulkner and Faulkner (1997) make the excellent suggestion that two psychologists from neighboring rural areas exchange offices once a week, to provide each other with a referral source so the clients do not have to travel the extra distance.

Finally, several writers suggest practical steps to take to prevent harm in multiple relationships. Kitchner (1988) urges professionals to be very cognizant of the potential for harm in all cases. It is important to clarify in the first counseling session what to do when meeting in another context. Some clients may be uncomfortable with even acknowledging they know the psychologist in a social setting, or may wish to keep such an interaction limited to small talk (Sterling, 1992). Coyle (1999) suggests having prepared statements for clients on the roles and expectations for the therapy relationship and any future relationships. Roberts, Battaglia, and Epstein (1999) recommend educating clients about standards of care, and working together to identify any potential problems and how to handle interactions outside the therapy context.

It seems clear that because multiple relationships cannot be avoided in rural areas, it does not 
mean the psychologist can relax their ethical standards. A psychologist may see clients in the community, and may have various levels of interaction in the community, but this does not mean the psychologist should feel free to have lunch with clients, or engage in behavior that can easily be avoided. Psychologists in rural areas need to be more diligent in examining their relationships than urban psychologists who can more easily avoid dual relationships (Jennings, 1992). This includes making these relationship issues clear to clients, defining and explaining role boundaries clearly, and making extra efforts to minimize any role confusion. Psychologists must also realize that when problems do arise, it is their responsibility to take action to remedy these problems as soon as they are evident (Kitchner, 1988; Koocher \& Keith-Spiegel, 1998). $\underline{\text { Confidentiality }}$

Rural psychologists face confidentiality issues in several areas including community members' awareness of who seeks treatment, support staff having relationships or being familiar with clients, and sharing of information between agencies. Roberts, Battaglia, and Epstein (1999) compare rural communities to fishbowls, where each person is very aware of others' behaviors. Spiegel (1990) states "any person who seeks psychotherapy is entitled to keep this fact confidential; but it may be exposed from many angles in a rural setting, without anyone discussing it” (p. 637). He also suggests that the stress of worrying about maintaining a client's confidentiality in this setting can contribute to psychologist burnout.

As mentioned in the introduction, persons in rural areas are less likely than their urban counterparts to seek mental health treatment. One potential reason is the stigma attached to seeking such services, and that everyone in the community may become aware the services are being sought when the client's car is seen in the clinic or mental health center parking lot. In addition, the support staff are often long-time members of the community, who may be more 
likely to share confidential information. Potential clients will be less likely to make use of group therapy, because group members are likely to know each other well, and to be concerned about confidentiality (Solomon, Heisberger, \& Winer, 1981). Psychologists, due to limited professional referral resources, may benefit from making use of natural resources in the community, such as kin and church organizations. However, involving volunteers and paraprofessionals may create confidentiality problems in small communities.

Psychologists need to be careful when engaging in small talk with community members. Because of the intensity and closeness of relationships in small towns, rural therapists may easily forget whether they heard community news in personal conversations with other community members, from community media, or if they heard it in the context of a therapy session (Cook, Copans, \& Schetky, 1998; Hargrove, 1982;). Sterling (1992) points out that therapists also have a wealth of information about clients that did not come from therapy sessions. Therapists should not be afraid to bring this public information into the counseling session so it does not remain a hidden agenda. Roberts, Battaglia, and Epstein (1999) bring to light the dilemma of breaking confidentiality for legal reasons. In the urban model, when psychologists are placed in a position of breaking confidentiality, they usually do not see the after effects of their decisions. However, in rural areas, even when it is a clear decision such as child abuse, the psychologist will see and experience the effects on families that may be broken up, and have to deal with possible community reactions to the break in confidentiality. Thus seemingly clear reasons to break confidentiality in an urban area, become more difficult and complex in rural areas where the psychologist is more intimately involved in community life.

The second confidentiality issue in rural areas concerns the sharing of information between referral sources and other agencies. Rural areas often have informal sharing of information, 
much like an agency in an urban area may discuss cases at staff meetings. Physicians, lawyers, police, teachers and other referral agents may expect the psychologist to provide information on how the client they referred is progressing, without appropriate informed consent. Many psychologists are trained to not even acknowledge that a client is being seen for treatment unless the client requests this information to be shared. The dilemma the psychologist faces is that in declining to share information in this informal information network, the psychologist can further alienate himself or herself from the community, and lose future referral opportunities (Sobel, 1984; Solomon, Hiesberger, \& Winer, 1981; Stockman, 1990). Hargrove (1986) points out that psychologists need to maintain confidentiality unless there is consent, or a clear and present danger, but, at the same time the psychologist needs to be sensitive to prevailing community standards. It may be very difficult for a new psychologist to come into a community and expect to immediately change existing standards, such as the informal sharing of information, without further fragmenting the few available existing resources. Elkin and Boyer (1989) found that most rural clients assume information will be shared even without consent, and that twenty-five out of the thirty psychologists responding to a survey reported difficulties keeping confidentiality.

It may be necessary to initially conform to this informal information sharing, making use of releases of information, and keeping information about progress very general, before trying to initiate systemic changes (Geczy, Sultenfuss, \& Donat, 1990; Hargrove, 1986, Sobel, 1984). Once the psychologist is established, they may take steps to educate referral agents about the importance of confidentiality for patients receiving psychological services. While other agencies or professionals in the community may have the best intentions at heart, they may not be aware of the vital role confidentiality can play in the therapist-patient relationship, or the patient's fear 
of stigmatism for seeking psychological services. In addition, psychologists clearly need to educate clients about confidentiality, and to be clear on what information will be shared under what circumstances. Solomon, Hiesberger and Winer (1981) suggest having workshops at community agencies on confidentiality, as this will also serve to educate support staff and paraprofessional staff who may unintentionally disclose confidential information. Finally, Elkin and Boyer (1989) suggest housing mental health services in nondescript buildings where other services are offered so clients are not so easily identified as coming to obtain mental health services.

\section{Competency}

The area of competency includes the need to be a generalist, lack of supervision and consultation resources, awareness of rural culture, and issues of burnout. Due to a lack of referral sources, rural practice often requires psychologists to be generalists, to be able to treat a wide range of problems for a wide range of people. However, one may pose the question: when does being creative and flexible in providing services cross into issues of competence, scope of practice and appropriate training? The isolation of rural communities often leaves psychologists without ongoing supervision, and a lack of resources for referral and consultation about ethical dilemmas, treatment decisions, and other concerns.

Several writers discuss the lack of specialists and referral sources in rural communities and that psychologists may be called on to provide care outside their usual areas of expertise without optimal supports (Birk, 1994; Cook, Copans, \& Schetky; Hargrove, 1982; Murray \& Keller, 1991; Roberts, Battaglia, \& Epstein, 1999; Wagenfeld \& Buffum, 1983). Keller, Murray, Hargrove, and Dengerink (1983) state the "single most accepted element for rural mental health training is that such persons must be generalists...the same individual may be required to 
provide services to children; senior citizens; marital couples; deinstitutionalized , chronically mentally ill; persons in crisis; and alcoholics;..." (p. 14).

In addition to working with a wide variety of clientele, psychologists will provide services for a wide range of problems. The dilemma lies in the psychologist being able to determine how far outside of their area of expertise they are practicing. They may choose to deny services, recognizing that psychologists can do harm if working outside their expertise, and that no treatment may be less harmful than the wrong treatment. However, they may also violate the principle of making every effort to protect the welfare of their clients when they deny treatment when there are no accessible referral sources. Sobel (1992) and Schank (1998) relate, respectively:

Small town practitioners may be called upon to treat situations which they may not feel totally competent to treat, but, realizing that alternative services are great distances away, may choose to do so in order to keep the patient functioning in the community...(p. 62).

Rural practitioners are sometimes put in a position of deciding how far they can stretch their own levels of competence in attempting to best meet the needs of their clients and yet still practice within the guidelines of the profession (p. 275).

The issue is further clouded in that the ethical code does not clearly define what is meant by competence. How many adolescent clients, for example, must one work with before declaring competency with that population? One? Five? Fifty? Haas, Malouf, and Mayerson (1986) in a national survey of psychologists found there was very little consensus on the boundaries of competence, and that psychologists were concerned about the assessment of their own, and their 
colleagues, level of competence. Koocher and Keith-Spiegel (1998) refer to compassionate exemption, the idea that there are times when it is reasonable to stretch one's area of competence. There are no easy guidelines for this dilemma, and it seems more dialogue and case examples are needed in the psychology literature on this topic. On the hopeful side, Elkin and Boyer (1987) in their survey, found that most professionals feel challenged and appreciate the diversity of their work, rather than feeling overwhelmed by the ethical dilemmas involved. However, this does not reflect any type of client outcomes or harm that may be done.

Working in a rural area can lead to a sense of professional isolation and lack of ongoing feedback and learning that is inherent in relationships with peers and supervisors in urban areas. This lack of feedback can lead to a psychologist rationalizing, moving outside areas of competence, and slipping into unethical behavior without being fully cognizant of the process. Rural psychologists have less opportunity for continuing education (Coyle 1999). Consultation, which should be a regular part of the practice of psychology, is more difficult in rural areas (Murray and Keller, 1991). The following quote from Roberts, Battaglia and Epstein (1999) will highlight this dilemma:

I was in over my head... the family member was sexually abusing my patient. I learned later that he was abusing other children too. But the family was the most powerful in the community...I agonized over the decision, alone. Ultimately I reported him. I lost my job, and we eventually had to leave the area. It was the right decision but I had no support (p. 501).

Although the counselor did make the right decision this case highlights the problem of operating in professional isolation. Although psychologists may obtain phone supervision, it does not replace the day to day learning and growing through daily interactions with peers. One 
possible resolution is to form close relationships with professionals in similar fields who understand the pressures inherent in ethical dilemmas and working in this field.

Sundet and Mermelstein (1983) point out competence also includes awareness of the interdependence and interaction of residents with social institutions, and that one needs to be aware of community standards. Wagenfeld and Buffum (1983) relate that psychologists need to appreciate the unique culture of a rural area, that many practitioners were educated in urban areas and may "be inclined to impose an urban value system or an urban model of service delivery where it is not appropriate” (p. 93). Cook, Copans, \& Schetky (1998) point out there may still be some debate as to whether a distinct rural culture exists, but highlight many characteristics common to rural communities as mentioned in this paper (e.g. strong family ties, avoidance of conflict, strong independent character, fatalistic and stoic attitudes, limited tolerance of diversity, fear and stigmatization of mental illness). Coyle (1999) writes of the sense of intrusion felt by a community when a highly educated individual comes into a closed community with his or her liberalizing tendencies. He goes on to state that, "It is often because of his or her participation in the community activities that the professional ultimately achieves acceptance, status, and respect" (p. 203). Cohen (1992) also relates that the "values, beliefs, expectations, and world views of most professional psychologists are fundamentally at odds with those of most isolated rural communities” (p. 23). Ethical standards dictate that psychologists become knowledgeable about the groups with whom they are working. Martinez-Brawley (1986) suggests psychologists get to know the physical, economic, organizational and culture aspects of the community. Sundet and Mermelstein (1983) suggest getting to know, and working with, natural healers; to learn from them about the existing culture of healing in the community. 
Lastly, psychologists need to be aware of the potential for burnout. They may be engaging in multiple relationships, experience role blurring, feel the weight of the community on their shoulders, have difficulty separating personal and professional time, and lack professional peers for consultation and support. All these variables can contribute to burnout and decreased therapist competence (Murray \& Keller, 1991; Reed, 1992; Roberts, Battaglia, \& Epstein, 1999). There is no evidence to this writer's knowledge indicating that rural psychologists experience more burnout that urban psychologists. This study collected data to address this empirical question. The literature to date does suggest that the above mentioned difficulties particular to rural areas may contribute to burnout. Several suggestions already mentioned in this paper to deal with burnout include: building support with other professionals; having at least a couple of close friends; taking time for self and family care; keeping a balanced caseload (i.e. do not take only the hardest cases (Cook, Copans, \& Schetky, 1998)); taking urban vacations; and taking advantage of aspects of rural life such as hiking and camping. $\underline{\text { Visibility }}$

Although visibility in the community may not directly lead to ethical dilemmas, it is an issue that is intertwined with the ethical dilemmas mentioned thus far. Self-disclosure may have harmful effects on clients and in an urban model it is a variable that is under therapist control. However, in a rural area the therapist may not have as much control over disclosure due to the therapist's visibility in the community. The ethics codes state that ethics apply only to psychologists' work behavior, but because the psychologist is so visible in the community, it is suggested here that psychologists need to be equally aware of their role model status in a rural community.

Although classical psychoanalysis espouses the view of therapist anonymity in the therapy 
relationship, it has generally been accepted by many different theorists that self-disclosure may cause harm to clients, contribute to negative transference, and can alter the nature of the therapy relationship. In fact, some writers have stated that the nature of rural practice, and being so visible, precludes the option of using psychodynamic therapy with clients (Sterling, 1992). Faulkner and Faulkner (1997) point out that therapist disclosure may be a boundary violation, and in most cases of ethical misconduct, it is the first step of a progression to serious ethical violations such as sexual intimacy. They also state self-disclosure may lead to a social hour instead of therapy, where roles become blurred. This view of self-disclosure is on the conservative end of the continuum, and few writers seem to suggest that all self-disclosure may be harmful. Some view self-disclosure in the here-and-now of the therapeutic relationship as appropriate and helpful to the client in learning how to conduct interpersonal interactions. Still other therapists may share similar personal experiences with clients in the belief that it helps the client to see they are not alone in their experience. Regardless of psychologists' stance on selfdisclosure, it is clear that many use it as therapeutic technique. Pope, Tabachnick, and KeithSpiegel (1987) found that $71.2 \%$ of psychologists used self disclosure 'sometimes' or more in their practice. The decision to self-disclose in this case is not significantly different in a rural community because the psychologist still has control over the disclosure.

Urban psychologists, however, may have more control over what is disclosed due to their relative anonymity, while in a rural community potential clients will often know a great deal about the therapist before they come to their first session (Cohen, 1992; Sterling, 1992). It will not be unusual for a client to know the psychologist's child was called to the principal's office, for example, or to know other such details of the psychologist's life. The client may also know of the therapist's family problems, work problems, financial problems, or even that their car is 
not running well. They will know about the psychologist's beliefs and values by knowing what church they attend, the stand they take on community concerns, what books they buy, and from their interaction with others in day to day community life.

Some suggest resolving this problem by keeping a low profile in the community, buying groceries and services from other communities. However, this contributes to the problem of creating trust, acceptance, and respect in the community. Psychologists will naturally feel the need to be accepted within the community in which they live and work. Several authors point out the paradox of becoming a trusted insider, and experiencing the ensuing ethical dilemmas, versus avoiding the dilemmas by remaining an outsider (Horst, 1989; Koocher \& Keith-Spiegel, 1998; Martinez-Brawley, 1986; Stockman, 1990). Generally, these authors suggest the need for psychologists to become involved and accepted in the community in order to provide effective services, and that they will have to adjust to being fairly well-known by the members of the community, and by their clients. Wilcoxon (1989) points out the need for psychologists to get involved in non-clinical activities, to attend meetings, give presentations at schools, and conduct home visits, in order to build trust and be accepted as a practitioner in the community.

As previously mentioned, it may be beneficial to have one or two intimate friends in the community with whom to share personal problems, and to be friendly but more superficial with others. In the therapy session it will be up to the psychologist to exert control of the therapy session, to have clear treatment contracts, and to remind clients that they are not there to discuss the therapist's life (Coyle, 1999). The treatment contract should discuss the fact the client will be self-disclosing, but for the therapist to remain objective, be of maximum effectiveness, and not become a client in the session, the therapist will not be self-disclosing as much, or at the same depth, as the client. 
The lack of control over what is known about the therapist may also increase therapist anxiety. When therapists do not have the anonymity buffer, they become more known as a human being (Sterling, 1992). However, several writers point out the positive aspect of this type of disclosure and visibility. Sterling (1992), who practices in Martha's Vineyard, draws on the work of Milton Mazer who worked in the same area, to describe several positive aspects of being known in the community. Such visibility, knowing the psychologist also faces problems and handles them, may help clients to see the therapist as more human, and inspire hope and confidence. It also allows the therapist to act and be more human, rather than trying to maintain the myth of the therapist as superperson with all the answers.

Although the ethical standards apply only to work related functions, the principles state that psychologists should be aware that personal "conduct may compromise their professional responsibilities or reduce the public's trust in psychology and psychologists" (Koocher and Keith-Spiegel, 1998, p. 446). This is particularly the case in rural communities where much is known about the psychologist, and personal and professional boundaries tend to become blurred. Cook, Copans, and Schetky (1998) assert that psychologists need to keep in mind that everything they do is a public act. Sterling (1992) and Sobel (1984) state psychologists must be concerned about their image in the community because local people will judge them on the basis of personal factors. It is important for the psychologist to be authentic, they will not be able to build trust if they say one thing in the therapy hour and do another on their personal time. In a sense, this requires rural psychologists to extend their thinking about ethical behavior into the realm of their personal lives, and to actively be a role model. On the positive side, Hargrove (1982) points out that due to greater public visibility the psychologist has a greater opportunity to have an impact on an entire community as a representative of the profession for which he or 
she practices. A survey respondent summed it up very well in saying, "You are a much more visible person and a much more significant person in the fabric of the community. I think because of that you have more of an opportunity as a professional to make a difference in the community" (Sullivan, Hasler, \& Otis, 1993, p. 500).

\section{Statement of the problem}

Ethical practices and standards are constantly evolving and changing. The ongoing development of ethical standards needs to be informed by theory, ideals, and the actual practices of psychologists. Theoretical ideals, or aspirations, are helpful only when it is possible to meet, or approximate those ideals. Therefore, we need to be aware of any gaps between our ethical ideals, ethical standards, and the actual practices of clinicians. As Pope (1991) states, “Our need for critical self-study, including the systematic collection of data regarding the occurrence and effects of dual relationships is apparent” (p. 27).

Secondly, the current ethical codes tend to prohibit behaviors, identifying those behaviors that are unethical. Pomerantz et al. (1998) point out there tends to be more agreement about behaviors that are unethical, and little agreement about behaviors that are uniformly ethical. The problem this leads to is that "psychotherapists have a clearer sense of what behaviors to avoid rather than which behaviors to enact when faced with an ethical dilemma” (p. 43). As mentioned earlier, this can lead to psychologists practicing in a defensive manner, rather than being proactive in their decision-making. Furthermore, we need to examine the interrelationship between ethical decision-making and clinical decision-making. Although this question is beyond the scope of the present study, it is hoped that this study will create an honest dialogue about the occurrence of ethical dilemmas in both rural and urban practice. The concern of this author is 
that clinicians do not feel comfortable talking about actual dilemmas in their practices for fear of censure. More honest dialogue about the ethical dilemmas faced in the practice of psychology will better inform ethical decision-making models, and future ethical codes.

A third issue is the many gray areas in the ethical codes in conjuncture with the use of ambiguous terms in the writing of the codes. It may not be that the codes need to be more explicit, but there is a need for discussion about these gray areas. Conte, Plutchik, Picard, and Karasu (1989) found "the results of the present survey of psychotherapists indicate a lack of consensus on the acceptability of behaviors cutting across most areas of clinical practice” (p. 38). They state this lack of consensus may be "interpreted in terms of lack of knowledge as well as in terms of genuine disagreement over inherently complex and ambiguous issues” (p. 41).

Finally, as discussed in the review of literature on rural psychology, we need more dialogue from persons who practice in specific types of communities that create more, or unique, ethical dilemmas. As stated previously, persons who practice in such a close knit community, whether in a rural area or the military for example, may be unwilling to discuss the reality of their practice for fear of censure by colleagues. Psychologists who practice in these areas are likely to feel isolated, that they do not have input into ethical standards, feel left out of discussions of what constitutes good practice, and may believe that mainstream urban-based ethics do not apply to them. Furthermore, practitioners working in specialized communities within urban areas, such as the deaf community, or gay/lesbian/bisexual community, face many of these same issues as rural psychologists. 


\section{Purpose of the Study}

The purpose of the present study is to build on previous research by gathering data concerning the ethical practices of psychologists. In particular, the field needs to be informed if there are, in fact, unique ethical concerns related to the practice of psychology in rural areas, and other small communities. This study will gather baseline data in order to generate honest dialogue regarding the practice of psychology in rural areas. The survey is intended to examine more closely those ethical dilemmas and problems that have already been identified in previous research as concerns of both urban and rural psychologists. Much of the previous research related to working in a rural area has been qualitative or theoretical. The survey-based research on ethical issues discussed herein did not focus specifically on comparing rural and urban communities. This study combines quantitative survey methods with the qualitative literature to begin the process of determining core ethical and practice issues across types of communities.

The goal of this project is not to highlight particular practices as unethical per se. Rather, the goal is to identify if there are unique problems that arise while practicing the profession of psychology in a rural community. The context used for this exploration is the ethical guidelines, highlighting ethical dilemmas that may arise in such a community. Similarly, the goal is not to criticize the ethics code, or the practice of psychology in urban areas. It does appear in the literature that psychology is an urban-based profession, primarily due to the fact most research institutions are located in urban settings. Whether or not rural practice is distinct from the practice of psychology in urban areas is an empirical question that this study only begins to address.

In addition to identifying potential ethical dilemmas and differences in the practice of psychology in rural areas, this study aims to identify ethical concerns for the field of psychology 
in general. As Pope, Tabachnick, and Keith-Speigel (1988) state "general surveys, as one among many sources of information on which psychologists base their professional opinions and decisions, can help to identify areas in which our formal and explicit professional standards are in need of clarification, revision, or more effective dissemination” (p. 549). Therefore, this study will examine other variables that may be related to ethical practices. For example, comparisons will be made across demographic variables, years of experience, theoretical orientation, work setting, and in comparison to previous survey results. This study will identify those ethical areas where there is consistency in practices among psychologists, as well as divergence, and determine which practices are of most concern across rural and urban practitioners.

\section{Research Questions}

1. Do rural psychologists encounter more ethical dilemmas and problems than urban psychologists? It is hypothesized that rural psychologists will report more multiple relationships, more confidentiality, burnout, competency, and visibility issues, than urban psychologists. It is further hypothesized rural psychologists will report more concern with these practices than urban psychologists.

2. Are there differences across gender with regard to these practices? It is hypothesized that males will report engaging in more dual relationships than females. Females will report more concerns with multiple relationship issues, and with ethical issues in general. No gender differences are expected with regard to other behaviors examined in this survey.

3. Are there differences across types of work settings? It is hypothesized that psychologists in private practice will report fewer behaviors indicative of burnout, more multiple 
relationships, more problems maintaining competency, and fewer problems with maintaining confidentiality.

4. Are there differences across years in practice (experience) on ethical practices? It is hypothesized that more experienced psychologists will engage in more behaviors related to multiple relationships. Furthermore, more experienced psychologists will report fewer behaviors associated with burnout.

5. Are there differences across theoretical orientation with regard to ethical practices? It is hypothesized that psychodynamic psychologists will report engaging in fewer multiple relationships than psychologists from other orientations. No other differences are expected across orientations. 


\section{CHAPTER II}

\section{METHODOLOGY}

\section{Introduction}

The purpose of this study was to examine differences in the practice of psychology across urban and rural areas. The context for studying these behaviors was the field of ethics and the current ethical standards. The study was not concerned, however, with identifying particular behaviors as unethical per se. The purpose of this study was to identify if, and how, the practice of psychology in rural areas leads to unique ethical dilemmas and problems that may not be encountered as frequently in urban areas. This is consequential because ethical practices and decision-making are often closely related to clinical decision-making and therapeutic practices (Gottlieb, 1994). Furthermore, we need to be aware of any gaps between our ethical ideals and the actual practices of psychologists. The current litigious atmosphere, with increases in lawsuits and ethical complaints against psychologists, makes it more exigent that we study our own behavior, with the goal of open and honest discussion regarding the ethical practice of psychology. This study also hoped to identify those areas that are controversial, behaviors for which there is little agreement or consensus among psychologists as to what constitutes ethical behavior. Additionally, data analysis examined differences across other demographic variables such as gender, theoretical orientation, work setting, and number of years experience.

Surveys provide a way to gather baseline data across a broad cross-section of the national population of psychologists. Studying the practice of rural psychology poses pragmatic problems, such as deciding which rural area to study, finding a representative rural area, or gaining access to rural therapists. Additionally, the goal of this study was to sample a wide range of communities, both urban and rural. By using a national survey of practices we could 
gather data from rural New England and rural New Mexico, rural areas with considerably different populations and resources, as well as across such culturally distinct urban areas as Boston and Albuquerque. The use of a survey instrument also allowed us to gather information confidentially, increasing the likelihood that we would obtain honest responses to sensitive questions. Finally, the use of a survey instrument enabled us to examine a broader range of behaviors, congruent with the goal of collecting baseline data on the actual practices of psychologists, and furthering honest discussion about defining the ethical practice of psychology.

\section{Definitions}

The primary independent variable in this study was the type of community, ranging from urban to rural. The definitions of rural and urban as used in this study were primarily derived from the U.S. Administration on Aging (Ricketts, Johnson-Webb, \& Taylor, 1998). This is a zip-code-based system developed in 1992 and is the same system the American Psychological Association used to stratify the current sample for this researcher. As with all other definitions of rural and urban, this system required a compromise between geographical and population considerations. The Administration on Aging defines rural as an area that is not urban. Urban communities comprise urbanized areas with a minimum population of 50,000 people or an incorporated or census designated place with 20,000-49,000 inhabitants outside an urbanized area. Thus, in this system a rural population was designated as a zip code area with less than 20,000 inhabitants. All other zip code areas were considered urban.

However, many people, including this researcher, may consider this definition overly broad and too simple. A population of twenty thousand people is rather large to be classified as a rural area. The Definitions of rural: A handbook for health policy makers and researchers (Ricketts, Johnson-Webb, \& Taylor, 1998) provides a variety of other, sometimes quite complicated, 
definitions based on geography, isolation, density, frontier status, and other criteria. It was not necessary to accommodate all aspects of these definitions for this study because the sampling frame was stratified by the American Psychological Association (APA) research office with the Administration on Aging definition. However, the demographics page asked participants to identify themselves as rural, small town, suburban, or urban. This allows for more sensitivity in comparison across groups, although the four groups were eventually collapsed into the urban/suburban and small town/rural dichotomy for statistical comparisons. (The collection of data based on the four groups, however, allows for future analysis of this data to answer other research questions). On the demographics page rural was defined as a population of less than 10,000. This figure represents another compromise, as the Census Bureau definition defines rural as less than 2,500 inhabitants, which is further subdivided into farm and non-farm classifications. Although more conservative, even the Census Bureau definition does not completely capture the essence of rural, as one can live in a small town, but be adjacent to a metropolitan area and have access to many urban resources. To address the proximity to urbanized areas, the U.S. Department of Agriculture includes urban influence codes in their definition, creating an urbanized continuum. A town of less than 10,000 and not adjacent to an urban area is considered less urbanized, while a town of less than 2,500 and not adjacent to an urban area is considered thinly populated.

This writer believed that for this study too conservative of a definition of rural, e.g. less than 2,500 inhabitants, would leave out many towns in which mental health practitioners do experience the difficulties described in the preceding rural literature review. Therefore, a final compromise was decided on to further categorize the 'community' independent variable. As stated, rural was defined as a population of less than 10,000 inhabitants and a small town was 
defined with a population of 10,000 to 19,999 inhabitants. The definitions of urban $(50,000)$ and suburban (20,000-49,999) were in keeping with the Administration on Aging classification, although it does not differentiate urban and suburban by zip code. As a third check of the classification, the demographics page asked the name of the town the subject lives in, which can then be checked against the handbook of definitions. It may be that a psychologist lives in a rural area as defined by our zip code, but works in an urbanized area. Therefore, the demographics page collects data on whether participants live and work in the same town or community.

Primary work setting was a second independent variable, comparing those in private practice to those who work in an agency or institution. Private practice consisted of either a solo or group practice. Agency settings included working in a hospital, mental health center, inpatient facility, a university setting, and an option to fill in another category. Based on previous research, it was expected there would be differences in behaviors and situations encountered between private practice psychologists and those who work for an agency. Another independent variable of interest was the theoretical orientation of the participant. As discussed previously, it was expected that psychodynamic psychologists are going to be more conservative in their relationships with patients compared to, say, humanistic psychologists. The major theoretical orientations were provided as options on the demographics page for the participants to choose from, including psychodynamic, behavioral, cognitive-behavioral, humanistic, gestalt, eclectic, and a space provided to write in other possible orientations. Gender was an independent variable of primary interest and differences were expected across gender for a variety of behaviors, particularly related to multiple relationships. Training cohort was defined by the number of years since graduating with the participant's current degree. 
Data for other variables was collected primarily for exploratory purposes. For example, we may expect differences based on relationship status, the number of years experience of the psychologist, the number of years in their current work setting, or the number of hours the psychologist sees clients for therapy. Race/ethnicity was collected to ensure a representative sample. Some questions on the demographics page were included for clarification purposes. For example, in comparing the experience of psychologists, it may be that one psychologist is new to the field, while another is also new to the field, but has many years of experience in a related field or in another employment setting (as discovered during respondent-expert review). Therefore one question asked for the number of years experience as a psychologist, while a second asked for the number of years experience in a related field, and to please specify that job title. Other questions that were included for their potential utility, or clarification, include the respondent's area of study, whether their program was APA accredited, and the number of years at the current work setting. The dependent variables for this study included the responses to the questions, whether considered together as a category, or as individual questions, as will be discussed in the section on the survey instrument.

\section{$\underline{\text { Participants }}$}

A computer-generated randomized list of 1,000 psychologists was obtained from the American Psychological Association (APA). This list was stratified, with 500 psychologists practicing in urban communities, and 500 in non-urban areas, as designated by their zip code. All participants are members of the APA. Rather than identifying practicing psychologists by their division (e.g. psychotherapy (29)) which is not representative of APA as a whole, the APA research office suggested using two other variables to identify those psychologists whose primary work is therapy. The first variable is that the psychologists are licensed in their state to 
practice psychology; the second is a special mental health fee that psychologists pay when they are practicing psychology. Using the zip code system to randomize the selection of the sample has its limitations. The list may include zip codes of psychologists that live in rural areas, but commute to urban areas or larger towns to work. Similarly, it may include psychologists who practice in rural areas, but live in a town without a 'rural' zip code. Therefore, the stratification of the sample was double-checked against information collected on the demographics page. As stated, the categories were eventually collapsed, as decided a priori, into a small town (including rural areas) and urban (including suburban areas) dichotomous variable. It was believed this would simplify between-group comparisons without changing the nature of the research (small town vs. urban), or the applicability of the results.

Another limitation with this sampling frame was that it is only generalizable to those psychologists who belong to the APA. Joining the APA, and the agreement to follow its ethical codes, is a self-selection process that may make APA members significantly different from psychologists who choose not to belong to APA. Psychologists who live and work in rural areas may be more likely not to join the APA than urban practitioners. Another limitation was, though the sample will consist of only licensed psychologists, in some states the respondent may have a masters' degree, creating an education confound. The demographics page collected data on the type of degree (Ph.D., M.S., Ed.D., Psy.D. etc.) and compared this to the general population of psychologists who belong to APA to test for significant educational differences. The selection of participants relied on random sampling, however, comparisons were made across community designation (comparing rural and urban groups) for many of the demographic variables, including gender and ethnicity, to ensure a representative sample. Comparisons were also made 
between this sample and the population of APA members as described shortly in the data analysis.

\section{$\underline{\text { Procedures }}$}

The survey instrument was mailed out to all members of the sample, along with a cover letter and postage paid return envelope. The cover letter explained the purpose of the research, and the importance of not responding in a socially desirable manner. This cover letter is included in Appendix A. Potential participants were informed of the voluntary nature of their participation, and that even if they choose to participate they were not required to answer every question; they were free to omit any question they found too sensitive. The cover letter contained assurances of confidentiality for the participants. No names were used on the survey itself. Initially the researcher had a list matching names to surveys through an identification number, though this is only for the purpose of data collection. Once all follow-up notices had been sent, after approximately eight weeks, data collection ceased and this researcher destroyed the list linking names to surveys. The cover letter also included an offer of sending results of the study to each participant, though this was kept separate from the survey data and does not identify a participant with a specific survey.

Four weeks after the initial mailing a follow-up reminder, in the form of a post card, was sent to those who had not returned the survey. Due to the size of the sample, it was not feasible to send an honorarium for each potential participant. Additionally, an honorarium or lottery offering a prize to participants was not believed to be necessary considering the professional level of the participants. A third mailing was conducted four weeks after the second reminder, though this mailing included another copy of the cover letter and a new survey form in case the first survey was misplaced. Data were collected by this researcher and entered into an SPSS 
program. Data were double-checked for accuracy during the initial entry of each survey. Additionally, this researcher randomly checked about every ten surveys to ensure accurate data entry. This researcher's goal was to obtain a response rate of $45-50 \%$, a rate compatible with previous surveys on ethics discussed in the previous chapter.

\section{Survey Instrument}

The final survey instrument consisted of 120 questions related to the practice of psychology. The instrument was based on other surveys discussed in Chapter 1, in some cases using the same questions, or modifications of questions from previous surveys (Ackerly, Burnell, Holder, \& Kurdek, 1988; Baer \& Murdock, 1995; Borys \& Pope, 1989; Lamb \& Catanzaro, 1998; Pope, Tabachnick, \& Keith-Spiegel, 1987; Rae \& Worchel, 1991). However, this investigator created many of the questions to address issues specific to rural areas. The instrument is included as Appendix B.

The survey questionnaire was divided into two sections. The first section contains demographic questions regarding age, sex, type of degree, theoretical orientation, type of community, number of years experience, training cohort, relationship status, and other relevant questions. The second part of the survey consisted of the 120 survey questions, followed by one open-ended question. The open-ended question allowed participants to clarify any of the questions they answered, particularly because many of these simple questions attempt to capture complex phenomena. Additionally, the open-ended question served to debrief participants, giving them a chance to express any thoughts or feelings that the questionnaire brought up for them. On the actual survey instrument the question order was mixed, although for analysis they were grouped according to the general categories of multiple relationships (34 questions), competency (34 questions), burnout (26 questions), visibility (11 questions), and confidentiality 
(14 questions). These particular groupings were based on topic areas from the previous surveys such as Pope et al. (1987) and the review of the literature.

For each question the respondent was asked to rate the frequency of the behavior in their practice. Ratings ranged along a scale from not applicable, never, rarely, sometimes, fairly often, and often. Participants were also asked to indicate whether the behavior is a concern for them. The goal of this was to capture whether participants feel particular situations or behaviors are a problem. For example, a psychologist may go out to lunch with clients, but not feel this is a problem or attempt to avoid the behavior. On the other hand, another psychologist may see a client at the gym on a regular basis, feel that it is a concern and be unsure of how to handle the situation. As stated in the research hypotheses, differences are expected across groups on the amount of concern expressed over these behaviors. A second goal of the 'concern' question was to determine which behaviors or situations are the most worrisome for psychologists in general. For this reason the question was not posed as a forced choice response, allowing respondents to check only those that cause the most concern or thought.

The questions were initially compiled from the literature on each category, to create a total of over 130 questions. The survey instrument was developed during a semester-long class on survey methods and scale development, allowing for continuous feedback from faculty and students from several disciplines. The survey was then given to several experts, and two respondent-experts for feedback on each of the questions. The experts were established professionals in the field of psychology, both clinical and academic. The respondent-experts were therapists who have worked in the field for close to twenty years. Experts were asked to evaluate the instrument for the content validity of the questions. In addition the experts were asked to evaluate wording, grammar, clarity, if the questions put them on the defensive, and 
whether the question seemed congruent with the topic area (e.g. multiple relationship or competency, etc.). A number of questions were changed on both the demographic page and the survey itself due to the feedback from the experts. There were too many changes to recount here, though changes reflected content, validity, grammar, wording that was likely to provoke defensiveness, as well as other changes. Although some items were eliminated in this process, others were added to get at a specific situation, or a single question that was too complex was reformatted into two questions.

Respondent-experts, on the other hand, were instructed to first take the survey as if they were a subject in the study, answering each question from their own experience. Then they were asked to provide similar feedback as the experts, only from the viewpoint of a respondent. This was particularly helpful to determine types of response patterns. For example, some questions were so obviously unethical that almost all respondents would answer "never". This may be important for some issues, and many of these questions needed to be retained, however too many questions of this type would lead to limited variability across participants, whereas the goal of this survey is to get at more frequently occurring behaviors. The respondent-expert responses also indicated where face-saving wording might encourage more honest responses. Holtgraves, Eck, and Lasky (1997) define face-saving wording as presenting the question in a way that either gives an excuse for the behavior, or shows that the researcher is understanding of the behavior. For example, the wording on the cover page of the survey was changed to show that these practices "involve complex issues and decisions" and that "sometimes agency or supervisory demands outweigh personal preferences." An example of a respondent-expert response differential came in the competency category. "Have to give assessment or psychological tests I do not feel adequately trained to give" was answered differently than "Administer a 
psychological test with which I have had little experience," with the latter resulting in a response of 'never', the former a response of 'sometimes'. It may be that not feeling adequately trained to give the test is face saving in that it puts the responsibility on the shoulders of a training program or supervisors. In this particular case, because both questions were asking about the same behavior, only the question that resulted in a response of 'sometimes' was retained.

Validity for the survey was not assessed by a quantifiable method resulting in a validity coefficient. However, the researcher used several methods to increase the content validity of the survey instrument. The review by experts and expert-respondents was one method to ensure the validity of the instrument, and to determine if the questions were valid indicators of the categories to which they were assigned. Additionally, the survey instrument was developed as part of a class project allowing for additional feedback from other students, several of whom came from different disciplines.

Another contribution to the validity of the current survey instrument, used in this context, was that many of the questions have been used repeatedly in the survey research discussed thus far (Ackerly, Burnell, Holder, \& Kurdek, 1988; Baer \& Murdock, 1995; Borys \& Pope, 1989; Hines, Ader, Chang, \& Rundell, 1998; Lamb \& Catanzaro, 1998; Percival \& Striefel, 1994; Pope, Tabachnick, \& Keith-Spiegel, 1987; Rae \& Worchel, 1991; Tubbs and Pomerantz, 2001). Because these questions have been utilized in several other studies, responses can be compared with the current study as an estimate of validity for those questions. For example, Tubbs and Pomerantz (2001) used the same survey as Pope, Tabachnick and Keith-Spiegel (1987) noting changes in responses from the original survey, though their study sample was limited to a single State (Illinois). These studies provide a rich source of response patterns across samples and populations for many of the questions. Furthermore, many of the previous studies also used 
expert panels to determine the validity of their questions, which, in addition to the expert review utilized for this study, suggests the questions are more likely to measure what they are intended to measure.

Reliability was assessed by two methods one formal, the other a more informal check of response patterns. The informal reliability check consisted of two sets of similar questions with slightly different wording, and spread out over the length of the survey. Question \#16 "Receive emotional support from a supervisor or mentor" and question \#119 "Receive support from a supervisory or mentoring relationship" should engender similar responses, as should question \#44 "Observe other therapists provide services outside their area of competence" and \#64 "Know colleagues who practice beyond their scope of training" though, admittedly, knowing and observing are not exactly the same. This method of estimating reliability has been used in several of the previous studies (Pope, Tabachnick, \& Keith-Spiegel, 1987; Tubbs \& Pomerantz, 2001). More formally, Cronbach's coefficient alpha was applied to each of the categories to determine if there is adequate internal consistency within each of the categories. It was not the intention of this project to develop specific scales for each category; however, higher internal reliability within the categories suggests that the category itself will be more meaningful as a unit of comparison, rather than having to work with the individual questions. Thus, the initial dependent variable was the category consisting of related questions (e.g. multiple relationships, competency), and only when this test was significant were the individual questions analyzed as dependent variables.

\section{$\underline{\text { Research Design and Analysis }}$}

The first step was to perform an exploratory analysis on the demographic data. Descriptive statistics included frequencies, means, and percentage rates that characterize the age, gender, 
ethnicity, years of experience, type of practice, and other demographic variables for the entire sample. Demographic characteristics were then compared across urban/suburban and small town/rural groups, and with the general population of the APA, using chi-square analysis (gender, ethnicity, orientation, etc.), or ANOVA (years experience, age, training cohort etc.) to ensure adequate sampling. Borys and Pope (1989) used a Factorial ANOVA to test for interactions between therapist characteristics and question responses and did not find any interactions. Therefore, it was decided it is not necessary to test for interactions with this sample. Next, Cronbach's coefficient alpha was applied to determine the internal consistency of responses to the survey items for the five categories of questions: multiple relationships, competency, burnout, confidentiality and visibility.

The primary research question compared differences in behaviors across 'community' categories. For this comparison, and subsequent comparisons, the four categories were collapsed into a dichotomous variable with urban/suburban as one category, and small town/rural as the second. Comparisons across groups for each question could have been done using chi-square and comparing the percentages for each category of the Likert scale (Pope, Tabachnick, \& KeithSpiegel, 1988). However, it was decided to weight each category (never $=1$, Rarely $=2$, etc.), and use a MANOVA to compare the two groups for each category of the dependent variable, and then follow-up with individual ANOVAs if the MANOVA was significant (Pomerantz et al., 1998; Rae \& Worchel, 1991). The level of significance for the MANOVA was set at .05, and the same level was used for follow-up ANOVAs.

In addition to reporting any questions in which there were significant differences, frequency data are reported for all questions for both urban/suburban and small town/rural categories. A table is provided that presents the percentages of responses for each Likert-scale category of each 
question. By reporting percentages for all of the data by community level, potentially useful response patterns may be identified even where the results were not significant. The converse may also hold true, we may find significant results that are not meaningful or important. For example, Pope, Tabachnick and Keith-Spiegel (1987) identified behaviors that are universal, those that are rare, and those that may be controversial, by frequency data alone. Similarly, in this study frequency data may inform which behaviors are common across communities, and which tend to occur mostly in one community or another. Finally, in testing our primary research question we identified differences across groups on the second part of each question, is the behavior or situation a concern for the respondent? This data is reported via tables highlighting the most reported concerns for psychologists from each community.

The other independent variables were tested using this same method of applying a MANOVA first, and if it was significant following up with ANOVA analyses. Gender was analyzed as it stands, comparing male and female psychologists. Work setting was collapsed into two categories, private practice and institutions or public agencies. This involved collapsing private practice-solo, and private practice-group into one category. The agency, or institution, category included all other settings: hospital, academic, community mental health center, and other. In regard to the research question it is only necessary to compare private practice with agency settings. Number of years experience remains a continuous variable, though it needed to be decided whether to use number of years as a psychologist, or number of years since obtaining the current degree, or both. By using the latter we can take experience and cohort effects into account at the same time. It was decided that this variable can best be dichotomized into 15 or more years of experience, and less than 15 years, to address the research question (less experienced versus more experienced psychologists). Only one of the research questions 
necessitated the use of post hoc analysis. The theoretical orientation independent variable remained as several categories because there was no meaningful way to collapse them, and therefore a Tukey HSD post hoc was performed to determine differences in responses across the orientations.

Although the demographics page was created to gather the maximum amount of potentially useful information for comparisons, not all of the information was to be used in this project. As mentioned above, we may loose some information due to the collapsing of categories even though this seemed the best method to answer the research question in an efficient and effective manner. Still other variables are included on the demographics page that were not hypothesis driven. These variables were intended for clarification or exploratory analysis. For example, comparisons may be made across APA accredited and non-accredited programs depending on the number of responses in each category. Number of hours of therapy per week was intended to ensure that the psychologists responding in the survey are actively seeing clients, as a double check with licensure status. However, it may also be hypothesized that those who see more clients are more likely to have more dual relationship experiences and to have more symptoms of burnout. Relationship status was not intended to address a specific research question, but may be used at a future time for exploratory purposes.

It was expected that a number of psychologists would respond to the open-ended question. As mentioned, this served two primary purposes. First it allowed respondents to clarify any responses they have made in the survey. Second, it provided a space for respondents to debrief, to express any frustration, experiences, feelings, or thoughts about taking the survey. It was also hoped that psychologists would choose to relate some personal experiences related to the questions raised in the survey. It was not intended as a qualitative study per se, but it was 
decided to include a summary of the qualitative responses in the discussion section. This was done in an informal manner, with this researcher organizing the responses into discrete categories, such as clarifications, responses to the survey, personal experiences, and suggestions. Then the qualitative data within each category were briefly summarized. 


\section{CHAPTER III}

Results

\section{$\underline{\text { Sample Characteristics }}$}

The total number of surveys returned was 534 (53.4\%), though six of these were returned as undeliverable. Eighty-seven returned blank surveys, as suggested in the cover letter in order to avoid receiving reminder cards, including some who have left the field of psychology, were hospitalized, or were otherwise unable to complete the survey. The total number of usable surveys for data analysis was 447 , for a response rate of $44.7 \%$, well within the goal range set by this researcher. Three mailings were conducted; the initial mailing of the survey, a follow-up reminder postcard, and a third mailing that involved resending the entire survey. At four weeks removed from the initial mailing, when the postcards were mailed, 276 surveys had been received. At this point there was still a steady stream of about five surveys per day received. Four weeks later, when the third mailing was sent, 352 surveys had been received. After another four weeks data collection was completed with the total of 447 completed surveys. The response rate is higher for urban and suburban areas, which was contrary to expectations as the survey was expected to appear highly applicable to rural practitioners, and it was expected that rural practitioners would have more of an investment in completing the survey. It may be, however, that the wording, which was carefully chosen so as not to create demand characteristics or be particularly focused on ethical issues related to a particular community type, was successful in achieving that affect. It may also be that rural practitioners are less likely to respond to surveys for a variety of reasons, including feeling overwhelmed with workloads, or not believing that research in this area sufficiently addresses rural practice. 
The majority of the demographic data will be considered in terms of contrasting the two community groups, urban/suburban, and small town/rural, however, comparisons between the overall sample and the population will be considered first. This study relied primarily on the use of a computer-generated random sampling method to ensure a representative sample. The American Psychological Association (APA) did provide some demographic data on the member population $(\mathrm{N}=71,825)$ from which the current sample was drawn. The mean age of the study sample is $51.35(\mathrm{SD}=8.2)$, and the population mean is $51.4(\mathrm{SD}=11.9)$. The mean number of years since obtaining their degree for the sample is $17.65(\mathrm{SD}=7.75)$, and for the population the mean number of years is $17.6(\mathrm{SD}=11.7)$. The percentage of female participants for this study is $57.1 \%$, and males $42.9 \%$, while the population percentages are females $49.2 \%$, and males $50.8 \%$. A $2 \times 2$ chi square analysis was conducted for gender, which was not significant, $\chi 2=$ $1.24, \mathrm{df}=1, \mathrm{p}>.05$. Due to the number of cells with expectancies less than five, chi square analysis could not be conducted for ethnicity. The sample appears to be more Caucasian (96.2 $\%$ ), compared to the APA membership (76.7\%). The sample has more private practitioners (69.5\%) compared to the APA population (36.2\%); however, this was an intended effect as the goal of sampling was to obtain a sample consisting primarily of psychologists who actively see clients in some capacity. This effect was achieved by having the APA research office use the criteria of having an active license to practice psychology, and paying the mental health fees to practice.

Other characteristics of the sample include the mean number of years in their current work setting $(M=11.88, \mathrm{SD}=8.40)$, number of years experience as a psychologist $(\mathrm{M}=18.09, \mathrm{SD}=$ $8.63)$, number of years in a related field $(\mathrm{M}=4.34, \mathrm{SD}=6.38)$, and number of hours respondents see clients for therapy each week $(M=21.29, \mathrm{SD}=12.71)$. Approximately 99\% (98.9) of the 
sample is licensed in psychology, as would be expected from the inclusion criteria, and $80 \%$ received their degree from an APA accredited institution. For highest degree awarded, 99.8 \% have a doctorate. Overall, it appears the sample is representative of the population of APA members, except for those variables in which representation was not the goal.

The breakdown of respondents by community type is reported with the work and educational demographics. It was decided a priori, for the purposes of data analysis, to combine urban and suburban into one group, (urb/sub), which accounts for $74.8 \%$ of the sample, and to combine small town and rural (sm/rural) into one category accounting for $25.2 \%$ of the sample. The demographics are thus reported, with percentages and total frequencies, by community type in Table 1 (personal characteristics) and Table 2 (work and educational characteristics).

Chi square analyses were conducted to determine if there were any differences between the two groups, comparing urb/sub versus sm/rural, though none is significant. A 2 × 2 chi square for gender resulted in $\chi^{2}=.20, \mathrm{df}=1, \mathrm{p}>.05$. Relationship status, due to several cells having expectancies less than five, was collapsed into a dichotomous variable, single or married, and the $2 \times 2$ chi square also is not significant $\chi^{2}=.69, \mathrm{df}=1, \mathrm{p}>.05$. Likewise, work setting was also collapsed into a dichotomous variable for all analyses, private practice and institutional settings, as this seems equally meaningful and simplifies data analysis. The $2 \times 2$ chi square for work setting by community is not significant $\chi^{2}=.15, \mathrm{df}=1, \mathrm{p}>.05$. For race/ethnicity almost all of the cells have expectancies less than 5, not allowing for an analysis. Because the entire sample was so highly represented by Caucasians, it does not appear that a meaningful difference exists between the two communities for race/ethnicity. Theoretical orientation also has several cells with expectancies less than five. Because there is no meaningful way to collapse the categories, those cells with less than five expectancies were left out, leaving psychodynamic, 
Table 1

Demographic Data by Urban/Suburban and Small Town/Rural Categories - Personal Data

\begin{tabular}{lccc}
\hline & & & \\
Demographics & Urb/Sub & Sm/Rural & Total N \\
& $(\%)$ & $(\%)$ & \\
\hline
\end{tabular}

Gender

Male 43.5

41.1

253

Female

56.5

58.9

190

$\underline{\text { Race/Ethnicity }}$

African American

$$
.9
$$

Asian

1.2

Caucasian

Hispanic/Latino

95.5

Native American

.6

Other

.3

1.5

0

3

0

4

98.2

0

428

2

$\underline{\text { Relationship Status }}$

Married

72.9

68.1

319

Remarried

6.9

8.0

32

Single

5.4

2.7

21

Divorced

Separated

9.6

9.7

43

Widow

.3

.9

2.7

2

Cohabitating

.9

2.7

Other

1.2

7.1

6

17

$\begin{array}{ll}.9 & 5\end{array}$

Note. Urb/Sub = urban and suburban; Sm/Rural = small town and rural. $\mathrm{N}=447$.

Not all frequency totals sum to 447 due to missing data. 
Table 2

Demographic Data by Urban/Suburban and Small Town/Rural Categories - Work/Education

\begin{tabular}{lccc}
\hline \multirow{2}{*}{ Demographics } & Urb/Sub & Sm/Rural & Total N \\
& $(\%)$ & $(\%)$ & \\
\hline
\end{tabular}

Work Community

$\begin{array}{lllr}\text { Urban } & 49.7 & -- & 222 \\ \text { Suburban } & 25.1 & -- & 112 \\ \text { Small town } & & 14.5 & 65 \\ \text { Rural } & & 10.7 & 48\end{array}$

Primary Work Setting

$\begin{array}{llll}\text { Private practice-solo } & 50.2 & 46.9 & 220\end{array}$

$\begin{array}{lll}\text { Private practice-group } & 19.8 & 21.2\end{array}$

Hospital $\quad 8.1 \quad 1.8 \quad 29$

$\begin{array}{llll}\text { University/Academics } & 5.1 & 2.7 & 20\end{array}$

$\begin{array}{llll}\text { Inpatient facility } & 2.7 & 4.4 & 14\end{array}$

$\begin{array}{llll}\text { Mental health center } & 4.2 & 10.6 & 26\end{array}$

$\begin{array}{llll}\text { Other } & 9.9 & 12.4 & 47\end{array}$

Current Theoretical Orientation

Psychodynamic 20.8

Behavioral 2.7

Cognitive-behavioral $\quad 38.1$

$\begin{array}{rrr}2.7 & .9 & 10\end{array}$

Humanistic

Gestalt

1.2

41.4

Eclectic

0

7.2

1.8

$\begin{array}{lll}30.5 & 32.4 & 137\end{array}$

4.5

82

10
172

12

Other

6.6

72.0

66.4

314

$15.7 \quad 19.5$

$.3 \quad 0$

$.3 \quad 0$

$5.1 \quad 8.0$

27

Clinical Psychology
Counseling Psychology

Experimental Psychology

I/O Psychology

1

School Psychology

6.6

6.2

Other

Note. Urb/Sub = urban and suburban; Sm/Rural = small town and rural. $\mathrm{N}=447$.

Not all frequency totals sum to 447 due to missing data. 
cognitive-behavioral, eclectic, and other, which are not significantly different between the two community categories in a $4 \times 2$ analysis $\chi 2=4.53, \mathrm{df}=3, \mathrm{p}>.05$. This same method was adopted for area of study, leaving clinical psychology, counseling psychology, school psychology, and other, which is not significant in the $4 \times 2$ analysis, $\chi 2=2.31, \mathrm{df}=3, \mathrm{p}>.05$.

ANOVAs were conducted with "community" as the independent variable, and the remaining demographic characteristics as dependent variables, none of which were significantly different. Mean age for urb/sub is 51.11 , and for $\mathrm{sm} / \mathrm{rural}$ is $52.05, \mathrm{~F}(1,428)=1.09, \mathrm{p}>.05$. The mean years on the job for urb/sub $=12.04$, and for sm/rural 11.39, $\mathrm{F}(1,439)=.510, \mathrm{p}>.05$. The mean number of years since obtaining degree for urb/sub is 17.44 , and for sm/rural $18.30, \mathrm{~F}(1,443)=$ $1.04, p>.05$. Mean number of years experience as a psychologist for urb/sub is 17.95 , and for $\mathrm{sm} /$ rural is $18.51, \mathrm{~F}(1,441)=.362, \mathrm{p}>.05$. The mean number of years in a related field for $\mathrm{urb} / \mathrm{sub}$ is 4.30 , and $\mathrm{sm} / \mathrm{rural} 4.45, \mathrm{~F}(1,442)=.043, \mathrm{p}>.05$. The mean number of hours participants see clients for therapy in urb/sub communities is 21.47 , and for sm/rural is 20.76 , $\mathrm{F}(1,439)=.252, \mathrm{p}>.05$. It appears the two community groups are equivalent on all of the demographic variables collected for this study.

\section{$\underline{\text { Reliability Checks }}$}

Reliability was assessed by several methods, both formal and informal. Formally, Cronbach's alpha was calculated for each of the categories that are used for MANOVA analyses. These categories were not created for the purpose of defining a specific scale, but rather to simply group questions for statistical consideration. Similarly, the categories were composed of questions that address different behaviors and situations that psychologists are likely to encounter in all communities, rather than choosing only those behaviors that were likely to create the most divergence between rural and urban communities. Questions are therefore included for 
each category for which the researcher did not expect to find differences between communities. The internal consistency of the categories, however, was very respectable. The category “multiple relationships” consists of 34 questions, and has a Cronbach's $\alpha=.8981, \mathrm{~N}=424$. "Competency" also consists of 34 questions and has a Cronbach's $\alpha=.8289, \mathrm{~N}=419$. The “burnout" category consists of 26 questions, and has a Crobnbach's $\alpha=.7059, \mathrm{~N}=431$. "Confidentiality" has the lowest internal consistency with Cronbach's $\alpha=.6278, \mathrm{~N}=429$. It should also be noted that the confidentiality category originally included 14 questions. However, question \#108, was left blank by a large percentage of respondents, and several remarked the question was too confusing. Therefore it was excluded from all analyses, leaving 13 questions for the confidentiality category. Visibility consists of 11 questions with Cronbach's $\alpha=.8413$, $\mathrm{N}=432$.

A second reliability check included comparison of three pairs of questions that were spaced widely apart in the survey, but have similar concepts and wording, to determine if the responses were correlated. Question \#16 “Receive emotional support from a supervisor or mentor," with a mean weighted response of $2.72(\mathrm{SD}=1.19)$ engendered similar responses as question \#119 "Receive support from a supervisory or mentoring relationship," with a mean response of 2.63 $(\mathrm{SD}=1.41)$, with $\mathrm{N}=445,446$ respectively. Pearson correlation for this question is significant $(\mathrm{r}=.667, \mathrm{p}<.01$, two-tailed $)$. A second set of questions included \#44 "Observe other therapists provide services outside their area of competence" having a mean weighted response of 2.20 (SD =1.0), while question \#64 "Know colleagues who practice beyond their scope of training" received a mean score of $2.22(\mathrm{SD}=.98)$. Pearson correlation is significant $(\mathrm{r}=.652, \mathrm{p}<.01$, two-tailed). The third pair of questions includes \#27 "Sometimes have to take clients that have problems that are beyond your scope of training and experience" with a mean score of 1.73 (SD 
$=.70$ ), and \#69 "Have to treat populations (children, ethnic groups) for which you do not feel you have adequate training" which received a mean score of $1.71(\mathrm{SD}=.70)$. Pearson correlation is also significant for this pair of questions $(\mathrm{r}=.501, \mathrm{p}<.01$, two-tailed).

A final, informal reliability check includes the question "Have accepted an offer of a handshake from a client" (\#115) to determine social desirability. Previous surveys have used this question to determine if participants were being overly defensive. The question was included in this survey for the same purpose, and to compare the results to previous surveys. In this survey, $1.5 \%$ of urb/sub respondents responded "never," while $0.0 \%$ of sm/rural psychologists responded "never," suggesting participants were not being overly defensive. This response rate is similar to previous studies, such as Pope et al. (1987) with $1.3 \%$ responding "never", and Rae and Worchel (1991) with .6 \% responding "never." This researcher also observed, while entering data, that question \#100 "Discuss clients with friends, using client names" has response rates of $97.9 \%$ (urb/sub) and $99.1 \%$ (sm/rural) for the rating of "never" (see Table 3), suggesting participants were still paying close attention to the wording of questions at this late point in the survey.

\section{Primary Research Questions}

Table 3 lists the response percentages for all 120 questions. The questions are grouped according to category, except for question $\# 115$, placed at the end of the table, which was included only as a measure of social desirability. Question \#108 is listed in the table although it was excluded from any analysis. Questions which resulted in a significant difference on the main research question of urb/sub versus sm/rural are marked with an asterisk or a double asterisk if the significance level was below .01. More detail on those questions that are significantly different, with their respective significance levels, follows after the MANOVA tests 
Rural Ethics 80

Table 3

Percentage of Responses for Each Survey Question Across Urban and Small Town Categories

\begin{tabular}{|c|c|c|c|c|c|c|c|c|}
\hline \multirow[b]{2}{*}{ Question } & \multicolumn{8}{|c|}{ Likert Rating } \\
\hline & $\mathrm{C}$ & 1 & 2 & 3 & 4 & 5 & 6 & $\mathrm{PC}$ \\
\hline \multicolumn{9}{|l|}{ Multiple Relationships } \\
\hline \multirow{2}{*}{ 2. Charge a client no fee for therapy } & $\mathrm{U}$ & 24.9 & 33.8 & 23.7 & 3.0 & 3.9 & 10.8 & 1.8 \\
\hline & $\mathrm{S}$ & 14.2 & 39.8 & 27.4 & 3.5 & 5.3 & 9.7 & 2.7 \\
\hline \multirow[t]{2}{*}{ 3. Provide therapy to one of your friends } & $\mathrm{U}$ & 87.7 & 8.4 & 1.5 & .3 & 0 & 2.1 & 1.2 \\
\hline & $\mathrm{S}^{*}$ & 81.4 & 13.3 & 1.8 & .9 & 0 & 2.7 & 3.5 \\
\hline \multirow[t]{2}{*}{ 6. Provide therapy to a relative of a friend } & $\mathrm{U}$ & 64.0 & 24.3 & 8.4 & 1.2 & 0 & 2.1 & 1.8 \\
\hline & $\mathrm{S} * *$ & 49.1 & 23.2 & 23.2 & .9 & .9 & 2.7 & 1.8 \\
\hline \multirow{2}{*}{$\begin{array}{l}\text { 7. Provide therapy to an employee or } \\
\text { coworker }\end{array}$} & $\mathrm{U}$ & 84.6 & 8.7 & 3.0 & .6 & .3 & 2.7 & 2.4 \\
\hline & $\mathrm{S}$ & 85.0 & 8.8 & 1.8 & 0 & .9 & 3.5 & .9 \\
\hline \multirow{2}{*}{$\begin{array}{l}\text { 8. Accept goods or services in lieu of a } \\
\text { fee }\end{array}$} & $\mathrm{U}$ & 85.9 & 9.0 & 2.4 & 0 & .3 & 2.4 & 6 \\
\hline & $\mathrm{S}^{*}$ & 70.8 & 20.4 & 3.5 & 0 & 0 & 5.3 & .9 \\
\hline \multirow{2}{*}{$\begin{array}{l}\text { 10. Use self-disclosure as a therapy } \\
\text { technique }\end{array}$} & $\mathrm{U}$ & 5.4 & 23.4 & 49.1 & 12.3 & 8.1 & 1.8 & 2.1 \\
\hline & $\mathrm{S}$ & 3.5 & 30.1 & 46.9 & 8.8 & 9.7 & .9 & .9 \\
\hline \multirow[t]{2}{*}{ 11. Invite clients to an open house } & $\mathrm{U}$ & 91.9 & 3.0 & 2.4 & 0 & .3 & 2.4 & 6 \\
\hline & $\mathrm{S}$ & 85.0 & 10.6 & 1.8 & 0 & 0 & 2.7 & .0 \\
\hline \multirow{2}{*}{$\begin{array}{l}\text { 12. Accept a client's gift worth at least } \\
\$ 50\end{array}$} & $\mathrm{U}$ & 85.3 & 9.6 & 3.0 & .6 & 0 & 1.5 & 1.8 \\
\hline & $\mathrm{S}$ & 86.7 & 9.7 & .9 & 0 & 0 & 2.7 & 1.8 \\
\hline \multirow[t]{2}{*}{ 13. Request favors from a client } & $\mathrm{U}$ & 86.2 & 12.3 & 1.2 & 0 & 0 & .3 & 1.8 \\
\hline & $\mathrm{S}$ & 86.7 & 11.5 & .9 & 0 & 0 & .9 & 2.7 \\
\hline \multirow{2}{*}{$\begin{array}{l}\text { 15. Attend a client's special event (e.g. } \\
\text { wedding, graduation) }\end{array}$} & $\mathrm{U}$ & 42.6 & 45.6 & 10.3 & .9 & 0 & .6 & 1.5 \\
\hline & $\mathrm{S}$ & 36.3 & 45.1 & 16.8 & 1.8 & 0 & 0 & 4.4 \\
\hline \multirow{2}{*}{$\begin{array}{l}\text { 17. Purchase goods or services from a } \\
\text { place or business where a client works }\end{array}$} & $\mathrm{U}$ & 43.4 & 35.9 & 16.2 & 1.5 & .9 & 2.1 & 1.5 \\
\hline & $\mathrm{S} * *$ & 11.5 & 27.4 & 33.6 & 14.2 & 9.7 & 3.5 & 2.7 \\
\hline \multirow{2}{*}{$\begin{array}{l}\text { 18. Work with a client in a community } \\
\text { setting (PTA, Church group) }\end{array}$} & $\mathrm{U}$ & 60.8 & 29.9 & 6.0 & 1.2 & .3 & 1.8 & 1.2 \\
\hline & $\mathrm{S} * *$ & 38.1 & 26.5 & 19.5 & 4.4 & 6.2 & 5.3 & 3.5 \\
\hline \multirow{2}{*}{$\begin{array}{l}\text { 19. Accept a gift worth less than } \$ 20 \\
\text { from a client }\end{array}$} & $\mathrm{U}$ & 23.1 & 44.0 & 30.5 & 1.2 & .6 & .6 & 2.1 \\
\hline & $\mathrm{S}$ & 27.4 & 43.4 & 21.2 & 3.5 & 2.7 & 1.8 & 1.8 \\
\hline
\end{tabular}

Note. $\mathrm{C}=$ community; $1=$ never; $2=$ rarely; $3=$ sometimes; $4=$ fairly often; $5=$ often; $6=$ not applicable; $\mathrm{PC}=$ percent concerned (percentage of psychologists who indicated by check mark a concern for the behavior).

$\mathrm{U}=$ urban/suburban; $\mathrm{S}=$ small town/rural.

${ }^{*} \underline{p}<.05 .{ }^{* *} \mathfrak{p}<.01$. (The community type with the asterisk is significantly greater) 
Rural Ethics 81

Table 3 (Continued from previous page)

Percentage of Responses for Each Survey Question Across Urban and Small Town Categories

Likert Rating

\begin{tabular}{|c|c|c|c|c|c|c|c|c|}
\hline \multirow{3}{*}{$\begin{array}{l}\text { Question } \\
\text { 23. Provide individual therapy to a lover } \\
\text { of an ongoing client }\end{array}$} & $\mathrm{C}$ & 1 & 2 & 3 & 4 & 5 & 6 & PC \\
\hline & $\bar{U}$ & 72.3 & 15.7 & 8.7 & .3 & .3 & 2.7 & .9 \\
\hline & $\mathrm{S}^{*}$ & 57.5 & 24.8 & 13.3 & 1.8 & 0 & 2.7 & .9 \\
\hline \multirow{2}{*}{$\begin{array}{l}\text { 24. Provide therapy to a child of one of } \\
\text { your friends }\end{array}$} & $\mathrm{U}$ & 79.3 & 15.0 & 1.8 & .6 & 0 & 3.3 & .6 \\
\hline & $\mathrm{S}^{*}$ & 69.0 & 18.6 & 7.1 & 0 & .9 & 4.4 & 2.7 \\
\hline \multirow{2}{*}{$\begin{array}{l}\text { 25. Become social friends with parents } \\
\text { of a former client }\end{array}$} & $\mathrm{U}$ & 86.5 & 10.8 & .9 & 0 & 0 & 1.8 & .3 \\
\hline & $\mathrm{S}^{*}$ & 71.7 & 18.6 & 3.5 & 0 & 0 & 6.2 & .9 \\
\hline \multirow{2}{*}{$\begin{array}{l}\text { 26. Find yourself working with two clients } \\
\text { who happen to have a relationship with } \\
\text { each other }\end{array}$} & $\mathrm{U}$ & 21.9 & 42.0 & 32.1 & 2.1 & .9 & .9 & 3.9 \\
\hline & $\mathrm{S}^{* *}$ & 17.7 & 30.1 & 35.4 & 10.6 & 4.4 & 1.8 & 7.1 \\
\hline \multirow{2}{*}{$\begin{array}{l}\text { 28. Provide therapy to a relative of } \\
\text { an ongoing client }\end{array}$} & $\mathrm{U}$ & 39.0 & 33.3 & 21.9 & 3.0 & .3 & 2.4 & 2.7 \\
\hline & $\mathrm{S}^{* *}$ & 25.7 & 31.9 & 29.2 & 10.6 & .9 & 1.8 & 2.7 \\
\hline \multirow{2}{*}{$\begin{array}{l}\text { 29. Attend a party or social gathering and } \\
\text { run into a client }\end{array}$} & $\mathrm{U}$ & 22.2 & 41.6 & 31.7 & 2.4 & 1.8 & .3 & 3.9 \\
\hline & $\mathrm{S} * *$ & 15.0 & 25.7 & 35.4 & 10.6 & 12.4 & .9 & 4.4 \\
\hline \multirow{2}{*}{$\begin{array}{l}\text { 30. Find that your children have become } \\
\text { friends with a client, or a client's children }\end{array}$} & $\mathrm{U}$ & 58.7 & 23.7 & 6.3 & .9 & .3 & 10.2 & 2.7 \\
\hline & $\mathrm{S} * *$ & 35.4 & 18.6 & 14.2 & 5.3 & 4.3 & 22.1 & 3.5 \\
\hline \multirow{2}{*}{$\begin{array}{l}\text { 32. Provide therapy to a client with whom } \\
\text { you have had a previous social relationship }\end{array}$} & $\mathrm{U}$ & 77.8 & 17.7 & 3.3 & 0 & 0 & 1.2 & 1.2 \\
\hline & $\mathrm{S}^{* *}$ & 54.0 & 34.5 & 8.0 & 0 & .9 & 2.7 & 5.3 \\
\hline \multirow[t]{2}{*}{ 34. Provide therapy to a fellow coworker } & $\mathrm{U}$ & 87.4 & 7.2 & 2.7 & 0 & 0 & 2.7 & 6 \\
\hline & $\mathrm{S}$ & 81.4 & 11.5 & 2.7 & 0 & .9 & 3.5 & .9 \\
\hline \multirow{2}{*}{$\begin{array}{l}\text { 35. Loan books or other personal } \\
\text { possessions to a client }\end{array}$} & $\mathrm{U}$ & 28.3 & 30.1 & 34.9 & 4.5 & 2.1 & 0 & .9 \\
\hline & $\mathrm{S}^{* *}$ & 17.7 & 33.6 & 30.1 & 8.0 & 9.7 & .9 & .9 \\
\hline \multirow{2}{*}{$\begin{array}{l}\text { 48. Socialize with a client after terminating } \\
\text { therapy }\end{array}$} & $\mathrm{U}$ & 77.2 & 21.0 & 1.5 & 0 & 0 & .3 & .3 \\
\hline & $\mathrm{S} * *$ & 57.5 & 35.4 & 3.5 & 1.8 & 0 & 1.8 & 4.4 \\
\hline \multirow{2}{*}{$\begin{array}{l}\text { 54. Become social friends with a former } \\
\text { client }\end{array}$} & $\mathrm{U}$ & 85.3 & 12.3 & 2.1 & 0 & .3 & 0 & 0 \\
\hline & $\mathrm{S}$ & 71.7 & 26.5 & 0 & 0 & 0 & 1.8 & .9 \\
\hline \multirow{2}{*}{$\begin{array}{l}\text { 57. Provide therapy to a friend of an } \\
\text { employee }\end{array}$} & $\mathrm{U}$ & 60.5 & 17.8 & 9.3 & 0 & 0 & 12.3 & 0 \\
\hline & $\mathrm{S}$ & 15.0 & 45.1 & 23.9 & 11.5 & 2.7 & 1.8 & 0 \\
\hline 71. Provide therapy to a client whom you & $\mathrm{U}$ & 46.1 & 33.1 & 15.7 & 2.1 & .6 & 2.4 & .6 \\
\hline $\begin{array}{l}\text { know of from being in the same social } \\
\text { sphere }\end{array}$ & $\mathrm{S} * *$ & 33.0 & 34.8 & 19.6 & 6.3 & 3.6 & 2.7 & 1.8 \\
\hline
\end{tabular}

Note. $\mathrm{C}=$ community; $1=$ never; $2=$ rarely; $3=$ sometimes; $4=$ fairly often; $5=$ often; $6=$ not applicable; $\mathrm{PC}=$ percent concerned (percentage of psychologists who indicated by check mark a concern for the behavior).

$\mathrm{U}=$ urban/suburban; $\mathrm{S}=$ small town/rural.

${ }^{*} \mathrm{p}<.05 .{ }^{* *} \mathrm{p}<.01$. (The community type with the asterisk is significantly greater) 
Rural Ethics 82

Table 3 (Continued from previous page)

Percentage of Responses for Each Survey Question Across Urban and Small Town Categories

Likert Rating

\begin{tabular}{|c|c|c|c|c|c|c|c|c|}
\hline Question & $\mathrm{C}$ & 1 & 2 & 3 & 4 & 5 & 6 & $\mathrm{PC}$ \\
\hline \multirow{2}{*}{$\begin{array}{l}\text { 78. Have a current or former client become } \\
\text { employed in your agency }\end{array}$} & $\overline{\mathrm{U}}$ & 74.6 & 10.2 & 1.8 & .6 & .6 & 12.3 & .6 \\
\hline & S & 59.3 & 19.5 & 5.3 & .9 & 0 & 15.0 & 1.8 \\
\hline \multirow{2}{*}{$\begin{array}{l}\text { 83. Provide therapy to a friend of a current } \\
\text { client }\end{array}$} & $\mathrm{U}$ & 34.6 & 28.0 & 30.1 & 4.5 & .9 & 1.8 & .3 \\
\hline & $\mathrm{S}^{* *}$ & 20.5 & 25.9 & 36.6 & 12.5 & 2.7 & 1.8 & 1.8 \\
\hline \multirow[t]{2}{*}{ 86. Go into business with a former client } & U & 97.0 & 1.2 & 0 & 0 & 0 & 1.8 & .9 \\
\hline & $\mathrm{S}$ & 95.5 & 0 & 0 & 0 & 0 & 4.5 & .9 \\
\hline \multirow{2}{*}{$\begin{array}{l}\text { 87. Find yourself working with a client } \\
\text { who discusses problems with a person } \\
\text { who is also your client }\end{array}$} & $\mathrm{U}$ & 35.4 & 43.2 & 17.7 & 1.8 & .3 & 1.5 & 1.8 \\
\hline & $\mathrm{S}^{* *}$ & 23.2 & 36.6 & 31.3 & 5.4 & 1.8 & 1.8 & 4.5 \\
\hline \multirow{2}{*}{$\begin{array}{l}\text { 88. Purchase goods or services from a } \\
\text { client }\end{array}$} & $\mathrm{U}$ & 76.3 & 20.1 & 2.1 & .3 & .3 & .9 & .9 \\
\hline & $\mathrm{S}^{* *}$ & 50.4 & 24.8 & 15.9 & 3.5 & 3.5 & 1.8 & 2.7 \\
\hline \multirow{2}{*}{ 93. Accept a client's invitation to a party } & U & 82.0 & 14.7 & .9 & .3 & 0 & 2.1 & .9 \\
\hline & $\mathrm{S}$ & 84.1 & 8.8 & 3.5 & .9 & 0 & 2.7 & .9 \\
\hline \multirow{2}{*}{ 106. Dine with a client after a session } & $\mathrm{U}$ & 95.5 & 3.6 & .3 & .3 & 0 & .3 & .3 \\
\hline & $\mathrm{S}$ & 92.0 & 4.4 & 1.8 & 0 & 0 & 1.8 & 0 \\
\hline \multicolumn{9}{|l|}{ Competency } \\
\hline \multirow{2}{*}{$\begin{array}{l}\text { 1. Read professional journals related } \\
\text { to your practice }\end{array}$} & $\mathrm{U}$ & .9 & 13.8 & 37.4 & 26.9 & 21.0 & 0 & 6.9 \\
\hline & S & .9 & 12.4 & 31.9 & 30.0 & 24.8 & 0 & 7.1 \\
\hline \multirow{2}{*}{$\begin{array}{l}\text { 4. Refer clients to other specialists in the } \\
\text { field of psychology }\end{array}$} & $\mathrm{U}$ & 0 & 6.0 & 38.4 & 27.9 & 26.7 & .9 & .6 \\
\hline & $\mathrm{S}$ & 0 & 9.7 & 41.6 & 22.1 & 23.9 & 2.7 & .9 \\
\hline \multirow{2}{*}{$\begin{array}{l}\text { 21. Consult with peers/colleagues on } \\
\text { difficult cases }\end{array}$} & $\mathrm{U}$ & .6 & 6.0 & 41.1 & 29.7 & 22.2 & .3 & .9 \\
\hline & $\mathrm{S}$ & 0 & 9.7 & 41.6 & 30.1 & 18.6 & 0 & 3.5 \\
\hline \multirow{2}{*}{$\begin{array}{l}\text { 27. Sometimes have to take clients that } \\
\text { have problems beyond your scope of } \\
\text { training and experience }\end{array}$} & $\mathrm{U}$ & 39.9 & 47.4 & 11.4 & .6 & 0 & .6 & 5.7 \\
\hline & $\mathrm{S}$ & 34.5 & 49.6 & 15.0 & 0 & 0 & .9 & 5.3 \\
\hline \multirow{2}{*}{$\begin{array}{l}\text { 31. Meet with peers to discuss clinical } \\
\text { casework }\end{array}$} & $\mathrm{U}$ & 6.6 & 17.7 & 32.6 & 23.1 & 19.8 & .3 & 2.1 \\
\hline & $\mathrm{S}$ & 8.8 & 23.0 & 29.2 & 23.0 & 13.3 & 2.7 & 0 \\
\hline \multirow{2}{*}{$\begin{array}{l}\text { 36. Have to administer assessments or } \\
\text { psychological tests you do not feel } \\
\text { adequately trained to give }\end{array}$} & U & 84.1 & 11.4 & 1.5 & 0 & .6 & 2.4 & .6 \\
\hline & $\mathrm{S}$ & 80.5 & 10.6 & 3.5 & 0 & 0 & 5.3 & .9 \\
\hline
\end{tabular}

Note. $\mathrm{C}=$ community; $1=$ never; $2=$ rarely; $3=$ sometimes; $4=$ fairly often; $5=$ often; $6=$ not applicable; $\mathrm{PC}=$ percent concerned (percentage of psychologists who indicated by check mark a concern for the behavior).

$\mathrm{U}=$ urban/suburban; $\mathrm{S}=$ small town/rural.

${ }^{*} \mathrm{p}<.05 .{ }^{*} \mathrm{p}<.01$. (The community type with the asterisk is significantly greater) 
Table 3 (Continued from previous page)

Percentage of Responses for Each Survey Question Across Urban and Small Town Categories

Likert Rating

\begin{tabular}{|c|c|c|c|c|c|c|c|c|}
\hline Question & $\mathrm{C}$ & 1 & 2 & 3 & 4 & 5 & 6 & $\mathrm{PC}$ \\
\hline 38. Have cases where more referral sources & $\bar{U}$ & 5.4 & 16.6 & 53.6 & 12.7 & 9.6 & 2.1 & 8.1 \\
\hline would have been helpful in your work & S & 1.8 & 9.1 & 50.0 & 20.0 & 13.6 & 5.5 & 10.9 \\
\hline \multirow{2}{*}{$\begin{array}{l}\text { 39. Provide therapy to a client whose } \mathrm{dx} \\
\text { is outside your area of competence }\end{array}$} & U & 46.1 & 45.5 & 6.3 & 0 & .3 & 1.8 & 3.6 \\
\hline & $\mathrm{S}$ & 46.0 & 45.1 & 7.1 & 0 & 0 & 1.8 & 3.5 \\
\hline \multirow{2}{*}{$\begin{array}{l}\text { 41. Consult with specialists within the field } \\
\text { of psychology }\end{array}$} & $\mathrm{U}$ & .9 & 17.5 & 52.7 & 19.3 & 9.6 & 0 & .6 \\
\hline & $\mathrm{S}$ & .9 & 29.2 & 40.7 & 21.2 & 8.0 & 0 & .9 \\
\hline \multirow{2}{*}{$\begin{array}{l}\text { 43. Take continuing education classes on } \\
\text { areas of psychology that are of interest }\end{array}$} & $\mathrm{U}$ & 0 & 3.6 & 18.9 & 33.9 & 43.5 & 0 & 2.1 \\
\hline & $\mathrm{S}$ & 1.8 & 5.3 & 10.6 & 36.3 & 46.0 & 0 & .9 \\
\hline \multirow{2}{*}{$\begin{array}{l}\text { 44. Observe other therapists provide } \\
\text { services outside their area of competence }\end{array}$} & $\mathrm{U}$ & 21.0 & 38.6 & 28.6 & 6.4 & 1.5 & 4.0 & 5.2 \\
\hline & $\mathrm{S}$ & 12.4 & 41.6 & 33.6 & 4.4 & 2.7 & 5.3 & 5.3 \\
\hline \multirow{2}{*}{$\begin{array}{l}\text { 45. Discuss theory and the practice of } \\
\text { psychology with colleagues }\end{array}$} & $\mathrm{U}$ & 1.5 & 9.6 & 39.9 & 29.1 & 19.8 & 0 & 1.8 \\
\hline & $\mathrm{S}$ & 0 & 15.0 & 38.9 & 29.2 & 16.8 & 0 & .9 \\
\hline \multirow{2}{*}{$\begin{array}{l}\text { 51. Provide regularly scheduled clinical } \\
\text { services via the telephone }\end{array}$} & $\mathrm{U}$ & 44.0 & 38.9 & 15.4 & .3 & 1.2 & .3 & .9 \\
\hline & $\mathrm{S}$ & 45.1 & 37.2 & 12.4 & 2.7 & 1.8 & .9 & 0 \\
\hline \multirow{2}{*}{$\begin{array}{l}\text { 52. Not be able to refer clients because of } \\
\text { a lack of referral services }\end{array}$} & $\mathrm{U}$ & 28.3 & 39.5 & 25.6 & 3.0 & 2.4 & 1.2 & 5.4 \\
\hline & $\mathrm{S}^{* *}$ & 12.6 & 28.8 & 39.6 & 10.8 & 6.3 & 1.8 & 9.8 \\
\hline \multirow{2}{*}{$\begin{array}{l}\text { 53. Refer clients after finding that the } \\
\text { client is not making any progress }\end{array}$} & $\mathrm{U}$ & 7.2 & 35.4 & 45.3 & 4.2 & 1.8 & 6.0 & 1.5 \\
\hline & $\mathrm{S}$ & 4.4 & 38.1 & 46.0 & 6.2 & 1.8 & 3.5 & .9 \\
\hline \multirow{2}{*}{$\begin{array}{l}\text { 55. Find that your ethical beliefs conflict } \\
\text { with those of other professionals with } \\
\text { whom you work }\end{array}$} & $\mathrm{U}$ & 19.6 & 54.5 & 20.5 & 2.4 & 1.2 & 1.8 & 2.4 \\
\hline & $\mathrm{S}$ & 14.2 & 55.8 & 26.5 & .9 & .9 & 1.8 & 4.4 \\
\hline \multirow{2}{*}{$\begin{array}{l}\text { 56. Have time to devote to professional } \\
\text { development }\end{array}$} & $\mathrm{U}$ & 0 & 6.9 & 44.4 & 32.4 & 16.2 & 0 & 3.9 \\
\hline & $\mathrm{S}$ & .9 & 6.2 & 47.8 & 36.3 & 8.8 & 0 & 3.5 \\
\hline \multirow{2}{*}{$\begin{array}{l}\text { 58. Obtain regular training and supervision } \\
\text { on new techniques and clinical skills }\end{array}$} & $\mathrm{U}$ & 2.1 & 20.1 & 35.4 & 26.7 & 15.3 & .3 & 2.4 \\
\hline & $\mathrm{S}$ & 4.4 & 13.3 & 36.3 & 30.1 & 14.2 & 1.8 & 1.8 \\
\hline \multirow{2}{*}{$\begin{array}{l}\text { 59. Have the opportunity to discuss } \\
\text { problems in work environment with peers }\end{array}$} & $\mathrm{U}^{* *}$ & 2.4 & 11.1 & 37.5 & 29.4 & 16.5 & 3.0 & 1.5 \\
\hline & $\mathrm{S}$ & 6.2 & 15.0 & 34.5 & 27.4 & 10.6 & 6.2 & 2.7 \\
\hline \multirow{2}{*}{$\begin{array}{l}\text { 60. Consult colleagues on special cases that } \\
\text { may be beyond your scope of competence }\end{array}$} & & 4.5 & 12.9 & 42.6 & 24.6 & 10.5 & 4.8 & .9 \\
\hline & $\mathrm{S}$ & 4.4 & 14.2 & 50.4 & 18.6 & 8.8 & 3.5 & .9 \\
\hline
\end{tabular}

Note. $\mathrm{C}=$ community; $1=$ never; $2=$ rarely; $3=$ sometimes; $4=$ fairly often; $5=$ often; $6=$ not applicable; $\mathrm{PC}=$ percent concerned (percentage of psychologists who indicated by check mark a concern for the behavior).

$\mathrm{U}=$ urban/suburban; $\mathrm{S}=$ small town/rural.

${ }^{*} \mathrm{p}<.05 .{ }^{* *} \mathrm{p}<.01$. (The community type with the asterisk is significantly greater) 
Rural Ethics 84

Table 3 (Continued from previous page)

Percentage of Responses for Each Survey Question Across Urban and Small Town Categories

Likert Rating

\begin{tabular}{|c|c|c|c|c|c|c|c|c|}
\hline Question & $\mathrm{C}$ & 1 & 2 & 3 & 4 & 5 & 6 & $\mathrm{PC}$ \\
\hline \multirow{2}{*}{$\begin{array}{l}\text { 61. Receive constructive feedback from } \\
\text { supervisors }\end{array}$} & $\overline{\mathrm{U}}$ & 13.3 & 16.0 & 20.2 & 13.0 & 7.2 & 30.4 & .6 \\
\hline & $\mathrm{S}$ & 11.6 & 14.3 & 17.0 & 12.5 & 3.6 & 41.1 & 1.8 \\
\hline \multirow{2}{*}{$\begin{array}{l}\text { 62. Receive constructive feedback from } \\
\text { colleagues or coworkers }\end{array}$} & $\mathrm{U}$ & 3.6 & 12.0 & 45.2 & 22.3 & 13.9 & 3.0 & .3 \\
\hline & $\mathrm{S}$ & 1.8 & 14.2 & 43.4 & 26.5 & 9.7 & 4.4 & 2.7 \\
\hline \multirow{2}{*}{$\begin{array}{l}\text { 63. Confer with another non-psychology } \\
\text { professional on a difficult case }\end{array}$} & $\mathrm{U}$ & 17.4 & 25.8 & 40.5 & 10.8 & 3.9 & 1.5 & 0 \\
\hline & $\mathrm{S}$ & 13.3 & 24.8 & 41.6 & 15.9 & 4.4 & 0 & .9 \\
\hline \multirow{2}{*}{$\begin{array}{l}\text { 64. Know colleagues who practice beyond } \\
\text { their scope of training }\end{array}$} & $\mathrm{U}$ & 17.5 & 40.5 & 30.5 & 6.3 & 1.5 & 3.6 & 4.8 \\
\hline & $\mathrm{S}$ & 16.8 & 41.6 & 31.9 & 2.7 & 2.7 & 4.4 & 4.4 \\
\hline \multirow{2}{*}{$\begin{array}{l}\text { 65. Receive technical support from } \\
\text { supervisors or coworkers }\end{array}$} & $\mathrm{U}$ & 10.3 & 16.7 & 35.5 & 13.6 & 5.8 & 18.2 & .3 \\
\hline & $\mathrm{S}$ & 8.2 & 15.5 & 37.3 & 15.5 & 1.8 & 21.8 & 0 \\
\hline \multirow[t]{2}{*}{ 66. Doubt your abilities as a therapist } & $\mathrm{U}$ & 9.6 & 52.1 & 31.7 & 2.4 & 1.8 & 2.4 & 1.2 \\
\hline & $\mathrm{S}$ & 11.5 & 50.4 & 32.7 & 2.7 & .9 & 1.8 & 1.8 \\
\hline \multirow{2}{*}{$\begin{array}{l}\text { 68. Feel frustrated with the lack of } \\
\text { alternative resources to help your clients }\end{array}$} & $\mathrm{U}$ & 9.0 & 30.3 & 45.9 & 9.6 & 4.2 & .9 & 9.6 \\
\hline & $\mathrm{S}^{*}$ & 3.5 & 23.9 & 47.8 & 15.9 & 7.1 & 1.8 & 12.4 \\
\hline \multirow{2}{*}{$\begin{array}{l}\text { 69. Have to treat populations for which you } \\
\text { do not feel you have adequate training }\end{array}$} & $\mathrm{U}$ & 38.9 & 48.5 & 11.1 & 0 & 0 & 1.5 & 3.9 \\
\hline & $\mathrm{S}$ & 34.5 & 48.7 & 14.2 & .9 & 0 & 1.8 & 3.5 \\
\hline \multirow{2}{*}{$\begin{array}{l}\text { 70. Feel supported in your work } \\
\text { environment }\end{array}$} & $\mathrm{U}$ & 1.2 & 4.8 & 17.1 & 41.0 & 29.3 & 6.6 & 2.1 \\
\hline & $\mathrm{S}$ & 0 & 8.8 & 26.5 & 31.9 & 23.9 & 8.8 & .9 \\
\hline \multirow{2}{*}{$\begin{array}{l}\text { 76. Discuss the ethics of practice with } \\
\text { colleagues }\end{array}$} & $\mathrm{U}$ & .3 & 10.2 & 48.3 & 26.1 & 15.0 & 0 & .9 \\
\hline & $\mathrm{S}$ & 0 & 6.2 & 48.7 & 28.3 & 16.8 & 0 & 1.8 \\
\hline \multirow[t]{2}{*}{ 99. Attend workshops on ethics } & $\mathrm{U}$ & 4.8 & 16.9 & 38.0 & 21.4 & 18.4 & .6 & .6 \\
\hline & $\mathrm{S}$ & 5.3 & 10.6 & 38.1 & 28.3 & 17.7 & 0 & 0 \\
\hline \multirow{2}{*}{$\begin{array}{l}\text { 101. Feel unprepared for the work you } \\
\text { do with clients }\end{array}$} & $\mathrm{U}$ & 29.5 & 56.9 & 13.3 & 0 & 0 & .3 & 1.8 \\
\hline & $\mathrm{S}$ & 27.4 & 61.1 & 9.7 & .9 & .9 & 0 & .9 \\
\hline \multirow{2}{*}{$\begin{array}{l}\text { 104. Have to use treatment approaches for } \\
\text { which you have not had adequate training }\end{array}$} & $\mathrm{U}$ & 54.1 & 39.0 & 4.8 & 0 & .3 & 1.8 & 1.5 \\
\hline & $\mathrm{S}$ & 51.3 & 44.2 & 3.5 & 0 & 0 & .9 & .9 \\
\hline \multirow{2}{*}{$\begin{array}{l}\text { 112. Discuss specific ethical dilemmas } \\
\text { with colleagues }\end{array}$} & $\mathrm{U}$ & 1.5 & 10.5 & 46.8 & 26.7 & 14.1 & .3 & 0 \\
\hline & $\mathrm{S}$ & 0 & 9.7 & 54.0 & 24.8 & 11.5 & 0 & .9 \\
\hline
\end{tabular}

Note. $\mathrm{C}=$ community; $1=$ never; $2=$ rarely; $3=$ sometimes; $4=$ fairly often; $5=$ often; $6=$ not applicable; $\mathrm{PC}=$ percent concerned (percentage of psychologists who indicated by check mark a concern for the behavior).

$\mathrm{U}=$ urban/suburban; $\mathrm{S}=$ small town/rural.

${ }^{*} \mathrm{p}<.05 .{ }^{* *} \mathrm{p}<.01$. (The community type with the asterisk is significantly greater) 
Table 3 (Continued from previous page)

Percentage of Responses for Each Survey Question Across Urban and Small Town Categories

\begin{tabular}{|c|c|c|c|c|c|c|c|c|}
\hline \multirow[b]{2}{*}{ Question } & \multicolumn{8}{|c|}{ Likert Rating } \\
\hline & $\mathrm{C}$ & 1 & 2 & 3 & 4 & 5 & 6 & $\mathrm{PC}$ \\
\hline \multicolumn{9}{|l|}{ Burnout } \\
\hline \multirow{2}{*}{$\begin{array}{l}\text { 5. Feel you have control over your } \\
\text { work environment }\end{array}$} & $\mathrm{U}$ & .6 & 2.7 & 10.8 & 26.3 & 59.3 & .3 & 2.1 \\
\hline & $\mathrm{S}$ & 2.7 & .9 & 8.0 & 23.9 & 64.6 & 0 & 1.8 \\
\hline \multirow{2}{*}{$\begin{array}{l}\text { 14. Have the opportunity to use your own } \\
\text { initiative and creativity at work }\end{array}$} & $\mathrm{U}$ & .3 & .9 & 12.3 & 29.9 & 56.0 & .6 & 1.8 \\
\hline & $\mathrm{S}$ & 0 & .9 & 8.0 & 26.5 & 64.6 & 0 & 0 \\
\hline \multirow{2}{*}{$\begin{array}{l}\text { 16. Receive emotional support from a } \\
\text { supervisor or mentor }\end{array}$} & $\mathrm{U}$ & 8.7 & 25.3 & 38.6 & 14.8 & 9.0 & 3.6 & 1.8 \\
\hline & $\mathrm{S}$ & 7.1 & 33.6 & 35.4 & 10.6 & 6.2 & 7.1 & 1.8 \\
\hline \multirow{2}{*}{$\begin{array}{l}\text { 22. Feel you don't do enough to help } \\
\text { your clients }\end{array}$} & $\mathrm{U}^{*}$ & 5.1 & 47.6 & 41.0 & 3.9 & 2.1 & .3 & 3.9 \\
\hline & $\mathrm{S}$ & 10.6 & 53.1 & 30.1 & 5.3 & .9 & 0 & 2.7 \\
\hline \multirow{2}{*}{$\begin{array}{l}\text { 37. Work allows you to reach goals you } \\
\text { have set for yourself }\end{array}$} & $\mathrm{U}$ & .3 & 2.4 & 18.9 & 35.9 & 41.6 & .9 & 2.7 \\
\hline & $\mathrm{S}$ & .9 & 3.6 & 19.6 & 26.8 & 48.2 & .9 & 0 \\
\hline \multirow{2}{*}{$\begin{array}{l}\text { 40. Find it difficult to keep a clear } \\
\text { boundary between home and work }\end{array}$} & $\mathrm{U}$ & 38.0 & 43.1 & 15.6 & 1.2 & 2.1 & 0 & 1.8 \\
\hline & $\mathrm{S}$ & 28.3 & 48.7 & 18.6 & 3.5 & 0 & .9 & 3.5 \\
\hline \multirow{2}{*}{$\begin{array}{l}\text { 50. Receive emotional support from } \\
\text { colleagues }\end{array}$} & $\mathrm{U}$ & 3.6 & 10.8 & 43.5 & 24.3 & 17.7 & 0 & .9 \\
\hline & $\mathrm{S}$ & 4.4 & 13.3 & 46.9 & 22.1 & 12.4 & .9 & .9 \\
\hline \multirow{2}{*}{$\begin{array}{l}\text { 72. Socialize with your friends outside of } \\
\text { your work sphere }\end{array}$} & $\mathrm{U}$ & .9 & 3.0 & 18.3 & 33.9 & 43.2 & .6 & .6 \\
\hline & $\mathrm{S}$ & 0 & 1.8 & 26.5 & 28.3 & 43.4 & 0 & 0 \\
\hline \multirow{2}{*}{$\begin{array}{l}\text { 73. Work when to distressed to be } \\
\text { effective }\end{array}$} & $\mathrm{U}$ & 21.3 & 64.0 & 14.4 & .3 & 0 & 0 & 3.0 \\
\hline & $\mathrm{S}$ & 21.2 & 57.5 & 20.4 & 0 & .9 & 0 & 2.7 \\
\hline \multirow{2}{*}{$\begin{array}{l}\text { 74. Disclose details of a current personal } \\
\text { stressor to a client }\end{array}$} & $\mathrm{U}$ & 54.1 & 35.1 & 9.9 & .6 & 0 & .3 & 1.2 \\
\hline & $\mathrm{S}$ & 45.1 & 44.2 & 9.7 & .9 & 0 & 0 & 0 \\
\hline \multirow{2}{*}{$\begin{array}{l}\text { 75. Feel you have control over the types of } \\
\text { clients you see }\end{array}$} & $\mathrm{U}$ & .9 & 1.8 & 17.4 & 34.2 & 44.7 & .9 & 1.2 \\
\hline & $\mathrm{S}$ & .9 & 4.4 & 19.5 & 34.5 & 39.8 & .9 & 0 \\
\hline \multirow{2}{*}{$\begin{array}{l}\text { 77. Find your work to be personally } \\
\text { satisfying }\end{array}$} & $\mathrm{U}$ & 0 & .6 & 8.7 & 30.5 & 60.2 & 0 & 2.1 \\
\hline & $\mathrm{S}$ & 0 & .9 & 10.6 & 30.1 & 58.4 & 0 & 0 \\
\hline \multirow{2}{*}{$\begin{array}{l}\text { 79. Find your work to be professionally } \\
\text { satisfying }\end{array}$} & $\mathrm{U}$ & 0 & .3 & 10.2 & 31.1 & 58.4 & 0 & 1.5 \\
\hline & $\mathrm{S}$ & .9 & 0 & 9.7 & 35.4 & 54.0 & 0 & 0 \\
\hline \multirow{2}{*}{$\begin{array}{l}\text { 80. Take your work home with you to } \\
\text { complete }\end{array}$} & $\mathrm{U}$ & 4.8 & 24.6 & 29.6 & 18.6 & 21.0 & 1.5 & 3.3 \\
\hline & $\mathrm{S}$ & 3.5 & 26.5 & 30.1 & 11.5 & 27.4 & .9 & 1.8 \\
\hline
\end{tabular}

Note. $\mathrm{C}=$ community; $1=$ never; $2=$ rarely; $3=$ sometimes; $4=$ fairly often; $5=$ often; $6=$ not applicable; $\mathrm{PC}=$ percent concerned (percentage of psychologists who indicated by check mark a concern for the behavior).

$\mathrm{U}=$ urban/suburban; $\mathrm{S}=$ small town/rural.

${ }^{*} \mathrm{p}<.05 .{ }^{* *} \mathrm{p}<.01$. (The community type with the asterisk is significantly greater) 
Rural Ethics 86

Table 3 (Continued from previous page)

Percentage of Responses for Each Survey Question Across Urban and Small Town Categories

Likert Rating

\begin{tabular}{|c|c|c|c|c|c|c|c|c|}
\hline \multirow{3}{*}{$\begin{array}{l}\text { Question } \\
81 . \text { Emotionally, or mentally, take your } \\
\text { work home with you }\end{array}$} & $\mathrm{C}$ & 1 & 2 & 3 & 4 & 5 & 6 & PC \\
\hline & $\mathrm{U}$ & 2.4 & 30.8 & 39.2 & 14.1 & 13.2 & .3 & 2.4 \\
\hline & $\mathrm{S}$ & .9 & 31.0 & 42.5 & 12.4 & 12.4 & .9 & .9 \\
\hline \multirow{2}{*}{$\begin{array}{l}\text { 82. Find yourself feeling responsible for } \\
\text { your clients' well-being }\end{array}$} & $\mathrm{U}$ & 6.9 & 32.1 & 43.8 & 11.1 & 5.4 & .6 & 3.3 \\
\hline & $\mathrm{S}$ & 10.6 & 26.5 & 47.8 & 11.5 & 3.5 & 0 & 3.5 \\
\hline \multirow{2}{*}{$\begin{array}{l}\text { 84. Feel you have control over what you } \\
\text { do during your work day }\end{array}$} & $\mathrm{U}$ & 0 & 2.1 & 13.8 & 40.8 & 42.9 & .3 & .6 \\
\hline & $\mathrm{S}$ & 0 & 1.8 & 15.9 & 35.4 & 46.9 & 0 & 0 \\
\hline \multirow{2}{*}{$\begin{array}{l}\text { 85. Receive emotional support from } \\
\text { coworkers }\end{array}$} & $\mathrm{U}$ & 2.7 & 8.7 & 35.4 & 27.6 & 14.4 & 11.1 & .6 \\
\hline & $\mathrm{S}$ & 3.6 & 8.9 & 40.2 & 24.1 & 9.8 & 13.4 & 0 \\
\hline \multirow{2}{*}{$\begin{array}{l}\text { 89. Feel that you are working harder for } \\
\text { change than your clients }\end{array}$} & $\mathrm{U}$ & 5.1 & 26.4 & 58.6 & 5.7 & 2.1 & 2.1 & 3.3 \\
\hline & $\mathrm{S}$ & 1.8 & 27.4 & 61.9 & 8.0 & .9 & 0 & 3.5 \\
\hline \multirow{2}{*}{$\begin{array}{l}\text { 90. Receive emotional support from } \\
\text { family and friends }\end{array}$} & $\mathrm{U}$ & .9 & .9 & 14.4 & 32.3 & 50.9 & .6 & .6 \\
\hline & $\mathrm{S}$ & 0 & 0 & 19.5 & 33.6 & 46.0 & .9 & 0 \\
\hline \multirow{2}{*}{$\begin{array}{l}\text { 91. Do not seek counseling for yourself } \\
\text { due to a lack of time }\end{array}$} & $\mathrm{U}$ & 42.8 & 24.1 & 12.0 & 3.3 & 3.3 & 14.5 & 2.1 \\
\hline & $\mathrm{S}$ & 36.6 & 19.6 & 15.2 & 3.6 & 3.6 & 21.4 & .9 \\
\hline \multirow{2}{*}{$\begin{array}{l}\text { 92. Establish clear boundaries between } \\
\text { your work and personal life }\end{array}$} & $\mathrm{U}$ & 2.1 & 1.5 & 10.8 & 32.3 & 53.0 & .3 & 1.2 \\
\hline & $\mathrm{S}$ & 0 & 3.5 & 11.5 & 30.1 & 54.9 & 0 & 0 \\
\hline \multirow{2}{*}{$\begin{array}{l}\text { 94. Do not seek counseling because you } \\
\text { feel to well-known by the therapists near } \\
\text { your home and work }\end{array}$} & $\mathrm{U}$ & 57.8 & 12.7 & 9.9 & 2.4 & 3.3 & 13.9 & 4.2 \\
\hline & $\mathrm{S}$ & 43.4 & 9.7 & 11.5 & 6.2 & 6.2 & 23.0 & 0 \\
\hline \multirow{2}{*}{$\begin{array}{l}\text { 95. Seek informal support such as from a } \\
\text { pastor or minister }\end{array}$} & $\mathrm{U}$ & 58.0 & 18.3 & 15.6 & 3.0 & .9 & 4.2 & 0 \\
\hline & $\mathrm{S}$ & 54.0 & 17.7 & 16.8 & 1.8 & 0 & 9.7 & 0 \\
\hline \multirow{2}{*}{$\begin{array}{l}\text { 96. Seek counseling from another } \\
\text { therapist }\end{array}$} & $\mathrm{U}^{* *}$ & 26.7 & 20.9 & 33.9 & 5.2 & 7.6 & 5.8 & 0 \\
\hline & $\mathrm{S}$ & 36.3 & 26.5 & 24.8 & 2.7 & 1.8 & 8.0 & 0 \\
\hline \multirow{2}{*}{$\begin{array}{l}119 . \text { Receive support from a supervisory } \\
\text { or mentoring relationship }\end{array}$} & $\mathrm{U}$ & 12.3 & 18.9 & 34.8 & 15.0 & 11.1 & 7.8 & .9 \\
\hline & $\mathrm{S}$ & 11.5 & 20.4 & 29.2 & 15.0 & 8.0 & 15.9 & .9 \\
\hline \multicolumn{9}{|l|}{ Confidentiality } \\
\hline \multirow{2}{*}{$\begin{array}{l}\text { 20. Discuss a client with a psychologist } \\
\text { colleague, without informed consent }\end{array}$} & $\mathrm{U}^{* *}$ & 29.4 & 26.1 & 30.3 & 9.3 & 3.3 & 1.5 & 3.9 \\
\hline & $\mathrm{S}$ & 37.2 & 33.6 & 22.1 & 4.4 & .9 & 1.8 & 3.5 \\
\hline \multirow{2}{*}{$\begin{array}{l}\text { 33. Discuss clients with friends, without } \\
\text { using client names }\end{array}$} & $\mathrm{U}^{* *}$ & 41.6 & 40.1 & 15.6 & 1.8 & .6 & .3 & 2.1 \\
\hline & $\mathrm{S}$ & 54.9 & 32.7 & 11.5 & 0 & 0 & .9 & 2.7 \\
\hline
\end{tabular}

Note. $\mathrm{C}=$ community; $1=$ never; $2=$ rarely; $3=$ sometimes; $4=$ fairly often; $5=$ often; $6=$ not applicable; PC $=$ percent concerned (percentage of psychologists who indicated by check mark a concern for the behavior).

$\mathrm{U}=$ urban/suburban; $\mathrm{S}=$ small town/rural.

${ }^{*} \mathrm{p}<.05 .{ }^{* *} \mathrm{p}<.01$. (The community type with the asterisk is significantly greater) 
Rural Ethics 87

Table 3 (Continued from previous page)

Percentage of Responses for Each Survey Question Across Urban and Small Town Categories

Likert Rating

\begin{tabular}{|c|c|c|c|c|c|c|c|c|}
\hline Question & $\mathrm{C}$ & 1 & 2 & 3 & 4 & 5 & 6 & $\mathrm{PC}$ \\
\hline \multirow{2}{*}{$\begin{array}{l}\text { 42. Discuss a client with a physician } \\
\text { without informed consent }\end{array}$} & $\overline{\mathrm{U}}$ & 63.1 & 24.6 & 9.6 & 2.1 & .3 & .3 & $\overline{1.8}$ \\
\hline & S & 67.0 & 21.4 & 8.9 & .9 & .9 & .9 & 1.8 \\
\hline \multirow{2}{*}{$\begin{array}{l}\text { 47. Discuss a client with other non-mental } \\
\text { health professionals without consent }\end{array}$} & U & 79.0 & 15.6 & 4.5 & .3 & 0 & .6 & .6 \\
\hline & S & 81.4 & 10.6 & 6.2 & 0 & 0 & 1.8 & 1.8 \\
\hline \multirow{2}{*}{$\begin{array}{l}\text { 67. Unintentionally disclose confidential } \\
\text { client information }\end{array}$} & $\mathrm{U}$ & 44.7 & 51.4 & 3.0 & 0 & 0 & .9 & 3.6 \\
\hline & S & 49.6 & 46.9 & 1.8 & 0 & 0 & 1.8 & 6.2 \\
\hline \multirow{2}{*}{$\begin{array}{l}\text { 97. Prepare clients for chance encounters } \\
\text { in the community }\end{array}$} & U & 25.5 & 25.5 & 24.0 & 11.7 & 10.8 & 2.4 & .3 \\
\hline & $\mathrm{S}^{* *}$ & 7.1 & 18.6 & 34.5 & 18.6 & 18.6 & 2.7 & 0 \\
\hline \multirow{2}{*}{$\begin{array}{l}\text { 98. Support staff you work with receive } \\
\text { training in confidentiality issues }\end{array}$} & $\mathrm{U}$ & 4.5 & 3.0 & 16.6 & 18.1 & 30.5 & 27.2 & 1.2 \\
\hline & S & 2.7 & 1.8 & 10.8 & 19.8 & 36.0 & 28.8 & .9 \\
\hline \multirow{2}{*}{$\begin{array}{l}\text { 100. Discuss clients with friends, using } \\
\text { client names }\end{array}$} & U & 97.9 & 1.2 & .3 & .3 & 0 & .3 & .3 \\
\hline & S & 99.1 & .9 & 0 & 0 & 0 & 0 & 0 \\
\hline \multirow{2}{*}{$\begin{array}{l}\text { 102. Discuss clients with referring } \\
\text { agencies, or the person who referred } \\
\text { the client, without informed consent }\end{array}$} & U & 60.2 & 28.7 & 6.9 & 3.0 & .6 & .6 & 1.5 \\
\hline & S & 66.4 & 23.0 & 8.8 & .9 & 0 & .9 & 1.8 \\
\hline \multirow{2}{*}{$\begin{array}{l}\text { 105. Discuss a client with other mental } \\
\text { health professionals without consent }\end{array}$} & $\mathrm{U}^{* *}$ & 40.3 & 34.5 & 20.3 & 3.6 & .6 & .6 & 2.1 \\
\hline & $\mathrm{S}$ & 53.2 & 29.7 & 14.4 & .9 & .9 & .9 & 1.8 \\
\hline \multirow{2}{*}{$\begin{array}{l}\text { 107. Discuss with clients how to deal with } \\
\text { a situation where you may run into each } \\
\text { other in public }\end{array}$} & U & 28.1 & 28.4 & 25.1 & 6.9 & 9.6 & 1.8 & .6 \\
\hline & $\mathrm{S}^{* *}$ & 10.7 & 25.9 & 39.3 & 9.8 & 10.7 & 3.6 & 1.8 \\
\hline \multirow{2}{*}{$\begin{array}{l}\text { 108. Hesitate to break confidentiality } \\
\text { because families are known to you }\end{array}$} & $\mathrm{U}$ & 36.3 & 11.8 & 6.9 & 2.7 & 10.7 & 31.7 & 1.1 \\
\hline & S & 17.4 & 9.8 & 5.4 & 4.3 & 27.2 & 35.9 & 0 \\
\hline \multirow{2}{*}{$\begin{array}{l}\text { 109. Felt uncomfortable acknowledging } \\
\text { a client when seeing them in the } \\
\text { community }\end{array}$} & U & 15.4 & 35.5 & 35.8 & 5.1 & 3.9 & 4.2 & 3.0 \\
\hline & S & 12.5 & 41.1 & 31.3 & 7.1 & 3.6 & 4.5 & 0 \\
\hline \multirow{2}{*}{$\begin{array}{l}\text { 110. Unintentionally learn information } \\
\text { about a client from other resources } \\
\text { in the community }\end{array}$} & U & 11.7 & 38.3 & 41.9 & 5.1 & 2.4 & .6 & .6 \\
\hline & $\mathrm{S}^{* *}$ & 1.8 & 17.7 & 50.4 & 14.2 & 13.3 & 2.7 & .9 \\
\hline
\end{tabular}

Note. $\mathrm{C}=$ community; $1=$ never; $2=$ rarely; $3=$ sometimes; $4=$ fairly often; $5=$ often; $6=$ not applicable; $\mathrm{PC}=$ percent concerned (percentage of psychologists who indicated by check mark a concern for the behavior).

$\mathrm{U}=$ urban/suburban; $\mathrm{S}=$ small town/rural.

${ }^{*} \underline{\mathrm{p}}<.05 .{ }^{*} \underline{\mathrm{p}}<.01$. (The community type with the asterisk is significantly greater) 
Rural Ethics 88

Table 3 (Continued from previous page)

Percentage of Responses for Each Survey Question Across Urban and Small Town Categories

\begin{tabular}{|c|c|c|c|c|c|c|c|c|}
\hline \multirow[b]{2}{*}{ Question } & \multicolumn{8}{|c|}{ Likert Rating } \\
\hline & $\mathrm{C}$ & 1 & 2 & 3 & 4 & 5 & 6 & $\mathrm{PC}$ \\
\hline \multicolumn{9}{|l|}{ Visibility } \\
\hline \multirow{2}{*}{$\begin{array}{l}\text { 9. Work on the same committee in the } \\
\text { community as a client does }\end{array}$} & $\mathrm{U}$ & 71.7 & 18.4 & 5.1 & .9 & 2.7 & 1.2 & 2.1 \\
\hline & $\mathrm{S}^{* *}$ & 42.5 & 23.0 & 18.6 & 1.8 & 8.8 & 5.3 & 4.4 \\
\hline \multirow[t]{2}{*}{ 46. Run into clients in the community } & $\mathrm{U}$ & 5.1 & 30.5 & 46.4 & 11.7 & 6.3 & 0 & 3.3 \\
\hline & $\mathrm{S}^{* *}$ & 1.8 & 9.7 & 29.2 & 24.8 & 32.7 & 1.8 & 4.4 \\
\hline \multirow{2}{*}{$\begin{array}{l}\text { 49. Work on the same committee with a } \\
\text { former client }\end{array}$} & $\mathrm{U}$ & 77.2 & 18.0 & 2.7 & .9 & .3 & .9 & .3 \\
\hline & $\mathrm{S}^{* *}$ & 44.6 & 27.7 & 16.1 & 0 & 5.4 & 6.3 & 2.7 \\
\hline \multirow{2}{*}{$\begin{array}{l}\text { 103. Have processed, during therapy, a } \\
\text { chance you have had with a client }\end{array}$} & $\mathrm{U}$ & 21.1 & 29.0 & 28.4 & 9.1 & 7.6 & 4.8 & .3 \\
\hline & $\mathrm{S}$ & 14.3 & 25.9 & 33.9 & 12.5 & 7.1 & 6.3 & 0 \\
\hline \multirow{2}{*}{$\begin{array}{l}111 . \text { Feel that you are a therapist } 24 \\
\text { hours a day }\end{array}$} & $\mathrm{U}$ & 33.0 & 39.6 & 20.1 & 3.3 & 2.4 & 1.5 & 1.2 \\
\hline & $\mathrm{S}^{*}$ & 27.4 & 34.5 & 28.3 & 3.5 & 4.4 & 1.8 & 0 \\
\hline \multirow{2}{*}{$\begin{array}{l}\text { 113. Attend the same church as a } \\
\text { client }\end{array}$} & $\mathrm{U}$ & 47.6 & 19.0 & 17.2 & 4.8 & 3.9 & 7.5 & .9 \\
\hline & $\mathrm{S}$ & 33.6 & 12.4 & 14.2 & 7.1 & 8.0 & 24.8 & 1.8 \\
\hline \multirow{2}{*}{$\begin{array}{l}\text { 114. See your clients in } \\
\text { restaurants }\end{array}$} & $\mathrm{U}$ & 15.9 & 42.8 & 33.2 & 4.8 & 2.1 & 1.2 & 1.5 \\
\hline & $\mathrm{S}^{* *}$ & 8.0 & 15.9 & 46.9 & 15.0 & 12.4 & 1.8 & 2.7 \\
\hline \multirow{2}{*}{$\begin{array}{l}\text { 116. Have clients who know more about } \\
\text { your personal life than you would prefer } \\
\text { they knew }\end{array}$} & $\mathrm{U}$ & 34.7 & 50.3 & 13.8 & .3 & .3 & .6 & 1.5 \\
\hline & $\mathrm{S}^{* *}$ & 17.7 & 50.4 & 24.8 & 3.5 & 3.5 & 0 & 1.8 \\
\hline \multirow{2}{*}{$\begin{array}{l}\text { 117. Belong to or join the same club } \\
\text { or organization as a former client } \\
\text { (e.g. political, religious, social) }\end{array}$} & $\mathrm{U}$ & 37.2 & 40.8 & 15.3 & 3.9 & 2.1 & .6 & .6 \\
\hline & $\mathrm{S}^{* *}$ & 23.9 & 30.1 & 24.8 & 8.0 & 8.0 & 5.3 & 2.7 \\
\hline \multirow{2}{*}{$\begin{array}{l}\text { 118. Participate in the same neighborhood } \\
\text { activity as a client (e.g. fundraiser, } \\
\text { community project) }\end{array}$} & $\mathrm{U}$ & 52.3 & 33.9 & 11.7 & .3 & .9 & .9 & .9 \\
\hline & $\mathrm{S}^{* *}$ & 31.0 & 30.1 & 22.1 & 6.2 & 7.1 & 3.5 & .9 \\
\hline \multirow{2}{*}{$\begin{array}{l}\text { 120. Have a client become aware of a } \\
\text { personal stressor in your life from a } \\
\text { source other than yourself }\end{array}$} & $\mathrm{U}$ & 45.6 & 42.6 & 10.3 & 0 & .3 & 1.2 & 1.2 \\
\hline & $\mathrm{S}^{* *}$ & 29.7 & 42.3 & 21.6 & 1.8 & 2.7 & 1.8 & 1.8 \\
\hline \multirow{2}{*}{$\begin{array}{l}\text { 115. Have accepted an offer of a } \\
\text { handshake from a client (reliability check) }\end{array}$} & $\mathrm{U}$ & 1.5 & 1.8 & 19.5 & 24.6 & 51.5 & 1.2 & .3 \\
\hline & $\mathrm{S}$ & 0 & 0 & 24.8 & 27.4 & 46.0 & 1.8 & 0 \\
\hline
\end{tabular}

Note. $\mathrm{C}=$ community; $1=$ never; $2=$ rarely; $3=$ sometimes; $4=$ fairly often; $5=$ often; $6=$ not applicable; $\mathrm{PC}=$ percent concerned(percentage of psychologists who indicated by check mark a concern for the behavior).

$\mathrm{U}=$ urban/suburban; $\mathrm{S}=$ small town/rural.

${ }^{*} \underline{p}<.05 .{ }^{* *} \mathfrak{p}<.01$. (The community type with the asterisk is significantly greater) 
are reported. The primary purpose of including the response rates for the entire survey is so that response patterns may be observed by the reader. Several patterns that do not become readily apparent with the research questions will be discussed later in the results section, such as the very low scores on questions related to burnout, suggesting psychologists enjoy their work, feel they have control over their work environment, and that they find work to be very satisfying. Additionally, Table 3 allows us to see patterns such that, for example, a question may reveal a significant difference between communities, but the behavior or situation occurs very infrequently. Finally, this table gives the reader an opportunity to see the results of all questions, so that comparisons may be made with previous surveys that make use of similar questions, as will also be briefly considered herein, or for the design of future surveys.

Research questions addressing differences across type of community. The main research question, addressing whether there are differences in the number of ethical issues encountered across types of communities is addressed using MANOVAs. The dependent variable is the category of related questions, as previously described. The independent variable is the type of community, collapsed into urban/suburban versus small town/rural. If the MANOVA is significant, post hoc ANOVAs are conducted. It was decided to use the more conservative degrees of freedom from the MANOVA, rather than to run independent ANOVA tests. Because the MANOVA requires the same number of participants in each cell, the degrees of freedom are reduced due to individuals choosing not to answer a question. This effect is additive within each MANOVA, such that in a category with 34 questions, if different individuals choose to not answer different questions within the category, the individuals are both excluded from that analysis. Although the degrees of freedom were not dramatically reduced, it did change some of the results when comparing the ANOVAs conducted independently (which have a larger N) 
compared to the ANOVAs conducted with the MANOVA's degrees of freedom. For example, with independent ANOVAs there were 4 significant questions for "competency" with the primary research question, but for the ANOVAs conducted with the reduced degrees of freedom there were only 3 significant questions. Thus, the latter, more conservative results are reported here.

The first MANOVA for the independent variable "community" with the dependent variable "multiple relationships" is significant, $\mathrm{F}(34,389)=3.521, \mathrm{p}<.01$. Follow-up analysis with ANOVAs revealed that 19 questions were significantly different. Table 4 lists those multiple relationship questions and their significance levels. As predicted, psychologists in small town/rural areas appear to encounter significantly more multiple relationship behaviors and situations than urban/suburban psychologists. Small town and rural psychologists are more likely to provide therapy to relatives of ongoing patients, to friends or persons known to the therapist, and to have relationships or interactions with clients or former clients outside the therapeutic context. Psychologists from small towns and rural areas are also more likely to have incidental contacts with clients in the community, such as buying goods or services from places where clients work, or running into clients in the community.

Although there are significant differences between some behaviors, they may still not occur frequently. For example, question \#48 asks about socializing with clients after terminating therapy. Clearly more sm/rural practitioners engage in this behavior than urb/sub $(57.5 \%$ and $77.2 \%$ respectively report never engaging in this behavior), but of those that do so, $35.4 \%$ of the $\mathrm{sm} /$ rural psychologists rarely socialize with clients after terminating, while only $5.3 \%$ do so sometimes or more. With some behaviors, however, the fact it does occur at all may be a concern, such as engaging in a romantic relationship with a client, or going into business with a 
Table 4

Community - Significantly Different ANOVA Results for Multiple Relationship Questions

Question Community

$\mathrm{p}$

3. Provide therapy to one of your friends $\mathrm{S} \quad .050$

6. Provide therapy to a relative of a friend S $\quad .001$

8. Accept goods or services in lieu of a fee S $\quad .037$

17. Purchase goods or services from a place of business where a client works S $\quad .001$

18. Work with a client in a community setting (PTA, church group)

23. Provide individual therapy to a lover of an ongoing client

24. Provide therapy to a child of one of your friends

25. Become social friends with parents of a former client S $\quad .042$

26. Find yourself working with two clients who happen to have a relationship with each other

28. Provide therapy to a relative of an ongoing client

29. Attend a party or social gathering and run into a client

30. Find that your children have become friends with a client or a client's children $S$

32. Provide therapy to a client with whom you have had a previous social relationship $S$

35. Loan books or other personal possessions to a client

48. Socialize with a client after terminating therapy

71. Provide therapy to a client whom you know of from being in the same social sphere

83. Provide therapy to a friend of a current client

87. Find yourself working with a client who discusses problems with a person who is also your client

Note. $\mathrm{S}=$ Small town/rural. $\mathrm{p}=$ significance level

The type of community listed (U or S) is significantly greater. In this instance small town/rural is significantly higher for all of these questions. 
client, while other behaviors may occur sometimes or more often, and not be as much a concern, such as loaning books to a client. The goal of this research is not to identify behaviors as more or less ethical, but rather, simply to quantify behaviors as they are occurring, and observe if there are differences across communities, or other variables of interest such as gender. Providing therapy to one of your friends is another behavior that does not occur frequently though there is a significant difference between communities. Although significantly different, a surprisingly high percentage of psychologists run into clients at parties or social gatherings (\#29) from all communities. Approximately $36 \%$ of urb/sub psychologists run into clients at social gatherings sometimes or more, and $58.4 \%$ or sm/rural practitioners run into clients sometimes or more often. Only $22 \%$ and $15 \%$, respectively, reported never running into clients at social gatherings or parties.

The MANOVA for the independent variable "community" with the dependent variable "visibility" is significant, $\mathrm{F}(11,420)=8.905, \mathrm{p}<.01$. Post hoc analyses with ANOVAs revealed nine significant questions as reported in Table 5. As predicted, therapists in small town and rural communities may be more likely to feel they are a therapist 24 hours a day, to run into clients in the community, and participate in activities in which clients are also participating. These results also tend to confirm the reports in the review of the rural literature that one has to be willing to be known as a person in rural communities, that clients are likely to know a great deal about the therapist, whether the therapist is comfortable with this or not.

The MANOVA for the independent variable "community" with the dependent variable "competency" is significant, $\mathrm{F}(34,384)=2.037, \mathrm{p}<.01$. Contrary to expectations, only three of the individual ANOVAs are significant. Those questions are listed in Table 6. It does appear that small town and rural practitioners struggle with the lack of referral resources for their 
Table 5

Community - Significantly Different ANOVA Results for Visibility Questions

Question

Community $\mathrm{p}$

9. Work on the same committee in the community as a client does

$\mathrm{S} \quad .001$

46. Run into your clients in the community

S $\quad .001$

49. Work on the same committee with a former client

$\mathrm{S} \quad .001$

111. Feel that you are a therapist 24 hours a day

$\mathrm{S} \quad .024$

114. See your clients in restaurants

$\mathrm{S} \quad .001$

116. Have clients who know more about your personal life than you would prefer they knew

$\mathrm{S} \quad .001$

117. Belong to or join the same club or community organization as a former client (e.g. political, religious, social, athletic)

$\mathrm{S} \quad .001$

118. Participate in the same neighborhood activity as a client (e.g. fundraiser, community project)

120. Have a client become aware of a personal stressor in your life from a source other than yourself

Note. $\mathrm{S}=$ small town/rural. $\mathrm{p}=$ significance level.

The type of community listed (U or S) is significantly greater. In this instance small town/rural is significantly higher for all of these questions. 
Table 6

Community - Remainder of Significantly Different ANOVA Results for Questions by Category

Question

Community

$\mathrm{p}$

Competency

52. Not be able to refer clients because of a lack of psychological referral sources

$\mathrm{S} \quad .001$

59. Have the opportunity to discuss problems in the work environment with peers

U $\quad .008$

68. Feel frustrated with the lack of alternative resources to help your clients

S $\quad .012$

$\underline{\text { Burnout }}$

22. Feel you don't do enough to help your clients

U $\quad .021$

96. Seek counseling from another therapist

U $\quad .001$

Confidentiality

20. Discuss a client with a psychologist colleague, without informed consent

33. Discuss clients with friends without using client names

97. Prepare clients for chance encounters in the community

S $\quad .001$

105. Discuss clients with other mental health professionals, without informed consent

107. Discuss with clients how to deal with a situation where you may run into each other in the community

110. Unintentionally learn information about a client from other resources or people in the community (i.e. social conversations)

$\mathrm{S} \quad .001$

Note. $\mathrm{S}=$ Small town/rural; $\mathrm{U}=$ urban/suburban. $\mathrm{p}=$ significance level.

The type of community listed ( $\mathrm{U}$ or $\mathrm{S}$ ) is the significantly greater. 
clients, an issue that will recur several times throughout analysis of the survey (e.g. highest rated concerns and general patterns of responses). Urban psychologists appear to have more opportunity to discuss their work with peers (and friends, and other professionals as well, as discussed shortly). It was predicted that psychologists from small towns and rural areas would have difficulty maintaining their competency, and they would struggle with having to take patients that are beyond their scope of training. This was not the case, however, at least according to self-report. As will be demonstrated in a later section, although therapists did not endorse items that concerned their own competency, they were much more likely to be concerned about their colleagues' competency, though this held true across types of community.

The MANOVA for the independent variable "community" with the dependent variable "burnout" also is significant, $\mathrm{F}(26,404)=1.672, \mathrm{p}<.05$, although only two of the individual ANOVAs are significant, as listed in Table 6. Contrary to predictions, small town and rural psychologists did not endorse more items indicative of burnout. In fact, psychologists from both urb/sub and sm/rural endorsed items suggesting they enjoy their work, feel they have control over their work environment, have autonomy, and find their work professionally and personally satisfying. Urban psychologists appear to be more likely to seek counseling from another therapist, but we cannot determine if this is due to different value systems or due to the availability of the resources. (A rough gauge as to whether this phenomenon is due to different needs/values or available resources is that for question \#94, "Not be able to seek counseling because of being to well-known by the other therapists," none of the participants from sm/rural listed this as a concern, while $4.2 \%$ of urb/sub were concerned. This suggests that therapists from small towns and rural areas are not as interested in seeking therapy for themselves). 
Regarding the independent variable "community" with the dependent variable "confidentiality", the MANOVA is significant $\mathrm{F}(13,415)=5.791, \mathrm{p}<.01$. Six of the thirteen ANOVAs are significant as listed in Table 6. As discussed above, urb/sub therapists are more likely to discuss their work, or clients, with friends, colleagues, and other professionals. On the qualitative, or open ended question at the end of the survey, several respondents emphasized that when discussing clients with others, as addressed by these questions, they do not use client identifying information. As expected, sm/rural psychologists are more likely to prepare their clients for chance encounters, and more likely to learn information about the client from sources other than the client. Although most psychologists learn information about clients from medical records, it can be quite a different issue to learn information about clients from other members of the community, or from other clients.

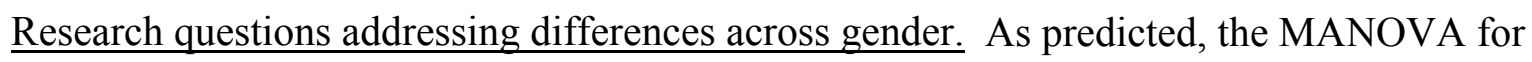
the independent variable "gender" with the dependent variable "multiple relationships" is significant $\mathrm{F}(34,385)=2.92, \mathrm{p}<.01$. Table 7 lists significantly different individual questions, with the significance level from the respective ANOVA. This researcher believes caution should be used in interpreting too much from any single question, every effort being made in this analysis to do so, because circumstances may not be known, and behaviors differ widely in how compromising they may be in terms of conflict of interest. Again, the goal in this survey is not to determine if the behaviors are ethical per se. It does appear, however, consistent with previous surveys mentioned herein, that males are significantly more likely to engage in many of these behaviors which may be considered indicative of a multiple relationship. These behaviors do vary greatly, as mentioned previously, self-disclosure is a behavior that tends to be ubiquitous, though more so for male practitioners, while providing therapy to a client with whom 
Table 7

Gender - Significantly Different ANOVA Results for Multiple Relationship Questions

Question

Gender

$\mathrm{p}$

2. Charge a client no fee for therapy

M

.005

8. Accept goods or services in lieu of a fee

M

10. Use self-disclosure as a technique

M

.001

19. Accept a gift worth less than $\$ 20$ from a client

F

.001

23. Provide individual therapy to a lover of an ongoing client

M

.013

24. Provide therapy to a child of one of your friends

M

.004

25. Become social friends with parents of a former client

M

.040

32. Provide therapy to a client with whom you have had a previous social relationship

M

35. Loan books or other personal possessions to a client

F

.006

54. Become social friends with a former client

M

.013

57. Provide therapy to a friend of an employee

M

71. Provide therapy to a client whom you know of from being in the same social sphere.

M

.004

78. Have a current or former client become employed at your agency

M

88. Purchase goods or services from a client

$\mathrm{M}$

.038

Note. $\mathrm{M}=$ male; $\mathrm{F}=$ female; $\mathrm{p}=$ significance level.

The gender listed ( $\mathrm{M}$ or $\mathrm{F}$ ) is significantly greater. 
you have had a previous social relationship does not occur very often, although males tend to engage in it more often than females (and practitioners from small towns and rural areas more so than their urban and suburban counterparts). Females are more likely to accept a gift worth less than $\$ 20$ and to loan books or other personal possessions. It should be noted that several respondents commented that they loan books, such as self-help books or a lending library, but not other personal possessions.

The MANOVA for the category "competency" is not significant, $F(34,380)=.954, p>.05$, and no predictions were ventured regarding competency and gender. The MANOVA for the independent variable "gender" with the dependent variable "burnout," however, is significant, with $F(26,400)=2.167, p<.01$. Surprisingly, as listed in Table 8,7 of the post hoc ANOVAs are significant. In general, it appears that females are significantly more likely to engage in behaviors to take care of themselves. Women are more likely to seek and receive emotional support from others including supervisory and mentoring relationships. Males were more likely to disclose details of a current personal stressor to a client, an interesting question because it is one of those questions that could belong to several categories. In this case the review of the literature suggested that revealing personal stressors to clients may be an indication of burnout (see Chapter I), but it could also be considered a multiple relationship issue. Overall then, it appears females are better at engaging in self-care behaviors than males, although it may be that male self-care behaviors are qualitatively different than they are for females (e.g. using exercise or other behaviors not assessed in this survey).

Although no predictions were made for the "confidentiality" and "visibility" categories, both are significant. The MANOVA for the dependent variable "confidentiality", across the independent variable "gender" is $F(13,412)=2.488, \mathrm{p}<.01$. Post hoc ANOVAs revealed four 
Table 8

$\underline{\text { Gender - Significantly Different ANOVA Results for Burnout Questions }}$

Question

Gender $\mathrm{p}$

16. Receive emotional support from a supervisor or mentor

F $\quad .001$

50. Receive emotional support from colleagues

F $\quad .003$

74. Disclose details of a current personal stressor to a client

M $\quad .001$

90. Receive emotional support from family and friends

F $\quad .011$

94. Do not seek counseling because you feel too well-known by all of the therapists near your home and work

F $\quad .039$

96. Seek counseling from another therapist

F $\quad .048$

119. Receive support from a supervisory or mentoring relationship

F $\quad .003$

Note. $\mathrm{F}=$ Female, $\mathrm{M}=$ male. $\mathrm{p}=$ significance level.

The gender listed (F or $\mathrm{M}$ ) is significantly greater. 
significant questions. Males were more likely to discuss a client with a physician without informed consent ( $\# 42, \mathrm{p}=.001)$, and to discuss clients with referring agencies without informed consent $(\# 102, \mathrm{p}=.033)$. Females were more likely to prepare client for chance encounters in the community ( $\# 97, \mathrm{p}=.005$ ), and to discuss with clients how to deal with running into each other $(\# 107, \mathrm{p}=.007)$. The MANOVA for "visibility" is $\mathrm{F}(11,416)=2.357, \mathrm{p}<.01)$, although only one question was individually significant. Females were more likely to have processed, during therapy, a chance encounter with a client $(\# 103, \mathrm{p}=.033)$. In general, female psychologists seem to be more sensitive to multiple relationship issues and encountering clients in contexts outside of the therapeutic environment, and are more likely to seek support from supervisors and colleagues.

Questions addressing differences across work setting. As previously mentioned, work setting was collapsed into a dichotomous category, with private practice group and solo being combined into "private practice". All other settings, such as hospitals, university, community mental health, and other (which included such settings as prisons), were considered to be an "institution". As predicted, work setting was related to both multiple relationships and burnout (it was predicted that private practice would have more multiple relationship issues, and endorse fewer items indicative of burnout). Work setting appears to be meaningfully related to the other three categories as well.

The MANOVA for "work setting" with the dependent variable "multiple relationships" is significant with $\mathrm{F}(34,389)=4.491, \mathrm{p}<.01$. Post hoc ANOVAs revealed 21 questions that were significantly different, and are listed with their significance level in Table 9. It was rather surprising to see how strongly practice setting appears to relate to a wide range of multiple 
Table 9

Work Setting - Significantly Different ANOVA Results for Multiple Relationship Questions

Question

2. Charge a client no fee for therapy

Setting

3. Provide therapy to one of your friends

PP $\quad .042$

6. Provide therapy to a relative of a friend

PP $\quad .001$

7. Provide therapy to an employee or coworker

I $\quad .011$

8. Accept goods or services in lieu of a fee PP $\quad .001$

12. Accept a client's gift worth at least $\$ 50$ PP $\quad .018$

13. Request favors from a client PP $\quad .038$

17. Purchase goods or services from a place of business where a client works

PP

18. Work with a client in a community setting (PTA, Church group)

PP

19. Accept a gift worth less than $\$ 20$ from a client

PP

23. Provide individual therapy to a lover of an ongoing client

PP

28. Provide therapy to a relative of an ongoing client

PP

29. Attend a party or social gathering and run into a client

PP

30. Find that your children have become friends with a client or a client's children

PP

32. Provide therapy to a client with whom you have had a previous social relationship

PP

35. Loan books or other personal possessions to a client

PP

48. Socialize with a client after terminating therapy

$\mathrm{PP}$

71. Provide therapy to a client whom you know of from being in the same social sphere PP

78. Have a current or former client become employed in your agency

83. Provide therapy to a friend of a current client

86. Go into business with a former client

PP .035

Note. $\mathrm{PP}=$ private practice, $\mathrm{I}=$ institution. $\mathrm{p}=$ significance level.

The setting listed (PP or I) is significantly greater. 
relationship behaviors and situations. Private practitioners are more likely to provide therapy to a friend, to relatives of friends, relatives of ongoing clients, and to clients with whom they have had a previous relationship. Some behaviors may occur infrequently, such as socializing with a client after terminating therapy, or going into business with a former client, but when the behavior does occur, it is more likely to happen with someone in private practice. Only two questions are significantly higher for persons who work in an institutional setting, and logically they both relate to providing therapy in an agency setting, (e.g. have a former client become employed in your agency, or provide therapy to an employee or coworker). Although for some questions it clearly makes sense that private practitioners would be more likely to run into the situation (e.g. accept goods or services in lieu of a fee), for other questions it does not seem intuitively obvious why it would be significantly higher for private practitioners (e.g. attend a party or social gathering and run into a client, or purchase goods or services from a place of business where a client works). This issue will be considered in more depth in the discussion. The results demonstrate, however, that therapists in private practice are more likely to engage in behaviors indicative of multiple relationships, and are more likely to have encounters with clients outside the therapeutic context.

For the independent variable "work setting" with the dependent variable "competency", the MANOVA also is statistically significant, $\mathrm{F}(34,384)=4.883, \mathrm{p}<.01$. Nine of the follow-up ANOVAs are significant as listed in Table 10. As can be seen in this table, therapists working in an institutional setting are more likely to get support and feedback from supervisors and peers in their work environment; but, they also may have to sometimes take clients that have problems beyond their scope of training and experience. Private practitioners are more likely to provide clinical services over the phone, and to refer their clients to other specialists in psychology. 
Table 10

Work Setting - Significantly Different ANOVA Results for Competency Questions

Question

Setting $\mathrm{p}$

4. Refer clients to other specialists in the field of psychology

PP $\quad .012$

27. Sometimes have to take clients that have problems that are beyond your scope of training and experience

I $\quad .036$

31. Meet with peers to discuss clinical casework

I $\quad .004$

51. Provide regularly scheduled clinical services via the telephone

PP $\quad .004$

59. Have the opportunity to discuss problems in the work environment with peers

61. Receive constructive feedback from supervisors

63. Confer with another non-psychology professional on a difficult case I $\quad .011$

65. Receive technical support from supervisors or coworkers

I $\quad .001$

70. Feel supported in your work environment

I $\quad .013$

Note. $\mathrm{PP}=$ private practice, $\mathrm{I}=$ institution. $\mathrm{p}=$ significance level

The setting listed (PP or I) in significantly greater. 
The MANOVA for the independent variable "work setting", with the dependent variable "burnout," revealed a significant difference, as expected, $F(26,404)=5.715, \mathrm{p}<.01$. Table 11 lists the 14 individual ANOVAs and the significance level for each question. Private practitioners are more likely to have control over their work environment and the types of clients they see, to find their work to be personally and professional satisfying, and have the opportunity to use their own initiative and creativity at work. These are behaviors that tend to be considered buffers against burnout (see Chapter I). Therapists working in institutional settings tended to endorse behaviors or experiences that are apt to be indicative of burnout, such as feeling they do not do enough to help clients, emotionally, or mentally, taking their work home with them, and working when too distressed to be effective. Practitioners in institutional settings, however, reported being likely to receive support from supervisory or mentoring relationships. Taken with the previous results in "competency," the latter lends more evidence to the suggestion that private practitioners may be operating more in professional isolation, though still more direct evidence is needed before making such a claim.

The MANOVA for the independent variable "work setting" with the dependent variable "confidentiality" is significant with $\mathrm{F}(13,415)=7.273, \mathrm{p}<.01$. Five follow-up ANOVAs are significant in this category. Private practitioners are more likely to prepare clients for chance encounters in the community (\#97, $\mathrm{p}=.005$ ); discuss with clients how to deal with running into each other (\#107, p = .001); feel uncomfortable acknowledging a client in the community (\#109, $\mathrm{p}=.039)$, and unintentionally learn information about clients from other sources $(\# 110, \mathrm{p}=$ .016). Psychologists in institutional settings, as one would expect, are more likely to have the support staff receive training in confidentiality $(\# 98, \mathrm{p}=.001)$. Again, it appears private practitioners are more likely to deal with confidentiality issues related to seeing clients or 
Table 11

Work Setting - Significantly Different ANOVA Results for Burnout Questions

5. Feel you have control over your work environment PP $\quad .001$

14. Have the opportunity to use your own initiative and creativity at work

PP $\quad .001$

16. Receive emotional support from a supervisor or mentor

I $\quad .019$

22. Feel you don't do enough to help your clients

I $\quad .005$

37. Work allows you to reach goals you have set for yourself

PP $\quad .002$

73. Work when too distressed to be effective

I $\quad .003$

75. Feel you have control over the types of clients you see

PP $\quad .001$

77. Find your work to be personally satisfying PP $\quad .001$

79. Find your work to be professionally satisfying PP $\quad .001$

81. Emotionally, or mentally, take your work home with you I $\quad .007$

84. Feel you have control over what you do during your work day PP $\quad .001$

85. Receive emotional support from coworkers I $\quad .001$

94. Do not seek counseling because you feel too well-known by all of the therapists near your home and work PP $\quad .036$

119. Receive support from a supervisory or mentoring relationship

I $\quad .001$

Note. $\mathrm{PP}=$ private practice, $\mathrm{I}=$ institution. $\mathrm{p}=$ significance level.

The setting listed (PP or I) is significantly greater. 
interacting with clients in contexts outside the therapeutic situation.

The MANOVA for the independent variable "work setting" with the dependent variable "visibility" is significant with $\mathrm{F}(11,420)=4.083, \mathrm{p}<.01$. Five post hoc ANOVAs are significant in this category, all in the direction of private practitioners. Thus, private practitioners were more likely to run into clients in the community ( $\# 46, \mathrm{p}=.001)$; process a chance encounter with a client during therapy $(\# 103, \mathrm{p}=.001)$; see their clients in restaurants $(\# 114, \mathrm{p}=.001)$; belong to or join the same club or organization as a former client $(\# 117, \mathrm{p}=$ $.001)$; and to participate in the same neighborhood activity as a client (\#118, $\mathrm{p}=.045)$.

Questions addressing differences across the number of years experience of the psychologist. It was predicted that therapists with more years of experience would endorse more questions indicative of multiple relationships than those with less experience. Because the mean number of years since obtaining degree $(\mathrm{M}=17.65, \mathrm{SD}=7.75)$ and the mean number of years experience as a psychologist $(\mathrm{M}=18.09, \mathrm{SD}=8.63)$ are essentially the same, it was decided to use the number of years since obtaining the degree as this would also take into account training cohort. The point of division for "more" experience is 15 or more years, and for "less" it is less than 15 years. (Analysis also was conducted by eliminating the middle third of this continuum, with 10 years or less and 15 or more years as the criteria, though this did not significantly change the outcomes. Therefore it was decided to stay with 15 or more years versus less than 15 years as the grouping criterion).

The MANOVA for the independent variable "years experience" with the dependent variable "multiple relationships" is significant, with $\mathrm{F}(34,387)=1.567, \mathrm{p}<.05$. The thirteen significant ANOVAs are listed in Table 12, along with the significance level for each question. 
Table 12

Years Experience - Significantly Different ANOVA Results for Multiple Relationship Questions

\begin{tabular}{ll}
\hline & $\begin{array}{l}\text { More or Less } \\
\text { Question }\end{array}$ \\
\hline
\end{tabular}

6. Provide therapy to a relative of a friend $\quad M \quad .021$

10. Use self-disclosure as a therapeutic technique $\quad M \quad .036$

$\begin{array}{lll}\text { 11. Invite clients to an open house } & \mathrm{M} \quad .045\end{array}$

15. Attend a client's special event (e.g. wedding, graduation) $\quad$ M $\quad .001$

23. Provide individual therapy to a lover of an ongoing client $\quad$ M $\quad .001$

24. Provide therapy to a child of one of your friends $\quad$ M $\quad .046$

$\begin{array}{lll}\text { 28. Provide therapy to a relative of an ongoing client } & \text { M } & .012\end{array}$

29. Attend a party or social gathering and run into a client $\quad$ M $\quad .018$

30. Find that your children have become friends with a client or a client's children

48. Socialize with a client after terminating therapy

M $\quad .036$

54. Become social friends with a former client

M $\quad .002$

71. Provide therapy to a client whom you know of from being in the same social sphere

83. Provide therapy to a friend of a current client

M $\quad .021$

Note. $\mathrm{M}=15$ or more years experience. $\mathrm{p}=$ significance level.

More experienced (M) were significantly higher than less experienced (L) for each of these questions. 
As predicted, those psychologists with more experience are significantly more likely to engage in a number of behaviors that would be indicative of a multiple relationship. Those with more than 15 years of experience are more likely to interact with clients outside of the therapeutic context (attend a client's special event, run into clients at a party, and become friends or socialize with a former client). Psychologists with more experience are more likely to use self-disclosure and provide therapy to relatives of ongoing clients, or to relatives of friends.

The MANOVA for the independent variable "years experience" with the dependent variable "competency" is not significant $F(34,382)=1.291, \mathrm{p}>.05$. Similarly, the MANOVA with the dependent variable "visibility" also is not significant $F(11,418)=1.147, \mathrm{p}>.05$. No predictions were made for either of these categories.

The MANOVA for the independent variable "years experience" with the dependent variable "burnout" is significant with $\mathrm{F}(26,402)=1.986, \mathrm{p}<.01$. Five of the post hoc ANOVAs are significant. Psychologists with less experience were significantly more likely to receive emotional support from a supervisor or mentor $(\# 16, \mathrm{p}=.001)$; receive support from a supervisory or mentoring relationships ( $\# 119, \mathrm{p}=.001$ ), (though it would be expected these two questions are in close agreement); and seek counseling from another therapist $(\# 96, \mathrm{p}=.010)$. Psychologists with 15 or more years experience are significantly more likely to disclose details of a current stressor to a client ( $\# 74, \mathrm{p}=.007)$, which could also be considered a multiple relationship; and to feel they have control over what they do during the day ( $\# 84, \mathrm{p}=.033)$.

For the independent variable "years experience" with the dependent variable "confidentiality," the MANOVA also is significant with $\mathrm{F}(13,413)=2.028, \mathrm{p}<.05$. Only three of these follow-up ANOVAs are individually significant. Psychologists with more experience are more likely to discuss a client with a physician without informed consent $(\# 42, \mathrm{p}=.004)$. 
Psychologists with less than 15 years experience are significantly more likely to prepare clients for chance encounters in the community $(\# 97, \mathrm{p}=.029)$; and to discuss with clients how to deal with chance encounters $(\# 107, \mathrm{p}=.006)$.

Questions addressing differences across theoretical orientations. Each of the categories is significant for theoretical orientation, although the patterns of results are not robust with regard to the individual questions. This may be due to the small number of participants in some of the cells of the MANOVA. It was decided to report this analysis as it stands because there does not appear to be a meaningful way to collapse the categories.

The MANOVA for the independent variable "theoretical orientation" with the dependent variable "multiple relationships" is significant, $\mathrm{F}(204,2304)=1.531, \mathrm{p}<.01$. Post hoc analysis using ANOVAs revealed six significant questions, though on several questions none of the individual Tukey HSD comparisons are significant (questions \#18, \#54, and \#57). For the remaining three questions, follow-up Tukey HSD analyses revealed significant differences between orientations (significance levels for each Tukey HSD analysis with the independent variable "theoretical orientation" is reported in parentheses). Behavioral psychologists are significantly more likely than psychodynamic $(\mathrm{p}=.002)$, cognitive-behavioral $(\mathrm{p}=.001)$, eclectic $(\mathrm{p}=.001)$, and "other" $(\mathrm{p}=.004)$ to invite clients to an open house. Gestalt psychologists also are significantly more likely than psychodynamic $(\mathrm{p}=.045)$, cognitive behavioral $(\mathrm{p}=.044)$, eclectic $(\mathrm{p}=.026)$, and other $(.040)$ to invite clients to an open house. Psychodynamic psychologists are significantly more likely than cognitive-behavioral $(p=.006)$ to provide therapy to one of their friends. Behavioral psychologists are significantly more likely than psychodynamic $(\mathrm{p}=.001)$, cognitive-behavioral $(\mathrm{p}=.002)$, humanistic $(\mathrm{p}=.007)$, eclectic (.001), and "other" (.005) to dine with a client after a session. It may be, however, that dining 
with a client after a session could be construed as an in vivo therapeutic intervention for those answering this question.

For the independent variable "theoretical orientation" with the dependent variable "competency" the MANOVA is significant, with $\mathrm{F}(204,2274)=1.328, \mathrm{p}<.01$. According to follow up analyses with ANOVAs seven of the individual questions are significant, though one did not have any Tukey HSD individual comparisons as significant (question \#31). For question \#45, post hoc Tukey HSD analysis revealed that psychodynamic therapists are significantly more likely than cognitive-behavioral psychologists to discuss the practice of psychology with colleagues $(\mathrm{p}=.015)$. Psychodynamic therapists are significantly more likely than cognitivebehavioral $(\mathrm{p}=.001)$ and "other" $(\mathrm{p}=.001)$ to provide clinical services via the telephone. On questions \#61 and \#62, respectively, psychodynamic therapists are more likely than cognitivebehavioral $(\mathrm{p}=.020)$ and eclectic $(\mathrm{p}=.002)$ to receive constructive feedback from supervisors $(\mathrm{p}$ $=.020)$ and more likely than cognitive-behavioral psychologists $(\mathrm{p}=.010)$ to receive constructive feedback from colleagues or coworkers. Further Tukey HSD analyses found that psychodynamic psychologists are more likely than behavioral $(\mathrm{p}=.027)$, humanistic $(\mathrm{p}=.043)$, and eclectic $(\mathrm{p}=.036)$ to confer with another non-psychologist professional on a difficult case. Psychodynamic therapists are significantly more likely than "other" $(\mathrm{p}=.013)$ to doubt their abilities as a therapist. It seems, in general, that psychodynamic psychologists are more likely to consult and discuss casework with colleagues, and to receive feedback from supervisors, than many of the other orientations.

The MANOVA for the independent variable "theoretical orientation" with the dependent variable "burnout" also is significant, $\mathrm{F}(156,2394)=1.379, \mathrm{p}<.01)$ with ANOVA follow-up analyses revealing four questions that are significantly different. Tukey HSD post hoc analysis, 
with significance levels reported in parentheses reveals that psychodynamic therapists are significantly more likely than cognitive-behavioral therapists $(p=.008)$ to receive emotional support from a supervisor or mentor. Cognitive-behavioral therapists are more likely than "other" $(p=.001)$ to feel they are working harder for change than their clients. Psychodynamic therapists are significantly more likely than cognitive-behavioral $(\mathrm{p}=.001)$, eclectic $(\mathrm{p}=.004)$, and "other" $(\mathrm{p}=.019)$, to seek counseling from another therapist. Eclectic therapists also are significantly more likely than cognitive-behavioral therapists $(\mathrm{p}=.009)$ to seek counseling from another therapist. Psychodynamic therapists are more likely than cognitive-behavioral $(\mathrm{p}=.002)$ and eclectic $(\mathrm{p}=.031)$ to receive support from a supervisory or mentoring relationship. Overall, it appears that psychodynamic therapists may be more likely than cognitive-behavioral therapists, to receive support from supervisors or mentors.

The MANOVA for the independent variable "theoretical orientation" with the dependent variable "confidentiality" is significant, $F(78,2472)=1.428, \mathrm{p}<.01$. Post hoc ANOVAS found only three questions with significantly different responses. Tukey HSD analyses revealed that cognitive-behavioral psychologists are more likely to discuss a client with a physician, without informed consent, than psychodynamic therapists $(\mathrm{p}=.032)$. For question \#98, support staff receiving ethics training, cognitive-behavioral and eclectic are both more likely to do so than psychodynamic $(\mathrm{p}=.001)$. Humanistic therapists are significantly more likely than cognitivebehavioral $(\mathrm{p}=.044)$ to discuss with a client how to deal with a chance encounter in the community.

For the independent variable "theoretical orientation" with the dependent variable "visibility," the MANOVA is significant with $F(66,2490)=2.113, p<.01$. Again, only three questions are significant with the ANOVA follow-up analysis, though for question \#49 none of the individual 
Tukey HSD comparisons are significant. Tukey HSD post hoc analysis did find that psychodynamic therapists are significantly more likely than behavioral $(\mathrm{p}=.042)$, cognitivebehavioral $(\mathrm{p}=.001)$, eclectic $(\mathrm{p}=.002)$ and "other" $(.014)$ to have processed during therapy a chance encounter with a client. Humanistic psychologists are more likely than "other" to have clients know more about their personal lives than they would like.

Highest rated concerns reported by respondents. Rather than completing statistical comparisons, it was decided to simply report the highest rated concerns, first by community, then by gender. For this part of the survey, respondents were encouraged to place a check mark in a box if they were concerned about the behavior. Admittedly, the term "concern" can have several different meanings. Respondents may have checked the box if, in theory or philosophically, they thought the behavior was a problem, or they may have only checked the box if they actually engage in the behavior and are concerned. A couple of respondents reported they were unsure which approach to take with this aspect of the survey, and thus did not check any of the questions as a concern. It did appear though, that overall, respondents primarily checked behaviors they were concerned about in the sense that either the behavior occurred in their practice, they gave the behavior a good deal of thought, or they were unsure if the behavior was a problem. Additionally, this was not a forced-choice response, thus it appears only those behaviors that tend to cause the most "concern" for a consistently large number of psychologists are going to surface by highlighting only the top concerns. Thus, this section will report the top ten (or slightly more if there is a tie) concerns by community (urban/suburban and small town/rural), and by gender (male and female).

Table 13 lists the highest rated concerns by respondents from urban and suburban communities. Psychologists are clearly frustrated with the lack of referral sources in the 
Table 13

Highest Rated Concerns by Community - Urban/Suburban

38. Have cases where more referral sources for your client would have been helpful (e.g. other community agencies)

1. Read professional journals related to your practice

27. Sometimes have to take clients that have problems that are beyond your scope of training and experience

52. Not be able to refer clients because of a lack of psychological referral services

44. Observe other therapists provide services outside their area of competence

64. Know colleagues who practice beyond their scope of training

94. Do not seek counseling for yourself because you feel too well-known by all of the therapists near your home and work

Six questions tied at the ninth spot:

20. Discuss a client with a psychologists colleague, without informed consent

22. Feel you don't do enough to help your clients

26. Find yourself working with two clients who happen to have a relationship with each other

29. Attend a party or social gathering and run into a client

56. Have time to devote to professional development

69. Have to treat populations (e.g. children, ethnic groups) for which you do not feel you have adequate training

Note. PC $=$ percent concerned. 
community to aid in the treatment of their clients. Respondents are concerned about having to take clients that have problems beyond their own scope of training or treat populations with which they have had little experience. Urban and suburban practitioners also have some unease with regard to observing or knowing other therapists who provide services beyond their area of competency. Only urban/suburban psychologists are worried about not being able to seek therapy for themselves because they feel too well-known by the other therapists in the area. Six concerns tied for the ninth spot. As previously reported, it was surprising that a fairly large percentage of urban/suburban psychologists run into clients at social gatherings, and it also appears they are concerned about this phenomenon.

Table 14 reports the top concerns for those living in small towns or rural areas. Many of these concerns, though rated by a higher percentage of respondents, are the same as those reported by their urban/suburban counterparts, such as feeling frustrated with a lack of referral resources (the top three concerns) and being able to read professional journals related to their practice. Some different concerns arise for small town/rural practitioners, such as being more apprehensive about unintentionally disclosing confidential client information. Small town/rural psychologists also are worried about treating clients who happen to have relationships with each other, and providing therapy to a client with whom they have had a previous relationship. Similar to urban/suburban psychologists they are concerned about sometimes having to take clients that have problems beyond their scope of training, and observing other therapists practice outside their area of competence. Seven behaviors were tied for the eleventh spot at $4.4 \%$, but not reported in the table. Those concerns included working on the same committee as client, attending a client's special event, running into clients in the community, attending a social event and running into a client, socializing with a client after termination, having one's ethical beliefs 
Table 14

Highest Rated Concerns by Community- Small Town/Rural

Question

$\mathrm{PC}(\%)$

68. Feel frustrated with the lack of alternative resources to help your clients

38. Have cases where more referral sources for your client would have been helpful (e.g. other community agencies)

52. Not be able to refer clients because of a lack of psychological referral services

1. Read professional journals related to your practice

26. Find yourself working with two clients who happen to have a relationship with each other

67. Unintentionally disclose confidential client information

27. Sometimes have to take clients that have problems that are beyond your scope of training and experience

32. Provide therapy to a client with whom you have had a previous social relationship

44. Observe other therapists provide services outside their area of competence

87. Find yourself working with a client who discusses problems with a person who is also your client

Note. $\mathrm{PC}=$ percent concerned. 
conflict with those of other professionals, and knowing colleagues who practice beyond their scope of competency.

Table 15 lists the top ten concerns as rated by female respondents. The top three concerns for this category, as with the small town/rural psychologists, are the lack of referral agencies and alternative resources that could serve as ancillary sources for a client's treatment. Female psychologists also are concerned about their own competency and other therapists providing services outside their area of competency. Female therapists tend to be solicitous about running into clients in the community, outside the therapeutic environment, which is congruent with the previous results suggesting females were more concerned with, or sensitive to, multiple relationships. Female practitioners are also more likely to report being concerned with taking work home with them, whereas males did not report this as a concern. In general, female psychologists appear to have been more likely to rate behaviors as concerns, resulting in higher overall percentage rates than their male counterparts.

Table 16 reports the top concerns for males. Males were generally concerned about many of the same behaviors, such as competency and referral resources, though the percentages may not have been as high, or the questions ranked in the same order. Males tend to be concerned about having time to devote to professional development and about working harder for change than their clients are, and feeling responsible for a client's well-being, whereas females did not report these behaviors. Other behaviors males reported, but females did not, include being concerned about unintentionally disclosing confidential client information, requesting favors from clients, and discussing a client with a colleague without informed consent. 


\section{Table 15}

Highest Rated Concerns by Gender - Female

68. Feel frustrated with the lack of alternative resources to help your clients

38. Have cases where more referral sources for your client would have been helpful in your work (i.e. other community agencies)

52. Not be able to refer clients because of a lack of psychological referral services

1. Read professional journals related to your practice

26. Find yourself working with two clients who happen to have a relationship with each other

44. Observe other therapists provide services outside their area of competence

27. Sometimes have to take clients that have problems that are beyond your scope of training and experience

46. Run into your clients in the community

29. Attend a party of social gathering and run into a client

80. Take work home with you to complete

Note. $\mathrm{PC}=$ percent concerned. 
Table 16

Highest Rated Concerns by Gender - Male

Question

$\mathrm{PC}(\%)$

68. Feel frustrated with the lack of alternative resources to help your clients

69. Have to treat populations (children, ethnic groups) for which you do not feel you have adequate training

1. Read professional journals related to your practice

27. Sometimes have to take clients that have problems that are beyond your scope of training and experience

38. Have cases where more referral sources for you client would have been helpful in your work (i.e. other community agencies)

89. Feel that you are working harder for change than your clients

44. Observe other therapists provide services outside their area of competence

56. Have time to devote to professional development

67. Unintentionally disclose confidential client information

Four questions tied at the tenth spot:

13. Request favors from a client

20. Discuss a client with a psychologist colleague, without informed consent

22. Feel you don't do enough to help your clients

82. Find yourself feeling responsible for your client's well-being

Note. $\mathrm{PC}=$ percent concerned. 


\section{CHAPTER IV}

Summary, Discussion, and Limitations of the Study

\section{Summary of the Study}

The primary objective of this study was to determine, quantitatively, if there are differences in the practice of psychology across different types of communities. Principally, we were interested in comparing rural communities to urban communities, though in the interest of sampling a broad cross-section of psychologists across the nation, it was decided to include small towns and rural populations in the same category. Examination of the qualitative results further revealed that it is difficult to capture the true essence of a "rural" community, and that towns with even larger populations than the small town criteria used herein may have rural characteristics, or conversely, small towns may be proximate enough to urban centers to have more suburban qualities.

Review of the literature. The impetus for this study derived from a review of the literature on the practice of psychology in rural communities which suggested that rural practitioners encounter more ethical dilemmas than their urban counterparts and that urban-derived ethical codes are not always congruent with a rural model of practice. It may be argued that psychology is an urban-based profession primarily because most of the universities and training sites where psychologists receive their initial training are located in urban areas. It appears that some practitioners in rural communities believe that the ethics codes do not speak to their experiences, such as the admonition to avoid dual relationships, and that speaking out about their real world experiences will only lead to censure. Although the ethics codes have begun to recognize that in rural communities some dual relationships cannot be avoided, very little research has addressed the issue of best practices for psychologists in a rural community. 
Moreover, there are many issues relevant to working in a rural community besides multiple relationships which need to be addressed, such as maintaining competency, or being highly visible in the community. Thus, the current study is not so much an effort to change or criticize the ethics code, or the practice of psychology in urban areas, or even to characterize certain behaviors as unethical, but is rather an attempt to quantify if, and how, the practice of psychology is distinctive in rural communities and small towns. Much of the existing literature in this area has been theoretical or qualitative. Although there have been several survey studies on ethical practices, none have specifically examined differences between urban and rural communities. Thus, the ethical codes provide the context, and criterion, with which to initially examine these practices. It is hoped that this study will generate honest discussion about the practice of psychology in rural areas and small towns so as to develop a guide to the best clinical practices, in addition to spurring discussion of methods to cope with ethical problems and dilemmas. Finally, several writers have asserted the need for critical self study (Pope, 1991), the utility of regular surveys of psychologists to inform the professional standards of practice (Pope, Tabachnick, \& Keith-Spiegel, 1987), and even the need to examine the differences in practices between small towns and large cities (Tubbs and Pomerantz, 2001).

This paper began with a general introduction into the study of ethics within the field of psychology, and defined the ethical issues that are explored in this study. Nonsexual dual relationships, or multiple relationships, are when a psychologist has a second relationship with a client in addition to the primary therapeutic relationship. Such a secondary relationship may occur before, during, or after the therapeutic relationship. For this study we excluded sexual relationships from consideration. It was articulated that multiple relationships can vary in intensity from simple self-disclosure (which may involve a role change by the therapist 
becoming more known to the client, or to a further extreme, the psychologist becoming the patient by discussing their current problems at length), to more intensive relationships such as becoming friends with a former client. Competency, though difficult to define, includes providing only services for which you have adequate training and experience. The distinction between obtaining and maintaining competency was described, and several authors highlight the importance of consultation and ongoing interactions with colleagues to maintain competency. The importance of knowing, and admitting, one's limits and weaknesses was articulated by several writers as well.

Burnout was described as a syndrome of emotional exhaustion, loss of purpose and energy, depersonalization or cynical attitudes, the loss of a sense of personal accomplishment or belief that one's work is rewarding. Several moderators of burnout have been explored in the literature, including having a sense of autonomy, having control over the work environment, types of clients seen by the therapist, and coworker or supervisor support. Several studies found that practitioners in private practice tend to have fewer symptoms of burnout and a higher sense of personal accomplishment, which in turn may be related to several of these moderators (Ackerly, Burnell, Holder, \& Kurdek, 1988; Dupree \& Day, 1995; Raquepaw \& Miller, 1989). Researchers have found both high and low rates of burnout among psychologists, and Coster and Schwebel (1997) strongly emphasized the importance of ongoing relationships with colleagues, and support from family and friends to buffer against burnout. Confidentiality was also defined, and some of the potential difficulties encountered when discussing clients, even when withholding client identifying information, were discussed. Previous surveys of ethical practices were reported next, noting that some difficulties encountered when working in rural areas were highlighted as early as 1969. Multiple relationships have been an ongoing concern and ethical 
dilemma for psychologists throughout many of these of studies. The survey instrument for this project included several questions from these various surveys, and the questionnaire style was particularly adopted from the Pope, Tabachnick, and Keith-Spiegel (1987) survey which has been replicated in many forms across various populations.

The review of the rural literature first describes the characteristics of rural communities. Rural communities tend to be quite complex interconnected communities with family, social, economic, and political systems interwoven over many generations. Rural citizens are likely to have multiple roles in the community, tend to rely on each other for support and to distrust outsiders. The myth of the rural citizen as independent and leading a quite peaceful life in the country was countered with data suggesting persons in rural communities encounter numerous environmental stressors, experience mental illness at rates at least as high as urban dwellers, and that suicide rates in rural communities have been higher than in urban areas for the last several decades. There is a need for psychologists in these communities, and the federal government has several programs designed to attract health care professionals to rural communities for this reason. Psychologists trained in urban areas, with their easy access to community resources (e.g. transportation, treatment programs, self-help groups, etc.), professional resources (e.g. supervision, colleagues, ability to refer to specialists, etc.), and the decreased likelihood of interacting with clients outside of the therapeutic relationship, may experience several difficulties, and ethical dilemmas, when adjusting to the practice of psychology in a rural community.

The first of these is multiple relationships. The psychologists faces the dilemma of the need to become involved in the community to build trust in order to encourage the utilization of services by rural community members, which in turn can create multiple relationships that may 
lead to conflicts of interests. Various types of multiple relationships that may arise in a rural community were articulated in the review of the literature. Several decision-making models that examine aspects of the therapeutic relationship, such as the intensity, duration, and power differential, were posited as a means to evaluate potential ethical dilemmas with regard to multiple relationships when they cannot be avoided. Although it may seem intuitively obvious that multiple relationships are more prevalent in rural areas, little research has specifically quantified the differences in the amount, and types, of relationships encountered between rural and urban communities.

Confidentiality is another concern in rural communities. Community members tend to know a great deal about each other, and may be more likely to know who is seeking services from a psychologist. Rural communities are likely to have well-established informal information sharing networks, such that within this culture psychologists may be expected to share with referral sources (e.g. police agency, school teacher, etc.) how the patient is progressing in treatment. If the psychologist is not forthcoming with information, referral agents may take this as an affront, and may not be as likely to refer in the future. Another confidentiality issue for the psychologist is keeping straight where they learn information they have about people, whether it came from community members, local media, or clients in therapy sessions. Therapists may also learn a great deal about their clients via other community members and need to decide whether to bring this into the therapy session. Thus, rural practitioners may know a great deal more about their clients' lives than their urban counterparts, who only have the information shared during the therapy hour with which to work.

Competency may become a problem in a rural community due to working in professional isolation, the lack of ongoing feedback from colleagues, and the lack of supervision. Rural 
practitioners may find it difficult to get ongoing training, and may not be offered nearly as many continuing education opportunities. Furthermore, due to a possible lack of referral sources, particularly other specialists, rural psychologists may need to take cases that are beyond the scope of their training and competency simply because they are the most qualified of the available resources. Burnout was considered as an ethical dilemma for this survey because it appeared in the rural literature that psychologists in rural communities may experience role blurring between their professional and personal lives, feel like they carry the weight of the whole community on their shoulders, have to cope with ongoing multiple relationships and operate in professional isolation. The concept of visibility reflected the fact the review of the literature suggests rural practitioners are likely to be well known by their clients, sometimes including personal information the psychologists might not wish to share with clients. Being highly visible suggests that psychologists may serve as a role model for their clients in the community, that they may have to practice what they preach outside of their work role, and they may at times feel like they are a therapist 24 hours a day.

Research methodology and questions. The survey instrument was derived from previous surveys, along with questions that were developed specifically for this project, in order to address each of these five areas, multiple relationships, competency, confidentiality, burnout, and visibility. The survey was refined through a class project on survey methods, feedback from graduate students and faculty, expert review, and respondent-expert review. The questionnaire collected various demographic data, some of which serve as independent variables to address the main research questions in this study. The primary independent variable was type of community, which was collapsed into small town/rural and urban/suburban. The other independent variables of interest for this study included gender, work setting, theoretical orientation, and years of 
experience. Research questions also addressed comparisons to the previous surveys in ethics, and patterns within this survey are also examined. Finally, it was decided to report the qualitative responses to the last question of the survey, which was open-ended and allowed respondents to relate personal experiences, qualify responses, or respond to the survey itself.

The first research question concerned differences between urban/suburban and small town/rural communities. It was hypothesized small town/rural psychologists would report more multiple relationships, more difficulty maintaining confidentiality, more burnout, and more difficulties related to maintaining competency and visibility than their urban/suburban counterparts. The second question addressed differences across gender. It was expected that female psychologists would report fewer multiple relationships than male psychologists. The third research question examined differences across work setting. It was hypothesized that psychologists in private practice would report fewer behaviors indicative of burnout, more multiple relationships, more problems maintaining competency, and fewer problems with confidentiality than psychologists working in a public agency. The fourth research question addressed years of practice. It was expected that psychologists with more experience would engage in more multiple relationship behaviors and report fewer indicators of burnout. The fifth question addressed theoretical orientation. The only hypothesis was that psychologists with a psychodynamic orientation would report fewer multiple relationships than the other orientations.

The sample was obtained from a computer-generated randomized list of 1000 APA members stratified into urban and non-urban by zip-code. The response rate was satisfactory with $44.7 \%$ of usable surveys returned and utilized for all analyses. The study sample appears to be representative of the population of APA members, and there were no significant differences between the stratified groups (urban/suburban and small town/rural) on any demographic 
variables. Reliability as assessed by Cronbach's alpha for internal consistency of the categories is good, with the possible exception of confidentiality which has an acceptable alpha value. An informal reliability check involved paired questions in the survey that were spaced widely apart, but expressed similar concepts and wording. These paired questions did engender similar response patterns.

\section{Discussion and Implications of Research Findings}

Research question \#1. For the first research question it was expected that rural practitioners would experience more multiple relationships, struggle to maintain competency, have difficulty maintaining confidentiality, experience more visibility in the community, and experience more burnout as a result of these issues. Results of the statistical analysis give support for some of these hypotheses. It appears that rural practitioners encounter significantly more multiple relationships than their urban counterparts. Nineteen questions were significantly different, all in the direction of small town/rural, ranging from incidental contacts, such as purchasing goods or services from a client, to more intensive relationships such as providing therapy to a client with whom you have had a previous social relationship or becoming social friends with a former client. The goal of this survey is simply to quantify differences between communities, and therefore more research is needed to determine the effects of these multiple relationships. Likewise, no judgment is made with regard to how ethical these behaviors may be, as it was believed at the outset that it is more important to gather baseline data on often these behaviors or situations occur rather than to categorize the behaviors by ethicality.

This significant difference between communities with regard to multiple relationships suggests it may be worthwhile to begin to address in the literature, and perhaps in graduate 
training programs, how to deal with these multiple relationships. Several decision-making models were discussed in this paper that may guide decisions with regard to such relationships, but which also provide a structured framework for future research on multiple relationships and client outcomes related to multiple relationships. Future research should build on the work of Anderson and Kitchner (1998) by examining the impact of different types of multiple relationships, whether incidental, social, collegial, and so forth. It seems likely that graduate training programs, which are generally located in urban areas, do not address how to deal with multiple relationships in small towns, or as mentioned by several respondents, in small communities within larger cities. Another important point becomes apparent when examining the results of these questions in that it is not just the relationship between therapist and client that needs to be considered, but also relationships between two clients who know each other and are seeing the same therapist, or therapists who provide therapy to friends of friends, or children of friends, and other similar third-party situations.

As expected, psychologists in rural areas are much more "visible" in their communities in that they are more likely to be seen by clients in the community. Nine of the eleven questions are significant in this category, and they do suggest that psychologists are likely to have clients know more about their lives than the psychologist would prefer they knew, to belong to or join the same organizations as client, and sometimes feel they are a therapist 24 hours a day. More research is needed to examine the impact of being so visible in the community on the psychologist, and the impact on clients, as well as discussion of methods to cope with being so well-known by clients, would benefit the rural literature greatly. Some methods to cope with visibility were discussed in Chapter I of this document, such as sitting on committees but avoiding leadership positions on boards to avoid conflicts of interest (Stockman, 1990). Several 
writers mentioned herein also discuss the positive impact of being more known to the client, of not having to maintain, or create, the aura of super-therapist with all the answers, and that clients may benefit when they learn that the psychologist has problems too, and is able to work through them.

Although each of the statistical tests (MANOVAs) are significant for the independent variable “community," for some of the dependent variables only a few of the follow-up ANOVAs are significant. This is the case with "competency" and "burnout." Although we did not test for clinical versus statistical significance in this survey, it does seem apparent that some results are more robust than others. Thus, while the MANOVA for the independent variable "community" with the dependent variable "competency" is significant, the results of the individual ANOVAs, with only three significantly different results out of 34 questions, suggest the results are not meaningful with regard to competency. This is not to say the individual questions are not meaningful, as two of the three questions involved frustration with a lack of alternative referral sources. It does suggest, however, that we cannot draw any conclusions about competency issues in rural or small town communities versus larger cities. This was contrary to predictions and quite surprising. Although psychologists did not appear concerned about their own competency, or have to take clients beyond their scope of training, they were more concerned about their colleagues doing so, though this held true across communities. Compared to the Pope et al. (1987) survey, psychologists in this survey appeared to more often take clients whose diagnosis is beyond their competency, or clients who have problems beyond their scope of training, but this held true across communities as well. It may simply be that therapists in rural areas do not have difficulty maintaining competency or find they have to stretch the limits of 
their competency, or it may be due to poorly phrased questions in the survey, or it may be due to socially desirable response patterns with regard to the therapist's own competency.

Similarly and contrary to expectations, it does not appear that rural practitioners have more indications of burnout that their urban counterparts, even though the statistical test for the category was significant. Only two questions are significant and they do not suggest any patterns. In fact, it appears that psychologists from all communities enjoy their work, find it satisfying and rewarding, and have many buffers in place against burnout.

For the issue of confidentiality almost half of the questions were significant across community types, although not in the pattern expected. It was expected that rural practitioners would have more difficulty maintaining confidentiality. Small town and rural practitioners do prepare their clients for chance encounters more than urban psychologists. The other pattern that emerged is that urban and suburban practitioners are more likely to discuss clients with colleagues, friends, and others (without client identifying information). This researcher does not believe this speaks solely to the issue of confidentiality, though it may be that small town and rural psychologists are more sensitive to disclosing confidential information and are therefore less likely to discuss clients with others (and they also may be aware that it is more difficult to disguise client identifying information in a small town). This researcher suggests this pattern may be due to the fact rural and small town psychologists have fewer opportunities to discuss their clients with others (such as colleagues, or other mental health professionals) in general, which may have negative connotations, such as less opportunity to consult on difficult cases. It also may be a combination of the two, such that rural practitioners hesitate to discuss casework even with other professionals due to the fear of clients being recognized from the case discussion. This seems an area worth further exploration as many psychologists maintain their 
competency through the practice of case presentations and discussions with colleagues.

Additionally, many settings today rely on multidisciplinary case discussions for a more holistic, and coordinated treatment approach, which may pose more particular difficulties in small town and rural areas.

Some interesting results surfaced with regard to the questions respondents checked as a “concern.” Small town/rural practitioners and urban/suburban practitioners both rated frustration with a lack of alternative resources to refer clients as a major concern. Small town/rural psychologists, as expected, rated this as a concern at a higher rate than the urban/suburban psychologists. It was surprising, however, to find these concerns rated so highly by urban/suburban practitioners. This is an important finding in that psychologists in both communities feel there are not enough resources to help with the treatment of their clients. This question deserves more investigation and discussion. Unfortunately, this survey did not explore what types of alternative resources psychologists believe are needed and whether there have been trends over time. For example, are the lack of referral resources due to recent cutbacks in funding, or has this been an ongoing problem in these communities? It seems to be a problem that deserves immediate attention, as it was the most agreed upon concern across both community type and gender. More research may be needed to explore how managed care and cutbacks in the public sector are affecting psychologists' use of ancillary services. Research in this area may inform what types of ancillary services psychologists believe would be of the most benefit to clients, and how we may go about filling those gaps.

As expected, small town/rural psychologists rated many more multiple relationship behaviors as concerns than did urban/suburban. Interestingly, both community groups are concerned about their colleagues practicing outside their areas of competency. Although the percentage of 
respondents checking behaviors as a concern is quite low, it seems the relative percentages are indicative of some differences between communities, such as small town/rural practitioners being concerned about having to take clients with problems that are beyond the psychologist's scope of training and experience. Similarities between communities also are informative, such as with the aforementioned concern about referral resources.

Research question \#2. The primary hypothesis with regard to gender was that males would be more likely to engage in multiple relationships. It was also predicted that females would be more concerned and sensitive to multiple relationship issues. Congruent with previous surveys mentioned in Chapter I, the findings herein suggest that males are significantly more likely to engage in multiple relationship behaviors. These relationships ranged from incidental, such as purchasing goods or services from a client, to more intensive relationships such as becoming social friends with a former client. In addition to engaging in fewer multiple relationship behaviors, females also appear to be more sensitive to these issues, as they are significantly more likely to prepare clients for chance encounters in the community, to discuss with clients how to deal with situations where they might run into each other, and to have processed during therapy chance encounters with clients. Additionally, a higher percentage of female psychologists indicated a concern with seeing clients in the community than did male psychologists. Taking together these findings suggests females are both less likely to engage in multiple relationships and are more sensitive to any relationship with a client that occurs outside the therapeutic context. This finding appears robust across studies and future research might begin to explore the reasons for this difference across gender, as well as the impact on client outcomes. For example, if we find that even in small/town or rural communities, females engage in fewer multiple relationships than males, this would suggest some of these relationships are in fact 
avoidable, though it still would be open to debate if they should be avoided. As stated in the review of the rural literature, getting involved in the local community by sitting on boards or through other activities may actually increase the community's trust and use of mental health services, though at the same time it may increase the number of multiple relationships.

No other predictions were made for gender, though there was a significant difference in the "burnout" category that appears meaningful. Males are more likely to disclose details of a personal stressor to a client, which is considered a symptom of burnout in this study. It may also be considered a multiple relationship, as it involves, to some extent, switching roles with the client. This question may be meaningfully related to the self-disclosure question which is also significant with males using self-disclosure as a therapeutic technique more than females. Therapists may use self-disclosure for a variety of reasons, (and this survey found it is used rather ubiquitously), including to instill hope in the client, to give the client someone to identify with (e.g. share a similar problem), or to build trust. Thus, sharing a current personal stressor may be considered another type of self-disclosure, though it is of a type that is more likely to lead to a role change in the therapy session. Research needs to continue to evaluate the role of self-disclosure in therapy sessions and its impact on clients, and we need to evaluate particularly the use of self-disclosure in small communities.

The other pattern that emerged with regard to burnout and gender is that females are significantly more likely to seek and receive support from supervisors, colleagues, and family and friends. These questions were included in the survey because they tend to be considered buffers against burnout, as discussed in Chapter I. One might conclude that female psychologists are more likely to have a stronger buffer against burnout because of this support network. On the other hand, it may also be that these particular questions favor female psychologists, as it appears 
that females, in general, are more likely to make use of support networks and helping relationships as a coping tool. It may be that males are more likely to have other buffers against burnout that are not assessed by this survey. Research needs to continue to examine if such support is indeed a buffer against burnout, and investigate the impact of having or not having emotional or other support from colleagues, supervisors, and mentors. Intuitively, it seems that such support would be particularly beneficial for therapists because they work so intensely with others all day long, and therapists would need the opportunity to debrief, share, and work through their experiences. In this case it would suggest the need to examine what the barriers may be to males engaging or seeking support from supervisory or mentoring relationships. If we examine the highest rated concerns for males, we also notice that males rated highly several behaviors that may also be indicative of burnout, such as feeling they are working harder for change than their clients, feeling responsible for their client's well-being, and feeling they are not doing enough to help their clients. Thus, the issue of burnout, coping styles, and gender differences appears to be a fruitful area for continued research.

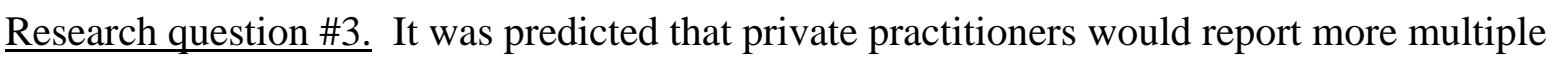
relationship behaviors, more problems maintaining competency, fewer symptoms of burnout, and fewer problems maintaining confidentiality. Fairly strong support was found for the first three hypotheses. Private practitioners are significantly more likely than institution, or public agency, practitioners to engage in a wide range of multiple relationship behaviors. As mentioned in the results section, for some of these behaviors it seems obvious that private practice psychologists are going to more likely to run into the situation, such as charging a client no fee for therapy or accepting goods or services in lieu of a fee (they have more control over fees). It is not as clear, however, why private practitioners may be more likely to purchase goods or 
services from a place of business where a client works or attend a party and run into a client (incidental contacts). As for more intensive relationships, such as providing therapy to a friend, a relative of a friend, or to a friend of a current client, this may be due to the process of expanding the client base through word of mouth and referrals from current clients, which is not necessarily the case with public agency clients.

Providing therapy to a client whom you know of from the same social sphere, or socializing with a client after terminating therapy, as previously discussed, may be due to the fact that clients who seek therapy, and therapists, both often have very similar values, avocations, social and cultural interests. This sharing of similar interests may only become problematic in a small town where the range of activities is restricted. To paraphrase one respondent, who stated in the qualitative section "if you eliminate all the people who share similar interests to the psychologist as potential clients, there are none left.” Conversely, it also may be that clients, who come to community mental health centers, and other agencies such as corrections, are not as likely to engage in activities and to move in the same social circles as they psychologists who work in those agencies. Although this difference between private practice and public agency practitioners was predicted, the robustness of the results is surprising. The field would most definitely benefit from a more focused study on the differential experiences of psychologists who work in mental health centers, clinics, and the like, from those who work in a private practice setting, and to further test hypotheses with regard to the reasons for such differences as those found here. As the reader may recall from Chapter I, several studies seemed to find that multiple relationships are more likely to be engaged in by male practitioners in private practice who do not have a psychodynamic orientation (Borys and Pope, 1989; Hines, Ader, Chang, \& Rundell, 1998), which is also the case in this study. 
As predicted, the results suggest that psychologists in institution or public agency settings may have an easier time maintaining competency. This makes sense in that practitioners in such a setting have more day-to-day interaction with colleagues. The results seem to reflect this pattern of practitioners in agencies being more likely to meet with peers to discuss casework and to get feedback from supervisors and colleagues. It would be premature to conclude from these results alone that private practitioners have difficulty maintaining competency, particularly considering that only a small percentage of the competency questions are significantly different in this case. Additionally, private practitioners may maintain their competency through other means, such as attending workshops, working in a group practice, talking with others on the phone, and meeting with other professionals as several respondents mentioned in the qualitative section. It also appears that therapists in institutional settings are more likely to take clients with problems beyond their scope of competency. Intuitively this makes some sense, as workers in an agency may have less control over the types of clients they see. Overall this research does suggest that being in a small town, and being in private practice may make it difficult to maintain competency, although we cannot draw this conclusion from the results herein with the certainty that was expected.

The significant findings with regard to burnout are more robust and in the expected direction. Private practitioners endorsed questions that suggest they have more control over their work environment, the types of clients they see, what they do during their workday, and are able to use their own initiative and creativity. They also find their work to be personally and professionally satisfying more so than persons who work in institution settings. These questions represent moderators that have been found to be related to burnout, as discussed in Chapter I. Psychologists who work in institution settings, on the other hand, are significantly more likely to 
work when too distressed to be effective, to take their work home with them, and to feel they do not do enough to help their clients, all indicators of burnout. Institution practitioners, however, also responded in ways that suggest they may have some buffers against burnout that the private practitioners may not have, such as receiving emotional support from coworkers, supervisors or mentors. Although the results are not unequivocal, it appears that psychologists in private practice receive more positive rewards and reinforcers from their work, while psychologists in public agency settings may be exposed to more stressors, but also have some support in place in their work environment to help cope with those stressors (although such support may be a stressor in itself, depending on the environment).

It appears that psychologists in private practice are more likely to have concerns about confidentiality primarily because they are more likely to have multiple relationships such as previously discussed. Thus, if therapists are treating clients who know each other, or are related, or who may interact in the same social sphere as the psychologist, it makes sense there would be more confidentiality concerns. Conceptually, the visibility category was meant to capture the essence of being known as a person, and being visible in the community, as distinct from confidentiality or multiple relationships. The survey instrument's ability to capture this distinction will be discussed in a following section on limitations of this study. It does appear here, that private practitioners are more likely to be visible in the community, e.g. run into clients at restaurants, belong to the same club or organization, or participate in the same neighborhood activity as a client. These questions are different from multiple relationship questions in that participating at the same activity (e.g. a $5 \mathrm{~K}$ run to benefit a cause) gives people, and potential clients, information about the values and beliefs of the psychologist, thus making the psychologist more "known" as a human being. It appears this is more likely to happen for 
private practice therapists than those who work for institutions though the implications of being more known to clients needs to be explored in more depth through future research.

Research question \#4. It was predicted that therapists with more years of experience would engage in more multiple relationships, which was supported by several significant results. The reasoning behind this hypothesis was that psychologists with more experience would be more flexible with their boundaries, be more willing to make exceptions to standard practices, and be more open about themselves with clients. The reasons for these results cannot be verified by this study. It does appear, however, that therapists with more experience engage in more multiple relationship behaviors, ranging from using self-disclosure as a therapeutic technique, to becoming social friends with a former client. Another possible explanation for this significant difference may be the fact that therapists with more experience simply are more likely to encounter these situations, thus the effect would simply be due to time. A third possibility is training cohort. Psychologists with less than 15 years since obtaining their degree are more likely to have received training that reinforced more stringent ethical behaviors as well as training in more recent ethical standards, whereas boundaries were likely not discussed in as much depth in training programs more than 15 years ago. The qualitative results were not particularly helpful in giving clarity to this question, as some psychologists reported they have become much more conservative with boundaries over time, after learning from experience, while other psychologists report becoming more flexible with time and experience, and becoming more willing to be known as a human being to their clients.

It also was hypothesized that therapists with more years of experience would endorse fewer items indicative of burnout, which was not supported as no patterns related to burnout surfaced, even though the MANOVA is significant. It does appear from the questions related to burnout 
that newer psychologists, those with less than 15 years experience, are more likely to seek support from supervisors or mentors. Those with less experience also are more likely to seek therapy from another therapist which is an interesting finding of its own merit. It appears that early in the development of the field of psychology, particularly when psychodynamic models were prevalent, it was very common for therapists to receive therapy as a part of training, and throughout their early careers. It seems, as a general observation by this researcher, with the growth of the cognitive-behavioral therapies in the 1980s, as well as ethical concerns in training programs (such as faculty seeing a student for therapy and having evaluative power over the student), it fell out of favor for therapists to seek therapy, and perhaps even came to be seen as a weakness of the therapist if they sought therapy. This researcher believes the pendulum may be swinging back again, that therapists in training, or having recently started in their careers, are becoming more comfortable seeking therapy for themselves. This opinion, however, is only the conjecture of this author. This phenomenon may also be partially accounted for by the fact that many psychologists within theoretical orientations have, over the last decade, become more open to the strengths of other orientations such as the role of personal therapy in the course of the training experience.

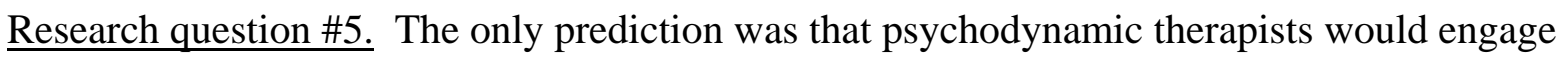
in significantly fewer multiple relationships than the other orientations, which was not supported. This may be due to the small number of subjects in some orientations, or it may be that since previous surveys such as Pope et al. (1987) psychologists of all orientations have received significantly more training in the area of multiple relationships and therapeutic boundaries across all theoretical orientations. In general the findings for theoretical orientation were not very robust, even where there were significant differences. The pattern that did seem to emerge is that 
psychodynamic therapists are significantly more likely than many of the other orientations to discuss their work with colleagues, other professionals, and supervisors; to receive constructive feedback from colleagues and supervisors, and, still, to seek counseling from another therapist. It may be that psychodynamic therapists attend to transference and countertransference issues more than other orientations and are therefore more likely to consult with colleagues on these issues. Transference and countertransference concerns would likely become even more problematic in rural areas where the therapist is more likely to see the client in the community. Interestingly, as noted in Table 2, a much smaller percentage of psychologists identified as psychodynamic in small town/rural areas compared to urban/suburban areas. In summary, it appears that both female therapists and psychodynamic therapists are more likely to receive emotional and consultative support from colleagues, supervisors or mentors.

\section{Comparisons of this Survey with Previous Surveys and Emerging Patterns}

Previous surveys, some using the same questions, provide a rich resource of information and potential comparisons across time and populations. For this project, however, only a few of these questions will be examined across surveys to get a sense of the similarities and differences between this survey and other surveys of ethical behaviors. Similarly, an infinite number of patterns and observations may be made from the data in Table 3. In this section though, a few of the most noticeable emerging patterns will be discussed. The comparisons across previous surveys include Pope et al. (1987), Borys and Pope (1989) which focused solely on dual relationships, Tubbs and Pomerantz (2001) which was a direct comparison to Pope et al. (1987), but limited to a state wide sample ( $\mathrm{N}=92)$, and Rae and Worchel (1991) whose sample was 
limited to pediatric psychologists. The reader is referred to Chapter I for a more detailed review of these surveys.

In general, the respondents in the current study answered questions more conservatively than the respondents did on the Pope et al. (1987) survey, but in many cases slightly more liberally than the Tubbs and Pomerantz (2001) study, which has a much smaller sample. For example, on the question of accepting goods or services in lieu of a fee, $92.4 \%$ responded “never" on the Tubbs and Pomerantz survey, only $66.9 \%$ on the Pope et al. survey, $82.6 \%$ for the Borys and Pope, and for this survey 85.9 \% of urban, and $70.8 \%$ of rural responded “never.” Going into business with a former client on Pope et al. engendered only an 83.1 \% response rate for “never,” while Tubbs and Pomerantz obtained a $96.7 \%$ response rate, and this survey a $97 \%$ for urb/sub, and $95.5 \%$ rate for sm/rural for "never.” Response rates for other questions show this same pattern, with responses becoming more conservative over time. Asking favors of a client lead to the following response rates for “never,” Pope et al. 60.5\%, Rae and Worchel $84.0 \%$, Tubbs and Poemrantz $90.2 \%$, this survey urb/sub $86.2 \%$, sm/rural $86.7 \%$. Accepting a client’s invitation to a party brought about the following “never” response rates: Pope et al. 59.6 \%, Borys and Pope 64 \%, Tubbs and Pomerantz 85.9\%, this survey urb/sub $82.0 \%$ and sm/rural $84.1 \%$. For unintentionally disclosing client information, although the "never” category showed the same response pattern as the above questions, the "sometimes” category remained consistent from 1987 to 2002: Pope et al. 3.3 \%, Tubbs and Pomerantz $3.3 \%$, this survey urb/sub $3.0 \%$, and sm/rural $1.8 \%$.

Although over time it appears psychologists are responding more conservatively with regard to ethical issues, it is not clear if this is due to changes in behaviors, or to being more aware of the socially desirable response to specific questions. Even if it is the latter, this suggests 
psychologists are more knowledgeable about ethical practices in general. Another pattern that emerges is that urban and suburban psychologists tended to respond to some questions much more conservatively than small town and rural psychologists, and in some cases the small town/rural psychologists' responses are closer to the earlier surveys. For example, becoming social friends with a client after treatment engendered only a $42.1 \%$ response rate of "never” for Pope et al. (1987), a 69.0 \% rate of “never” in Borys and Pope (1989), and for this survey, 85.3 \% “never” for urb/sub, while for sm/rural $71.7 \%$ responded “never.” This is not to imply that rural psychologists are less ethical, only that the circumstances that may lead to these differential response rates need to be explored in more depth.

Self-disclosure continues to be used as a therapeutic technique by psychologists. For the Pope et al. survey $71.2 \%$ used it “sometimes” or more often, while on this survey $69.5 \%$ of urb/sub, and $66.4 \%$ of sm/rural practitioners use it “sometimes” or more. A very interesting question concerned competency. Pope et al. (1987) directly asked if respondents provided services outside their area of competence, and received responses of $74.8 \%$ “never,” $22.8 \%$ “rarely,” and 1.8 \% “sometimes.” This survey asked the question with more face saving, or less direct wording, and received much higher ratings. Providing treatment to a client whose diagnosis is outside their area of competence received responses of $46.1 \%$ "never,” $45.5 \%$ “rarely,” and 6.3 \% “sometimes” (for urb/sub only, sm/rural was very similar and would create a confound in comparison). A smaller percentage of participants responded "never", which means a higher percentage, or rate, of persons engage in the behavior. Question \#27, sometimes have to take clients that have problems that are beyond your scope of training and experience, engendered even higher rates, with 39.9 \% “never,” 47.4 \% “rarely,” and 11.4 \% “sometimes” (urb/sub only). Question \#69 on this survey, have to treat populations for which you do not feel 
you have adequate training received similar responses for the urb/sub group, $38.9 \%$, $48.5 \%$, and $11.1 \%$ respectively. The increase in response rates for engaging in this behavior may be due to other reasons than the face saving wording, such as more demands being placed on psychologists such that they feel more pressure to take on clients who may have problems beyond their scope of training or competency. The change in wording, however, seems to be the most immediate and plausible reason.

Response rates for some questions appear to have increased over time from 1987 to 2002. Charging a client no fee for therapy received a rate or $18.7 \%$ for "sometimes" or more often on Pope et al. (1987), and for this survey $30.6 \%$ (urb/sub) and $36.2 \%$ (sm/rural) responded "sometimes" or more. A second question demonstrating a clear increase in the behavior is working when too distressed to be effective. Pope et al. recorded rates of 38.8 \% "never," 48.5 \% “rarely,” and 10.5 \% “sometimes.” For this survey, urb/sub responded 21.3 \% “never,” 64.0 \% “rarely,” and 14.4 \% “sometimes,” while for sm/rural, $21.2 \%$ “never,” $57.5 \%$ “rarely,” and 20.4 \% "sometimes" work when too distressed to be effective. This should be a cause for concern.

Response rates for other questions appear to have remained stable over time. Buying goods or services from a client, for example, received “never” responses for Borys and Pope (1989) of $77.7 \%$, for this survey $76.3 \%$ urb/sub and as expected for sm/rural $50.4 \%$. Going out to eat after a session lead to responses for Borys and Pope $87.4 \%$ "never,” and for this survey 95.5 \% for urb/sub, and $92.0 \%$ for sm/rural. Provide therapy to one of your employees brought about a response of 79.6 \% “never” for Pope et al., and on this survey $84.6 \%$ (urb/sub) and $85.0 \%$ (sm/rural). Several other questions may be referenced across these surveys, though these examples seem sufficient to demonstrate the general pattern of responses becoming more 
conservative (e.g. less multiple relationships reported) over time (as suggested by Tobbs and Pomerantz (2001)), and the noteworthy exceptions to this pattern, such as psychologists more often working when too distressed to be effective.

Several notable patterns also emerged from within the survey as well. The most hopeful and pleasantly surprising is within the "burnout” category. It appears that overall, psychologists enjoy their work and find their work satisfying. It seems worth reporting the results of the specific questions at this point. Most psychologists feel they have control over their work environment “fairly often” or “often” ( $85.6 \%$ of urb/sub, though this percentage rises to $96.4 \%$ if we include the "sometimes” response, while $88.5 \%$ of sm/rural psychologists responded “fairly often” or “often”). Similar responses were engendered for question \#84, have control over what you do during your work day (83.7 \% “fairly often” or more for urb/sub, and $82.3 \%$ for sm/rural). Control over the types of clients psychologists see also garnished a high response percentage with $78.9 \%$ urb/sub and $74.3 \%$ sm/rural for "fairly often” or higher. The above questions tend to be related to autonomy and a sense of power in the work place, characteristics that tend to be inversely related to burnout. Psychologists also find work to be personally satisfying with $90.7 \%$ of urb/sub, and $88.5 \%$ of rural psychologists responding “fairly often” or higher, as well as professionally satisfying $89.5 \%$ urb/sub, and $89.4 \% \mathrm{sm} / \mathrm{rural}$. Work allows respondents to reach goals they have set for themselves $(77.5 \%$ urb/sub and $75.0 \% \mathrm{sm} / \mathrm{rural}$, “fairly often” or “often”). Psychologists also feel they get support from family and friends (83.2\% urb/sub and $79.6 \%$ sm/rural, “fairly often” or higher), which is considered to be a buffer against burnout.

Extrapolating from the responses of “N/A,” not applicable, it appears that rural psychologists are not as likely to have a supervisor or mentor, or possibly a colleague, with whom to discuss 
casework. For question \#16, receive emotional support from a supervisor or mentor, $7.1 \%$ of sm/rural practitioners responded with "N/A" compared to $3.6 \%$ for urb/sub. Question \#119, support from a supervisor or mentor, also engendered twice as many "N/A” responses for sm/rural (15.9\%) as for urb/sub (7.8\%). Question \#59, have the opportunity to discuss problems in the work environment, received a $6.2 \%$ response rate for " $\mathrm{N} / \mathrm{A}$ ” by sm/rural psychologists, compared to $3.0 \%$ for urb/sub. It should be noted that it is assumed here that the respondents chose "N/A" because of the lack of access to a supervisor, mentor, or peers, though in fact it could be due to other reasons as well.

A similar pattern, however, emerges with other questions that suggest rural psychologists are less likely to discuss their work with others. Psychologists from rural areas are less likely to discuss clients with friends, without using client names (\#33, reported with ANOVAs), discuss a client with a psychologist colleague, without informed consent (\#20, also previously reported), discuss a client with other mental health professionals, without informed consent (\#105, previously reported), and have the opportunity to discuss problems in the work environment with peers (\#59, a previously reported significant ANOVA as well). It should be noted that several respondents reported that they do not use client identifying information when discussing clients with peers without informed consent. This pattern could be interpreted as small town and rural psychologists being more sensitive with regard to discussing clients, and their work in general, or it may also be that rural and small town psychologists simply do not have the opportunity to discuss their work with peers and supervisors, or the opportunity to consult on cases. This pattern of results may reflect that small town and rural psychologists are operating in more professional isolation compared to their urban and suburban counterparts. 
Another interesting pattern emerged with regard to competency. As previously discussed, it seems that the less direct wording of the questions in this survey lead to more open and less guarded responses compared to the Pope et al. (1987) survey which used a very direct question. Additionally, it appears that subjects do not report stretching their own limits of competency, but willingly report observing or knowing other therapists who do practice outside their areas of competency. For example, question \#39, provide therapy to a client whose diagnosis is outside your area of competence engendered responses of $6.6 \%$ (urb/sub) and $7.1 \%$ (sm/rural) for “sometimes” or more often. Question \#44, on the other hand, observe other therapists provide services outside their area of competence, received response rates of $36.5 \%$ (urb/sub) and 40.7 \% (sm/rural) for “sometimes” or more often. Similarly, question \#64, know colleagues who practice beyond their scope of training, engendered rates of $38.3 \%$ (urb/sub) and $37.3 \%$ (sm/rural) for "sometimes” or more. These are just a couple of the patterns that most immediately stood out during data analysis, though many other interesting patterns also likely exist. The goal of this particular project, however, is to examine and quantify the larger patterns of results through the use of statistical testing between groups, rather than relying on the results of individual questions as other surveys have already done, hence considerably more space was devoted to the MANOVA data analysis.

\section{$\underline{\text { Qualitative Results }}$}

Numerous respondents made comments on the open-ended question at the end of the survey. This question was utilized to allow participants to qualify or clarify any of their responses, noting that these simple questions do attempt to capture what can be quite complex behaviors, as well as to allow respondents to relate personal experiences, or to make comments about the survey. It 
was decided to categorize the comments and present a summary of each category in this section. The first category consists simply of comments about the survey. The second category reflects personal experiences, which is further organized into rural experiences, other multiple relationship issues, types of communities, and miscellaneous comments. The final category of qualitative responses is clarifications of questions.

Comments on the survey. Responses pertaining to the survey included both positive and negative reactions. Some responses were general "Good important work," or "This is one of the best survey instruments I've seen, very little ambiguity” and "I find ethical issues interesting and I am glad you are exploring them.” Another psychologist responds more specifically, “This is an excellent survey probing a sensitive and rarely discussed area in the professional literature boundaries and boundary issues. I appreciated the opportunity to review my own.” This researcher found the most rewarding responses to be those in which the psychologist stated the survey made them think about these issues more deeply. Several responses were along this line such as "I liked taking this survey as I believe it gets to real issues many of us find challenging (e.g. self-disclosure, stress, ethical issues). Also I find that I was not especially well prepared for a lot of the issues you address...” Another respondent states, “These are good questions and made me think about issues I struggle with practicing in my own small community.” Finally, one psychologist relates, “Thank you. Completing your questionnaire forced me to take a closer look at these ethical/boundary issues, especially situations without clear right/wrong answers.”

Several psychologists offered critical feedback as well, some responding to the survey instrument, others to the overall goal of the survey. On respondent noted, quite accurately, that there is a dramatic difference between a town of one-thousand residents and one of ten-thousand residents, particularly in terms of available resources and the lack of anonymity in the former. 
This is a serious issue, one addressed by this researcher in the Method section. As with any sampling decision, compromises are made, and in this case it was decided to utilize the largest definition of rural. This problem becomes further exacerbated by collapsing small town and rural into the same category. It is still believed, however, that this is the best method with which to obtain a large national sample representing a cross-section of practitioners across the country. It is hoped this research will stimulate further research focusing more directly on rural communities of smaller sizes, and perhaps sampling counselors and other health care professionals in rural areas.

Other critical responses included "You are clearly repeating questions to evaluate consistency in responding, which I experienced as obvious," which is the case, and "Demand cues in this survey are prolific”, although this respondent did not provide detail about which demand cues. Two psychologists thought the survey too long, one of which left out so many questions it could not be used in the analysis. Another psychologist, though, did complete the survey but responded that “Too many questions!!! I almost through [spelling quoted intact] it out in frustration.” One respondent provided a very thoughtful criticism along the same lines, stating “It’s presumptuous to think professionals and practitioners would have interest and time to answer the questions asked...The issues your questions touch upon are important to the ethical practice of professional psychology, but most of these issues are multidimensional...I often felt you would need to know my particular circumstances.” This raises some very important issues, some of which were given considerable thought before distributing the survey. This researcher struggled with the length of the survey, but pilot study and expert review determined that most of the questions lent themselves to quick responses without much deliberation. In general the survey took about 20 minutes to answer. Although most of us get frustrated at, or throw away, 
surveys we receive in the mail (as over 500 did in this case, as was expected), on the other hand, as a scientific based profession we often expect clients, or research participants, to take hours to complete instruments such as the MMPI, or a battery of shorter questionnaires, so that we can further our professional knowledge base. It seems that we, as psychologists, should also be willing to take time to answer questionnaires to further our knowledge base about our own profession. The respondent was also quite correct that these are complex, multidimensional issues, which is why this researcher spent a considerable amount of time testing and rewriting the questions used in the survey in an attempt to strike a balance between short easy-to-answer questions, and still maintain the goal of capturing complex behaviors that often involve qualifying circumstances. Secondly, the complexity of these behaviors was the impetus for including an open-ended question at the end of the survey. Additional respondent critical comments will be considered in the following sections as well.

Multiple relationships. In regard to the experiences related by psychologists, many of whom appear to be rural or small town respondents, they appeared to fall into two broad categories, multiple relationships and competency issues. Multiple relationships included incidental contacts, boundary issues, general comments, and methods respondents use to cope with multiple relationships. As reported in the review of the literature, psychologists may sometimes feel they should present themselves as having their lives under complete control, and that clients should not see their weaknesses, or know the difficulties they may be experiencing. Even incidental contacts with clients in the community can challenge this presentation, as some respondents reported. One psychologist states "Sometimes I feel uncomfortable running into clients in the community because I feel this gives them too much information about my personal life (my children, how I dress when I'm home, etc.)...,” and also reports that it is better when the 
therapist can control disclosure. Another relates that "I find it personally awkward sometimes in church, for example, if my children are misbehaving. I feel I should look as though I have it all under control.” This psychologist has become more proactive over time in preparing clients for those chance meetings in the community. A third respondent relates "I live in a very isolated rural community. I cannot avoid the fact that I will run into clients in public, my kids run into kids I've seen at school etc. However, confidentiality and boundaries are very important to me...”

Other responses concerned more intensive boundary issues around therapy and other ongoing relationships. One respondent suggests that in is very difficult to work in a small community, that dual relationships cannot be avoided and suggests we "need to develop a different ethical code when it is only you and three other psychologists for 100 miles.” In the review of the rural literature it was mentioned that it can be difficult for a small town psychologist to keep compartmentalized where they learned information, whether the information came from interactions with community members or from a client in a therapy session. One respondent spoke directly to this problem:

I see my clients everywhere but plan at the first meeting how to handle it when it happens...I avoid dual relationships involving power differentials...I know a lot about my clients and they about me; via mutual activities and acquaintances-it can be difficult to remember how I know what I do and I worry about violating confidentially that way. If I learn something relevant to treatment outside of treatment I am honest about it and bring it up and use it.

Earlier in this paper it was suggested that clients who seek therapy, and psychologists who provide therapy, often share similar interests through the process of self-selection. A 
psychologist discusses this issue as well, "These questions miss the point...People who value therapy (I have not done therapy for several years for this reason) are more educated/ with money people. These are my peers in clubs etc. When you eliminate all of these people as clients there are none left.” A final comment on boundaries comes from another psychologist who states:

Some questions about the friends/clients distinctions are hard because I live and work in a very small town and my clients interact with me everywhere-on the bus to a child's class fieldtrip, in the grocery store, city council meetings, stores, and businesses. My children have had former clients as teachers, doctors, scout leaders, etc. However, I am clear about who my "personal friends" are...Boundaries are a challenge to maintain, but not impossible. Family and friends of clients come to see me because they can't find help anywhere else, so we are all conscious of the boundaries and accommodate and adjust to it, and somehow it works.

Two comments of note, that fall under a general category, also speak to issues raised in the review of the literature. One respondent testifies "I have struggled with the issues suggested by your survey over the course of my career...have moved from more rigid/guarded to open/flexible. I am convinced bringing my humanity into therapy has benefited my patients...but I still have qualms over this and sometimes feel vaguely vulnerable.” Another commented on the difference between urban and rural practice after moving from the big city to a small town, stating they meet clients in the store, serve on committees with clients, but that they discuss these contacts with clients at the beginning of therapy. This respondent affirms that "small town practice is much different than practice in a large city." 
Several respondents suggest methods to cope with dual relationships problems. A common comment is that respondents learned quickly to set social boundaries. Some limit their range of activities, one stating that "I was not trained to deal with multiple relationships in graduate school...these are unavoidable and common in this area...I have most definitely limited my social activities as a way of reducing potential dual relationships... I admit this vigilance is sometimes stressful and hard on me (and my family), but we learn to live with it.” A second respondent states "I have avoided somewhat getting involved in community organizations due to not wanting dual relationships or uncomfortable encounters. I have avoided joining the health clubs for the same reason.” A third relates that "I usually go to another town for goods or services, but there is only one store [type of store left out] around, owned by a client.” These respondents are speaking directly to the paradox presented in the review of the literature, the need to become involved and accepted by the community on the one hand, and the ensuing multiple relationship dilemmas this level of involvement then brings about.

The primary method therapists reported to deal with multiple relationships is to discuss the issue with clients in the first session. "During the first therapeutic session, I attempt to establish out of the office boundaries to preserve confidentiality...It is possible to be a friendly psychologist without being currently a friend.” (Although, this respondent went on to say, some clients with personality disorders have trouble with this concept). A psychologist from a small town of less than three thousand states they "frequently encounter clients, former clients, and family members, in the store, art gallery, hiking etc. So it is important to discuss this with clients right away at the beginning stages of therapy. I ask them if they want me to greet them in public." This respondent goes on to state that "personal boundaries become highly more important in small towns where you are already known by a number of people.” Other 
respondents relate that they have chosen to live in a different small town than they work in, which is not always convenient when towns are spread out from each other, or one central area serves a number of neighboring communities.

Competency issues. Concerns about providing services outside one's area of competency and a lack of referral resources were raised by several respondents. One psychologist, states "You also end up providing a wide range of services because you have to deal with the situation, there is no one else.” Another respondent relates, “On rare occasions I have selectively opted to see someone and probably would not have if there were more resources here.” Still a third psychologist summarizes their experience in a small community, stating the professional community is very limited and that “...it’s been difficult to obtain consultation which feels useful...I'm asked to see clients who have problems/diagnoses which I don't have a lot of experience with, but I'm the person on the [location deleted] who is available and has the most relevant experience in the area.” Another respondent relates “The biggest problem I encounter is finding people to refer when I am not able to take the person due to a lack of training or conflict of interest.” Finally, three respondents referred to the lack of available resources, having more work than they can handle, thus not being able to devote time to professional development, and the lack of psychiatrists with whom to refer patients.

Defining rural communities and communities within communities. Respondents also discussed, at length in some cases, the difficulty with defining a small town or rural area. Several related that this survey categorized their towns as suburban or urban, using population, but that this was not an accurate characterization of their community. "Although my community is about 50,000 it remains a rather small town. I often feel that I expend a great deal of energy making sure boundaries are not crossed. At times I feel a bit isolated socially because I refrain 
from activities in the community in order to keep what I think is appropriate distance from my clients.” Another reports "you have described communities our size as suburban. However, we are 2 hrs away from the nearest urban area. This is a predominantly rural area. We are careful to define potential conflicts...” A third responds "Although [town deleted] and surrounding area has 89,000 people it could not be considered urban... this is a rural community...dual relationships are impossible to avoid.”

A second issue related to the definition of community, as discussed in the review of the literature, and emphasized in the relevance of this study, is that small communities often exist within larger communities. Examples given in the review of the literature included the gay/lesbian/bisexual community, the deaf community, and the military. Interestingly, respondents representing these communities responded in kind. On respondent sates "This item can be very misleading as many of us participate in small communities in large metro areas, such as gays and lesbians, Jews, ethnic groups etc.” Another related their experience working within the recovery community, and being apart of the Alcoholics Anonymous (or 12-step) culture, and coping with such norms as hugging each other on greeting. A third states "One issue for me is a small community within an urban setting due to my sexual orientation and work with that small community as well as a large urban population.” (This is the same respondent who used to barter and attend special events, but no longer does so after learning from experience). Finally, one respondent who works with a small community within a very large urban area states:

I work exclusively with the deaf and hard of hearing clients and I'm one of 2 therapists here doing that work and fluent in American Sign Language. We have a fairly large deaf community here, but all the deaf clients know each other, and we work extremely hard to maintain all clients' rights to privacy and confidentiality. There are also very different 
deaf cultural norms that weren’t addressed by your questionnaire such as: hugging, socializing in some situations is viewed as mandatory by deaf, but in other situations, I am not welcomed because of my professional status. Because I am very visible to deaf clients in the community, there is a tendency for them to want to know a great deal about my personal life, which I try extremely hard to keep as private as possible.

Miscellaneous comments. Several of these general comments seemed worthy of reporting. One respondent relates, "From my 20 plus years of experience and supervision...I believe that informed consent and ethics are poorly understood concepts, not because their definitions are not studied, but because the reasons (clinical) behind the issues are not addressed completely.” An assessment specialist reports "The ethics questions are quite germane. I find the large majority of licensed psychologists who do assessment: 1) are not knowledgeable about advances in the field of cognitive and personality assessment; 2) practice outside their expertise; 3) use outdated instrument or instruments inappropriate for the use to which they're being put.” Additionally, this respondent asserts that due to these shortcomings in assessment competency, psychologists misuse their influence, or allow it to be misused. Some respondents related that once they moved to private practice they felt they had more control over their work environment or the types of clients they see. Another respondent who primarily conducts research suggested that many of these same ethical issues apply to the research setting. One psychologist recounts "I loved doing the work of my profession and every session I gave my best to my client. I had mentors and some wonderful colleagues. I retired [within last two years]. I would never return to my profession, however. Many of the changes over the years in the profession have turned me from it.” This respondent did not specify in any more detail which changes were particularly disconcerting. A last comment from a respondent reflects the general belief of this researcher, 
that most psychologists work very hard to do the best job they can, and to practice ethically, states “...My experience is that most well-trained clinicians, especially, Ph.D. psychologists do a very good job of seeking out effective strategies for treatment and obtaining the necessary training to implement them...”

Clarifications of questions and responses. Finally, the last category of qualitative results relates entirely to clarifications on questions. There are too many to list here, and few affect the meaning of any of the aforementioned quantitative results. Some clarifications have already been mentioned, such as several psychologists who noted they loan books, but not personal items (question \#35). Several mentioned question \#108 was too confusing, and they left it blank, and as mentioned, it was thus left out of all analyses. One respondent remarked they were not currently in therapy or receiving supervision, but that they did go through therapy during and after graduate school, and had an intense mentoring/supervisory relationship for several years as well. A therapist related they did not have supervision but did attend a peer consultation group. Several therapists reported, as previously mentioned, they did not use identifying client information when discussing casework with colleagues or others. A very important clarification, and a rather large mistake by this researcher, that somehow slipped through several reviews of the survey, was question \#113 attend the same church as a client, or similarly question \#95 asking if sought informal support from a pastor or minister. These questions are inappropriately worded, and demonstrate our lack of multicultural perspective, as they do not take into account other places of worship, such as temples, synagogues, mosques, and so forth. One respondent noted that physicians do not expect, or respect confidentiality with clients. Some respondents noted they use long distance consultation by phone, or consult with colleagues at workshops. Respondents also commented that although they accept small gifts from clients they only do so 
at the holidays, or that they buy candy from clients who are selling it for school events. This concludes the qualitative results, which are generally helpful from several perspectives. Comments by psychologists on their personal experiences resonated with the preceding review of the literature, and the comments on the survey items were generally quite accurate, and the criticisms noted for future research.

\section{Limitations and Future Research}

Several limitations to the current study bear mentioning. As discussed in previous studies, survey research has the limitation of relying on self-report data (Rae \& Worchel, 1991; Tubbs \& Pomerantz, 2001). This researcher believes a survey was the best method to gather data from a diverse national population on such a wide array of practices. Additionally, this researcher made every effort to assure respondents that their responses would be kept confidential, that the database did not include any identifying information. Nevertheless, survey research does rely on the honesty of the respondents to provide accurate information. In keeping with previous surveys of ethical practices, this survey used one item as check of social desirability, question \#115 asked if respondents accepted a handshake from clients. Few respondents denied accepting a handshake from clients, suggesting participants were not overly defensive in their responses. Furthermore, responses in general were compared to previous surveys, and as predicted the responses were generally more conservative than some surveys (e.g. Pope et al. 1987), although response patterns also were more liberal than other recent surveys (Tubbs \& Pomerantz, 2001). Some areas, such as competency, may be more likely to lead to socially desirable responses than other areas, which may have accounted for the lack of differences across communities on the “competency" variable, although there are alternative hypotheses for this finding. 
Another potential limitation with this survey approach is that participants are allowed to anchor their own responses. In other words, rarely, sometimes, fairly often, and often are subjectively determined by each respondent. Perceptions of how often a behavior occurs, however, may be just as informative as the absolute frequency. Comparing absolute frequencies across behaviors does not make sense in this study, as some behaviors may happen quite often and not be of much concern, such as running into a client in the community, whereas other behaviors may occur infrequently due to decreased opportunity, but may be more of a concern, such as becoming social friends with a client, or going into business with a client. Pope, Tabachnick, and Keith-Spiegel (1989) in responding to this very criticism on absolute versus relative frequency data, point out the value of ipsative data in which participants are allowed to anchor their own scales. They assert that the participant’s perception, or denotation, of how often the behavior occurs gives us more information about whether the behavior may be a problem area for that participant, whereas a numerical value based on an absolute scale does not carry as much meaning. Thus, if one therapist rates questions related to burnout as occurring "often," when the actual number of times the behavior occurs is twice a week, we get a sense that this respondent is experiencing some burnout symptoms. Another respondent, on the other hand, may also experience burnout symptoms twice a week, but denote this as “rarely,” suggesting they do not find that particular behavior problematic.

The final sample for this study limits the generalizability of the results to psychologists who are members of the American Psychological Association (APA). It may be that becoming a member of APA is a self-selection process that distinguishes APA members from those who choose not to belong to APA. The ethical code discussed herein is created by the APA, disseminated through APA journals, and the process of joining the APA is in some ways making 
public a commitment to follow the ethical code. Furthermore, psychologists who practice unethically or engage in questionable practices may be less inclined to join APA or to respond to this type of survey. Another concern is that it may also be that psychologists who live and work in rural areas may be less inclined to join APA than psychologists in urban areas. This question needs to be explored in future research that examines, at a more molecular level, the practice of psychology in rural towns.

Other self-selection forces are at work with this study as well. The response rate was very respectable compared to other survey research in this area, however, less than $50 \%$ of potential participants responded to the survey, leaving the possibility that these respondents may differ on some significant characteristics from those who did not respond. A greater percentage of urban compared to rural psychologists responded to the survey. It may be that those rural psychologists that did not respond are too busy, overworked, or feel this research does not apply to them, all of which would have been valuable data to have.

This survey was an attempt to capture baseline data on a wide range of behaviors and situations, behaviors which in many cases may be quite complex and involve mitigating circumstances. The questions for the survey were kept brief and to the point in order to keep the amount of time to complete the survey in the twenty minute range, so as to not discourage potential participants. This disparity, between the complexity of the behaviors under study and the simplicity of the questions utilized, may have lead to some questions being too broad or vague, leaving room for multiple interpretations of some questions. As discussed previously, the open-ended question at the end of the survey was intended to allow subjects to clarify responses, and several participants clarified their responses to questions right on the survey instrument. 
Similarly, some of the constructs in this survey are not yet well defined, both within this study and in the literature in general. In the review of the literature it was mentioned that psychologists still do not agree completely on what constitutes a multiple relationship and that competency is quite difficult to define and measure. The construct "visibility” was created for this survey and has not been fully developed as a construct with previous scales or research on which to build. Although the goal of this study was not to create scales to measure these constructs per se, it became apparent during data analysis that one of the limitations of this study is the definition and measurement of the dependent variables. A great deal of work went into the creation of the survey instrument, with many, many revisions, including expert review and the use of respondent experts. It is still believed that the questions give a good overall picture of the dependent variables considered. It was only during data analysis, however, that it became readily apparent that some of the questions under one dependent variable could have easily been considered with one of the other dependent variables. Several of these examples were mentioned in the text, such as disclosing current stressors to a client, which was considered with the "burnout" category but could have also been considered with the "multiple relationships" category. The results with regard to "visibility" were fairly robust, and the Cronbach’s alpha was quite satisfactory, but several of the questions in this category, such as work on the same committee as a client does, could also be considered multiple relationships. It is believed more research is needed to get at the essence of being highly "visible" in the community when working in a small town.

The definition of the independent variable "community" also poses some limitations. As mentioned by one respondent in the qualitative results, there is a big difference between a town of one thousand, and one of ten thousand. This issue was addressed in the qualitative section, stating that compromises needed to be made in order to obtain a meaningful national sample of 
psychologists across communities, and thus small towns and rural areas were grouped together in this study. In the qualitative section several respondents mentioned that though their town met the criterion for a suburban area, their town was more rural in nature. Future research, now that we have national baseline data, may focus more intensely on rural towns that are more conservatively defined. In this study our sampling method involved using a zip-code generated list, whereas future research may obtain more representative samples of various community designations by focusing on a particular state, and utilizing the state licensing board, or state psychological association. Finally, as mentioned in the qualitative results, some questions appeared on the survey that this researcher should have edited, such as the questions about attending church or seeking support from a minister, which do not take into account other religious affiliations.

Throughout this paper several suggestions for future research have been mentioned, which will be reiterated here, along with others that have not been discussed. It seems clear that multiple relationships occur in the practice of psychology, and that they are more likely to occur in small towns and rural areas, with those who are in private practice, and that male psychologists are significantly more likely to engage in multiple relationship behaviors than female psychologists. It seems self-evident that instruction on recognizing and coping with multiple relationships is needed in graduate coursework. Although this survey targeted psychologists, this training would likely benefit masters' level therapists and counselors as well. Several decision-making models were presented which provide a structure to examine how different types of multiple relationships impact the therapeutic process, both in small towns and larger communities. More research is needed to determine the impact of various types of multiple relationships on both clients and therapists, from self-disclosure within the therapy 
session to social encounters with clients. Research has begun, and needs to be continued, on the client's perspective of ethical practices, such as boundary crossings. We did find differences between male and female psychologists with regard to engaging in multiple relationships, as did previous studies, which is an avenue worthy of further exploration. Likewise, females also are significantly more likely than males to utilize supervision, mentoring relationships, and discussions with colleagues. Such support may increase competency, or may simply be considered a form of social support, a question worth further study. Males may be more likely to utilize other coping resources than supervisory relationships and collegial support, though this begs the question of how this affects the maintenance of competency. Are females more likely to maintain competency because of their significantly greater use of supervision and consultation? Even some individual questions suggesting gender differences may be worthy of future study, such as males being more concerned about feeling they work harder for change than their client.

Although there are clearly differences between small town/rural communities and urban/suburban areas across several of these dependent variables, such as "multiple relationships” and “visibility,” many differences may have become blurred due to our definition of small town/rural. As mentioned, by using the broadest definitions of rural, and then combining small towns and rural into one category, we may have missed many differences that would be found in truly rural communities. Thus, future research would benefit from a more focused attempt to identify, and survey, rural practitioners, such as focusing the study within a single highly rural state. This research could also explore the ethical concerns of several disciplines in the helping professions. Suggestions for sampling methods to identify truly rural practitioners included state licensing boards and state psychological associations. 
Findings related to the independent variable "work setting” suggest several avenues of future research. The differences in experiences between private practice psychologists and public agency psychologists were robust. Research exploring these differences in more depth would be valuable in training psychologists regarding what to expect as they make career choices. It seems evident that private practitioners need more extensive training in how to manage multiple relationships, and as their client base often expands through word of mouth, how to handle situations with current clients who know each other or are related. Another research question may investigate in more depth how psychologists in private practice maintain their competency, particularly in smaller towns. Do public agency practitioners have an easier time maintaining their competency by virtue of more immediate access to colleagues and supervisors? What methods do private practitioners use for consultation, continuing education, and learning new skills? Concerning competency, more research is needed on how we define it, when therapists stretch their limits of competency, whether they receive supervision when working with new client populations or with clients who have diagnoses with which they may not have experience. Generating discussion and research about practicing beyond the limits of competency poses several methodological concerns, such as therapists not being willing to admit they stretch their limits, or not being aware of so doing. Psychologists in this survey were clearly concerned about their colleagues practicing beyond their limits, and there seems to be an increase from previous surveys in respondents working when too distressed to be effective, thus honest discussion is needed. It also may be that we need to normalize, rather than prohibit, practicing beyond our limits, as this is a part of the learning process, though we ideally only do so with supervision or consultation. Lastly, it seems highly likely, from these findings, that psychologists in public agencies are more likely to deal with issues of their own burnout, though this needs to be 
explored in more detail, as well as determining which aspects, or moderators, in the public agency environment contribute to burnout, and how psychologists cope in this environment. In this study we found that public agency psychologists may have more symptoms of burnout, but on the other hand, they seemed to get more support from colleagues and supervisors, which may attenuate any negative factors contributing to burnout.

The findings with regard to the dependent variable "visibility” suggest several prospects for further research, particularly research that is more focused on small rural communities, as described above. What is the impact on therapists of being so well known to their clients, of having clients know about their personal lives? How do therapists handle this in the therapy session and keep the focus on the client in therapy? What is the impact on clients of knowing so much about their therapists? For example, from a relational psychodynamic point of view, how does knowing so much about the therapist affect an idealizing transference? What impact does it have on clients to run into their therapists in the community, or to participate in the same activities, such as a community board, with their therapist? Do conflicts of interest arise in these cases and how are they handled?

Another avenue for future research studies would entail the development of scales to assess a range of ethical practices. As mentioned, this study primarily grouped questions together by face validity. A great deal of work went into the review, expert review, and rewriting of the questions of this survey. The category "visibility," for example, was developed solely for this survey. This researcher conceptually visualized the category "visibility” as being on the opposite end of the continuum of Freud's ideal of “anonymity” in the therapeutic relationship (though in reality Freud rarely kept to this ideal himself and shared a great deal about himself, and his other patients, with patients). If this anonymity-visibility continuum seems useful as a construct, 
future research can focus more specifically on developing a scale to measure the concept. Similarly, Anderson and Kitchner (1998) identified eight different dual relationships psychologists may engage in. Future research would benefit from the development of scales, or measures, of these different multiple relationships to make it easier to identify their occurrence and impact in actual practice, and make it possible to use the same measures across studies and populations.

Individual questions from this survey may also suggest opportunities for research. For example, it appears that therapists in rural areas do not have as much opportunity to discuss casework with others, or it may be that they are concerned about confidentiality and hesitate to discuss their casework. Research on rural communities would benefit from exploring how case discussions and consultation are handled, particularly with a new emphasis on multidisciplinary case presentations to ensure a holistic approach to treatment. Additionally, case discussions and consultation are considered basic tools for maintaining competency. What impact do concerns about confidentiality have on case conferences in small towns? Another issue raised herein, across all communities, is the lack of ancillary referral sources for clients. Future research might explore why this lack of referral sources exists, whether due to managed care or limited public funding. What gaps do psychologists believe most need to be filled (e.g. case management, transportation, day programs, self-help)? And what types of agencies could fill those needs?

Concluding remark. It was mentioned in the relevance for this study, and at the beginning of this discussion, that several researchers have emphasized the importance of self-study for the field of psychology. It is hoped that this project contributes to the body of literature concerning the practice of psychology, and gives useful suggestions for future research directions. Ethical codes need to be constantly evolving, and need to be informed by honest feedback on how actual 
practices mirror ethical principles and ideals. We need to monitor our practices and the impact of these practices on our clients. Some writers mentioned in this literature review suggested that we have become too defensive in our practices, that we have become to rigid and conservative in the way we relate to clients. Others described the importance of conservatively maintained boundaries to create a safe therapeutic frame. This type of debate and discussion, informed by data on psychologists' actual practices, will ultimately, it is hoped, help us identify the best practices psychologists may use, rather than just the safest practices. This writer also hopes that this survey contributes to our self-study in ways beyond just examining ethical practices; that these findings may contribute to our knowledge of the types of work environments in which psychologists' work, how we define our work, and the factors that contribute to our job satisfaction. 


\section{References}

Ackerly, G.D., Burnell, J., Holder, D.C., \& Kurdek, L.A. (1988). Burnout among licensed psychologists. Professional Psychology: Research and Practice, 19, 624631.

American Psychological Association (1987). General guidelines for providers of psychological services. American Psychologist, 42, 712-723.

American Psychological Association (1992). Ethical principles of psychologists and code of conduct. American Psychologist, 47, 1597-1611.

American Psychological Association (2002). Ethical principles of psychologists and code of conduct. American Psychologist, 57, 1060-1073.

Anderson, S.K., \& Kitchner, K.S. (1996). Nonromantic, nonsexual posttherapy relationships between psychologists and former clients: An exploratory study of critical incidents. Professional Psychology: Research and Practice, 27, 59-66.

Anderson, S.K., \& Kitchner, K.S. (1998). Nonsexual posttherapy relationships: A conceptual framework to assess ethical risks. Professional Psychology: Research and Practice, 29, 91-99.

Baer, B.E., \& Murdock, N.L. (1995). Nonerotic dual relationships between therapists and clients: The effects of sex, theoretical orientation, and interpersonal boundaries. Ethics and Behavior, 5, 131-145.

Baird, K.A., \& Rupert, P.A. (1987). Clinical management of confidentiality: A survey of psychologists in seven states. Professional Psychology: Research and Practice, 18, 347-352.

Berven, N.L., \& Scofield, M.E. (1987). Ethical responsibility in establishing and 
maintaining professional competence. Journal of Applied Rehabilitation Counseling, 18(4), 41-43.

Birk, J.M. (1992). Country Roads: Counseling Psychology's rural initiative. The Counseling Psychologist, 22, 183-196.

Borys, D.S. (1994). Maintaining therapeutic boundaries: The motive is therapeutic effectiveness, not defensive practice. Ethics and Behavior, 4, 267-273.

Borys, D.S., \& Pope, K.S. (1989). Dual relationships between therapist and client: A national study of psychologists, psychiatrists, and social workers. Professional Psychology: Research and Practice, 20, 283-293.

Brownlee, K. (1996). The ethics of non-sexual dual relationships: A dilemma for the rural mental health practitioner. Community Mental Health Journal, 32, 497-503.

Campbell, C.D., \& Gordon, M.C. (2003). Acknowledging the inevitable: Understanding multiple relationships in rural practice. Professional Psychology: Research and Practice, 34, 430-434.

Claiborn, W.L. (1982). The problem of professional incompetence. Professional Psychology, 13, 153-158.

Clayton, S., \& Bongar, B. (1994). The use of consultation in psychological practice: Ethical, legal, and clinical considerations. Ethics and Behavior, 4, 43-57.

Cohen, D. (1992). Occupational hazards of the rural psychologist. Psychotherapy in Private Practice, 10(3), 13-35.

Conte, H.R., Plutchik, R., Picard, S., \& Karasu, T.B. (1989). Ethics in the practice of psychotherapy: A survey. American Journal of Psychotherapy, 43, 32-43. 
Cook, A.D., Copans, S.A., \& Schetky, D.H. (1998). Psychiatric treatment of children and adolescents in rural communities. Child and Adolescent Psychiatric Clinics of North America, 7, 673-690.

Coster, J.S., \& Schwebel, M. (1997). Well-functioning in professional psychologists. Professional Psychology: Research and Practice, 28, 5-13.

Coyle, B.R. (1999). Practical tools for rural psychiatric practice. Bulletin of the Menninger Clinic, 63, 202-222.

Deutsch, C.J. (1985). A survey of therapists’ personal problems and treatment. Professional Psychology: Research and Practice, 16, 305-315.

Dupree, P.I., \& Day, H.D. (1995). Psychotherapists' job satisfaction and job burnout as a function of work setting and percentage of managed care clients. Psychotherapy in Private Practice, 14(2), 77-93.

Ebert, B.W. (1997). Dual-relationship prohibitions: A concept whose time never should have come. Applied \& Preventive Psychology, 6, 137-156.

Elkin, B., \& Boyer, P.A. (1987). Practice skills and personal characteristics that facilitate practitioner retention in rural mental health settings. Journal of Rural Community Psychology, 8(1), 30-39.

Epstein, R.S., Simon, R.I. (1990). The exploitation index: An early warning indicator of boundary violations in psychotherapy. Bulletin of the Menninger Clinic, 54, 450465.

Faulkner, K.K., \& Faulkner, T.A. (1997). Managing multiple relationships in rural communities: Neutrality and boundary violations. Clinical Psychology: Science and Practice, 4, 225-234. 
Geczy, F., Sultenfuss, J.F., \& Donat, D.C. (1990). Psychologists in state mental hospitals: Problems and recommendations. Professional Psychology: Research and Practice, 21, 392-397.

Gibson, W.T., \& Pope, K.S. (1993). The ethics of counseling: A national survey of certified counselors. Journal of Counseling and Development, 71, 330-336.

Golden, L., \& Schmidt, S.J. (1998). Unethical practice as perceived by mental health professionals: The next generation. Counseling and Values, 42, 166-170.

Gordon, R.M. (1993). Ethics based on protection of the transference. Issues in Psychoanalytic Psychology, 15(2), 95-106.

Gottlieb, M.C. (1993). Avoiding exploitative dual relationships: A decision-making model. Psychotherapy, 30, 41-48.

Gottlieb, M.C. (1994). Ethical decision making, boundaries, and treatment effectiveness: A reprise. Ethics and Behavior, 4, 287-293.

Gross, D.R., \& Robinson, S.E. (1987). Ethics in counseling: A multiple role perspective. TACD Journal, 15, 5-15.

Gutheil, T.G. (1994). Discussion of Lazarus’s “How certain boundaries and ethics diminish therapeutic effectiveness”. Ethics and Behavior, 4, 295-298.

Gutheil, T.G., \& Gabbard, G.O. (1993). The concept of boundaries in clinical practice: Theoretical and risk management dimensions. American Journal of Psychiatry, 150, 188-196.

Haas, L.J. (1993). Competence and quality in the performance of forensic psychologists. Ethics and Behavior, 3, 251-266. 
Haas, L.J., Malouf, J.L., \& Mayerson, N.H. (1986). Ethical dilemmas in psychological practice: Results of a national survey. Professional Psychology: Research and Practice, 17, 316-321.

Hargrove, D.S. (1982). The rural psychologist as generalist: A challenge for professional identity. Professional Psychology, 13, 302-308.

Hargrove, D.S. (1986). Ethical issues in rural mental health practice. Professional Psychology: Research and Practice, 17, 20-23.

Hargrove, D.S., \& Breazeale, R.L. (1993). Psychologists and rural services:

Addressing and new agenda. Professional Psychology: Research and Practice, 24, 319-324.

Hines, A.H., Ader, D.N., Chang, A.S., \& Rundell, J.R. (1998). Dual agency, dual relationships, boundary crossings and associated boundary violations: A survey of military and civilian psychiatrists. Military Medicine, 163, 826-833.

Holtgraves, T., Eck, J., \& Lasky, B. (1997). Face management, question wording, and social desirability. Journal of Applied Social Psychology, 27, 1650-1671.

Horst, E.A. (1989). Dual relationships between psychologists and clients in rural and urban areas. Journal of Rural Community Psychology, 10(2), 15-24.

Hutt, M. (1981). A survey of two state psychological associations: Reflections and national implications. Clinical Psychologist, 34(3), 4-5,8.

Jennings, F.L. (1992). Ethics of rural practice. Psychotherapy in Private Practice, 10, 85-104.

Johnston, S.H., \& Farber, B.A. (1996). The maintenance of boundaries in psychotherapeutic practice. Psychotherapy, 33, 391-402. 
Keller, P.A., Murray, J.D., Hargrove, D.S., \& Dengerink, H.A. (1983). Issues in training psychologists for rural settings. Journal of Rural Community Psychology, 4(1), 11-23.

Kitchner, K.S. (1988). Dual role relationships: What makes them so problematic? Journal of Counseling and Development, 67, 217-221.

Koeske, G. F., \& Kelly, T. (1995). The impact of overinvolvement on burnout and job satisfaction. American Journal of Orthopsychiatry, 65, 282-292.

Koocher, G.P. (1979). Credentialing in psychology: Close encounters with competence? American Psychologist, 34, 696-702.

Koocher, G.P., \& Keith-Spiegel, P. (1998). Ethics in psychology. New York, N.Y.: Oxford University Press, Inc.

Lamb, D.H. (1999). Addressing impairment and its relationship to professional boundary issues: A response to Forrest, Elman, Gizara, and Vacha-Haase. The Counseling Psychologist, 27, 702-711.

Lamb, D.H., \& Catanzaro, S.J. (1998). Sexual and nonsexual boundary violations involving psychologists, clients, supervisees, and students: Implications for professional practice. Professional Psychology: Research and Practice, 29, 498503.

Lazarus, A.A. (1994). How certain boundaries and ethics diminish therapeutic effectiveness. Ethics and Behavior, 4, 255-261.

Lee, R.T., \& Ashforth, B.E. (1996). A meta-analytic examination of the correlates of the three dimensions of job burnout. Journal of Applied Psychology, 81, 123-133. Martinez-Brawley, E.E. (1986). Beyond cracker-barrel images: The rural social work 
specialty. Social Casework, 67, 101-107.

Maslach, C., \& Florian, V. (1988). Burnout, job setting, and self-evaluation among rehabilitation counselors. Rehabilitation Psychology, 33(2), 85-93.

McCray, B.W., Mcminn, M.R., \& Meek, K.R. (1998). Questioning the "slippery slope": Ethical beliefs and behaviors of private office-based and church based therapists. Counseling and Values, 42, 142-152.

Murray, J.D., \& Keller, P.A. (1991). Psychology and rural America: Current status and future directions. American Psychologist, 46, 220-231.

Percival, G., \& Striefel, S. (1994). Ethical beliefs and practices of AAPB members. Biofeedback and Self-Regulation, 19, 67-93.

Peterson, D.R., \& Bry, B.H. (1980). Dimensions of perceived competence in professional psychology. Professional Psychology, 11, 965-970.

Pomerantz, A., Ross, M.J., Gfeller, J.D., \& Hughes, H. (1998). Ethical beliefs of psychotherapists: Scientific findings. Journal of Contemporary Psychotherapy, 28, $35-44$.

Pope, K.S. (1990). Ethical and malpractice issues in hospital practice. American Psychologist, 45, 1066-1070.

Pope, K.S. (1991). Dual relationships in psychotherapy. Ethics and Behavior, 1, 21-34.

Pope, K.S., \& Tabachnick, B.G. (1994). Therapists as patients: A national survey of psychologists' experiences, problems and beliefs. Professional Psychology: Research and Practice, 25, 247-258. 
Pope, K.S., Tabachnick, B.G., \& Keith-Spiegel, P. (1987). Ethics of practice: The beliefs and behaviors of psychologists as therapists. American Psychologist, 42, 9931006.

Pope, K.S., Tabachnick, B.G., \& Keith-Spiegel, P. (1988). Good and poor practices in psychotherapy: National survey of beliefs of psychologists. Professional Psychology: Research and Practice, 19, 547-552.

Pope, K.S., Tabachnick, B.G., \& Keith-Spiegel, P. (1989). Reply to Koltko. American Psychologist, 43, 846-847.

Pope, K.S., \& Vetter, V.A. (1992). Ethical dilemmas encountered by members of the American Psychological Association: A national survey. American Psychologist, 47, $397-411$.

Rae, W.A., \& Worchel, F.F. (1991). Ethical beliefs and behaviors of pediatric psychologists: A survey. Journal of Pediatric Psychology, 16, 727-745.

Raquepaw, J.M., \& Miller, R.S. (1989). Psychotherapist burnout: A componential analysis. Professional Psychology: Research and Practice, 20, 32-36.

Reed, D.A. (1992). Adaptation: The key to community psychiatric practice in the rural setting. Community Mental Health Journal, 28, 141-150.

Ricketts, T.C., Johnson-Webb, K.D., \& Taylor, P. (1998). Definitions of rural: A handbook for health policy makers and researchers. Bethesda, MD: Office of Rural Health Policy.

Roberts, L.W., Battaglia, J., \& Epstein, R.S. (1999). Frontier ethics: Mental health care needs and ethical dilemmas in rural communities. Psychiatric Services, 50, 497-503. 
Ross, R.R., Altmaier, E.M., \& Russell, D.W. (1989). Job stress, social support, and burnout among counseling center staff. Journal of Counseling Psychology, 36, 464-470.

Savicki, V., \& Cooley, E. (1987). The relationship of work environment and client contact to burnout in mental health professionals. Journal of Counseling and Development, 65, 249-252.

Schank, J.A. (1998). Ethical issues in rural counselling practice. Canadian Journal of Counselling, 32, 270-283.

Schank, J.A., \& Skovholt, T.M. (1997). Dual-relationship dilemmas of rural and small town psychologists. Professional Psychology: Research and Practice, 28, 4449.

Sears, S.F., Evans, G.D., \& Perry, N.W. (1998). Innovations in training: The University of Florida rural psychology program. Professional Psychology: Research and Practice, 29, 504-507.

Sharkin, B.S., \& Birky, I. (1992). Incidental encounters between therapists and their clients. Professional Psychology: Research and Practice, 23, 326-328.

Shore, M.F., \& Golann, S.E. (1969). Problems of ethics in community mental health: A survey of community psychologists. Community Mental Health Journal, 5, 452460.

Skorupa, J., \& Agresti, A.A. (1993). Ethical beliefs about burnout and continued professional practice. Professional Psychology: Research and Practice, 24, 281285. 
Sladen, B.J., \& Mozdzierz, G.J. (1989). Distribution of psychologists in underserved areas: Changes over time, 1970-1981. Professional Psychology: Research and Practice, 20, 244-247.

Smith, D., \& Fitzpatrick, M. (1995). Patient-therapist boundary issues: An integrative review of theory and research. Professional Psychology: Research and Practice, 26, 499-506.

Sobel, S.B. (1984). Independent practice in child and adolescent psychotherapy in small communities: Personal, professional, and ethical issues. Psychotherapy, 21, $110-117$.

Sobel, S.B. (1992). Small town practice of psychotherapy: Ethical and personal dilemmas. Psychotherapy in Private Practice, 10(3), 61-69.

Sonne, J.L. (1994). Multiple relationships: Does the new ethics code answer the right questions? Professional Psychology: Research and Practice, 25, 336-343.

Spiegel, P.B. (1990). Confidentiality endangered under some circumstances without special management. Psychotherapy, 27, 636-643.

Solomon, G., Hiesberger, J., \& Winer, J. (1981). Confidentiality issues in rural community mental health. Journal of Rural Community Psychology, 2(1), 17-31.

Sterling, D.L. (1992). Practicing rural psychotherapy: Complexity of role and boundary. Psychotherapy in Private Practice, 10(3), 105-127.

Stockman, A.F. (1990). Dual relationships in rural mental health practice: An ethical dilemma. Journal of Rural Community Psychology, 11(2), 31-45.

Street, E., \& Rivett, M. (1996). Stress and coping in the practice of family therapy: A British survey. Journal of Family Therapy, 18, 303-319. 
Sullivan, W.P., Hasler, M.D., \& Otis, A.G. (1993). Rural mental health practice:

Voices from the field. Families in Society, 74, 493-502.

Sundet, P.A., \& Mermelstein, J. (1983). The meaning of community in rural mental health. International Journal of Mental Health, 12, 25-44.

Tabachnick, B.G., Keith-Spiegel, P., \& Pope, K.S. (1991). Ethics of teaching: Beliefs and behaviors of psychologists as educators. American Psychologist, 46, 506-515.

Tarvydas, V.M., Leahy, M.J., Saunders, J.L., Chan, F., Thielsen, V.A., \& Murray, G. (2001). Beliefs about the ethics of practice among CRCs: A national survey. Journal of Applied Rehabilitation Counseling, 32(2), 9-18.

Thorenson, R.W., Miller, M., \& Krauskopf, C.J. (1989). The distressed psychologist: Prevalence and treatment considerations. Professional Psychology: Research and Practice, 20, 153-158.

Tubbs, P., \& Pomerantz, A.M. (2001). Ethical behaviors of psychologists: Changes since 1987. Journal of Clinical Psychology, 57, 395-399.

Venier, K. (1998). Confidentiality and therapeutic practice. British Journal of Psychotherapy, 15, 229-239.

Wagenfeld, M.O. (1988). Rural mental health and community psychology in the post community mental health era: An overview and introduction to the special issue. Journal of Rural Community Psychology, 9(2), 5-11.

Wagenfeld, M.O., \& Buffum, W.E. (1983). Problems in, and prospects for, rural mental health services in the United States. International Journal of Mental Health, 12(1-2), 89-107. 
Weiner, I.B. (1989). On competence and ethicality in psychodiagnostic assessment. Journal of Personality Assessment, 53, 827-831.

Whyte, C. (1994). Competencies. British Journal of Psychotherapy, 10, 568-569.

Wilcoxon, S.A. (1989). Leadership behavior and therapist burnout: A study of rural agency settings. Journal of Rural Community Psychology, 10(2), 3-13.

Williams, M.H. (1997). Boundary violations: Do some contended standards of care fail to encompass commonplace procedures of humanistic, behavioral, and eclectic psychotherapies? Psychotherapy, 34, 238-249.

Wood, K.A., Rogers, J.H., McCarthy, S.M., \& Lewine, R.R.J. (1994). Psychologists in public inpatient psychiatric settings: Ethical dilemmas. Professional Psychology: Research and Practice, 25, 234-240. 
Rural Ethics 178

APPENDIX A 
September 25, 2002

Dear Colleague:

My name is Craig M. Helbok, I am a doctoral candidate in counseling psychology at the West Virginia University. I am conducting research on the types of situations and experiences encountered by psychologists in a variety of population areas such as urban, suburban, small towns, and rural areas. In my research, and from anecdotal reports, psychologists have quite different experiences working in each of these different population densities. I hope that my research will inform the practice of psychology by gathering data on how population density interacts with the practice of psychology.

I am requesting your help in gathering data on a variety of practice issues. Enclosed is a questionnaire that should take you only 20-30 minutes to complete. This questionnaire has been reviewed by several expert reviewers, and has been used by this researcher in a pilot study. Your participation in this study is entirely voluntary, and your return of the survey will indicate informed consent. Although complete data sets are my goal, you are free to not answer any of the individual questions in the survey. Please feel free to make any comments on the questions in the space provided at the end of the survey.

As you know, a high return rate and honest answers on the survey are of utmost importance in gathering baseline data. Your responses will be kept entirely confidential. The survey itself will have an identification number, which will be matched with the list of names in order to determine which surveys have been returned. Once the data have been gathered, in approximately eight weeks, the list of names will be destroyed by this researcher. There is only one copy of the list, and no other person will have access to it from now until it is destroyed. This survey is a part of this researcher's dissertation. I will be happy to send you a summary of the results of this study, just tear off the bottom of this sheet, include a name and address, and return it with the survey. Your name and address will be kept separate and in no way identified with your survey responses.

Thank you very much for taking the time to complete this survey and for participating in the study. If you choose not to participate, please return the blank survey so you will not receive any follow-up notices. I do believe this is important and highly salient research for the practice of psychology, and that it addresses issues that have been raised in the literature over the last decade. Again, thank you for your time.

Sincerely,

Craig M. Helbok, M.S., CRC, NCAC

Doctoral Candidate, West Virginia University

Enclosed are my completed survey materials. I would like to have a summary of your results.

My name and address are:

Correspondence may be addressed to:

\begin{tabular}{ll}
\hline Craig M. Helbok & Dissertation Chairperson \\
P.O. Box 83 . & Robert P. Marinelli, Ed.D. \\
Morgantown, WV 26507 & Dept. of Counseling, Rehabilitation Counseling, \& Counseling Psychology \\
chelbok@hsc.wvu.edu & P.O. Box 6122 \\
(304) 292-8956 & Morgantown, WV 26505-6122
\end{tabular}


Rural Ethics 180

APPENDIX B 


\section{SURVEY OF PSYCHOLOGICAL PRACTICES}

\section{ACROSS RURAL AND URBAN COMMUNITIES}

The following survey is a series of questions about the experiences you encounter in your day to day practice. The purpose of this survey is to examine actual practices and behaviors. In order to create an honest discussion about the practice of psychology, in urban and rural areas, it is important to obtain accurate baselines of the kinds of situations psychologists do encounter. Therefore, please answer each question as accurately and honestly as possible. The entire survey should only take you 25-30 minutes.

It is sometimes difficult to answer closed-ended questions about practices that involve complex issues and decisions. For example, sometimes agency or supervisory demands outweigh personal preferences. Therefore, space is provided at the end of the survey to make any comments on individual questions, or to relate personal experiences. Any comments you have time to make will be greatly appreciated. 
Please circle only one response for each question

\section{Primary work setting:}
a. Private practice-solo
b. Private practice-group
c. Hospital
d. University / Academics
e. Inpatient Facility
f. Mental Health Center
g. Other:

\section{Current work community}
a. Urban area (pop 50,000 +)
b. Suburban area (20,000-49,999)
c. Small town $(10,000-19,999)$
d. Rural Community (pop<10,000)

\section{Highest Degree:}
a. B.S. or B.A.
b. M.S. / M.A.
c. Ed.D.
d. Ph.D.
e. Psy.D.
f. Other:

\section{Area of Study:}
a. Clinical Psychology
b. Counseling Psychology
c. Experiential Psychology
d. I/O Psychology
e. School Psychology
f. Other:

5. Current Orientation:
a. Psychodynamic
b. Behavioral
c. Cognitive-Behavioral
d. Humanistic
e. Gestalt
f. Eclectic
g. Other:

6. Race/Ethnicity:
a. African American
b. Native American
c. Asian
d. Caucasian
e. Hispanic/Latino
f. Pacific Islander
g. Other:

\section{Relationship Status:}
a. Married
b. Remarried
c. Single
d. Divorced
e. Separated
f. Widow
g. Cohabitating
h. Other:

\section{Gender:}

a. Female

b. Male

9. Your Age:

10. What city (or town) and state do you live in?

11. What city (or town) and state do you work in?

12. Do you live in the same community in which you work? yes / no

13. Number of years in current work setting:

14. Number of years since graduating with current degree:

15. Was your program of study APA accredited? yes / no

16. Are you a licensed psychologist? yes / no

17. Number of years experience as a psychologist:

18. Number of years experience in a related field: Specify job title:

19. How many hours a week do you see clients for therapy? 
Please rate the frequency of occurrence of each of the following situations in your practice by circling your response. If the behavior does not apply to your setting, please circle " 0 " for Not Applicable. Then, in the last column, please place a check " $\sqrt{ }$ " if the behavior or situation is a concern for you (leave blank if you are not concerned about the behavior). Please be honest in your responses, all questionnaires will be kept confidential.

\begin{tabular}{|c|c|c|c|c|c|c|c|}
\hline & Never & Rarely & $\begin{array}{l}\text { Some } \\
\text { times }\end{array}$ & $\begin{array}{l}\text { Fairly } \\
\text { Often }\end{array}$ & Often & N/A & $\begin{array}{l}\sqrt{ } \text { if a } \\
\text { concern } \\
\end{array}$ \\
\hline 1. Read professional journals related to your practice & 1 & 2 & 3 & 4 & 5 & 0 & \\
\hline 2. Charge a client no fee for therapy & 1 & 2 & 3 & 4 & 5 & 0 & \\
\hline 3. Provide therapy to one of your friends & 1 & 2 & 3 & 4 & 5 & 0 & \\
\hline 4. Refer clients to other specialists in the field of psychology & 1 & 2 & 3 & 4 & 5 & 0 & \\
\hline 5. Feel you have control over your work environment & 1 & 2 & 3 & 4 & 5 & 0 & \\
\hline 6. Provide therapy to a relative of a friend & 1 & 2 & 3 & 4 & 5 & 0 & \\
\hline 7. Provide therapy to an employee or coworker & 1 & 2 & 3 & 4 & 5 & 0 & \\
\hline 8. Accept goods or services in lieu of a fee & 1 & 2 & 3 & 4 & 5 & 0 & \\
\hline 9. Work on the same committee in the community as a client does & 1 & 2 & 3 & 4 & 5 & 0 & \\
\hline 10. Use self-disclosure as a therapeutic technique & 1 & 2 & 3 & 4 & 5 & 0 & \\
\hline 11. Invite clients to an open house & 1 & 2 & 3 & 4 & 5 & 0 & \\
\hline 12. Accept a client's gift worth at least $\$ 50$ & 1 & 2 & 3 & 4 & 5 & 0 & \\
\hline 13. Request favors from a client & 1 & 2 & 3 & 4 & 5 & 0 & \\
\hline 14. Have the opportunity to use your own initiative and creativity at work & 1 & 2 & 3 & 4 & 5 & 0 & \\
\hline 15. Attend a client's special event (i.e. wedding, graduation) & 1 & 2 & 3 & 4 & 5 & 0 & \\
\hline 16. Receive emotional support from a supervisor or mentor & 1 & 2 & 3 & 4 & 5 & 0 & \\
\hline $\begin{array}{l}\text { 17. Purchase goods or services from a place of business where a client } \\
\text { works }\end{array}$ & 1 & 2 & 3 & 4 & 5 & 0 & \\
\hline 18. Work with a client in a community setting (PTA, Church group) & 1 & 2 & 3 & 4 & 5 & 0 & \\
\hline 19. Accept a gift worth less than $\$ 20$ from a client & 1 & 2 & 3 & 4 & 5 & 0 & \\
\hline 20. Discuss a client with a psychologist colleague, without informed consent & 1 & 2 & 3 & 4 & 5 & 0 & \\
\hline 21. Consult with peers/colleagues on difficult cases & 1 & 2 & 3 & 4 & 5 & 0 & \\
\hline 22. Feel you don't do enough to help your clients & 1 & 2 & 3 & 4 & 5 & 0 & \\
\hline 23. Provide individual therapy to a lover of an ongoing client & 1 & 2 & 3 & 4 & 5 & 0 & \\
\hline
\end{tabular}




\begin{tabular}{|c|c|c|c|c|c|c|c|}
\hline & Never & Rarely & $\begin{array}{l}\text { Some } \\
\text { times }\end{array}$ & $\begin{array}{l}\text { Fairly } \\
\text { Often }\end{array}$ & Often & N/A & $\begin{array}{l}\sqrt{\text { if a }} \\
\text { concern } \\
\end{array}$ \\
\hline 24. Provide therapy to a child of one of your friends & 1 & 2 & 3 & 4 & 5 & 0 & \\
\hline 25. Become social friends with parents of a former client & 1 & 2 & 3 & 4 & 5 & 0 & \\
\hline $\begin{array}{l}\text { 26. Find yourself working with two clients who happen to have a } \\
\text { relationship with each other }\end{array}$ & 1 & 2 & 3 & 4 & 5 & 0 & \\
\hline $\begin{array}{l}\text { 27. Sometimes have to take clients that have problems that are beyond } \\
\text { your scope of training and experience }\end{array}$ & 1 & 2 & 3 & 4 & 5 & 0 & \\
\hline 28. Provide therapy to a relative of an ongoing client & 1 & 2 & 3 & 4 & 5 & 0 & \\
\hline 29. Attend a party or social gathering and run into a client & 1 & 2 & 3 & 4 & 5 & 0 & \\
\hline $\begin{array}{l}\text { 30. Find that your children have become friends with a client or a client's } \\
\text { children }\end{array}$ & 1 & 2 & 3 & 4 & 5 & 0 & \\
\hline 31. Meet with peers to discuss clinical casework & 1 & 2 & 3 & 4 & 5 & 0 & \\
\hline $\begin{array}{l}\text { 32. Provide therapy to a client with whom you have had a previous social } \\
\text { relationship }\end{array}$ & 1 & 2 & 3 & 4 & 5 & 0 & \\
\hline 33.. Discuss clients with friends, without using client names & 1 & 2 & 3 & 4 & 5 & 0 & \\
\hline 34. Provide therapy to a fellow coworker & 1 & 2 & 3 & 4 & 5 & 0 & \\
\hline 35. Loan books or other personal possessions to a client & 1 & 2 & 3 & 4 & 5 & 0 & \\
\hline $\begin{array}{l}\text { 36. Have to administer assessments or psychological tests you do not feel } \\
\text { adequately trained to give }\end{array}$ & 1 & 2 & 3 & 4 & 5 & 0 & \\
\hline 37. Work allows you to reach goals you have set for yourself & 1 & 2 & 3 & 4 & 5 & 0 & \\
\hline $\begin{array}{l}\text { 38. Have cases where more referral sources for your client would have } \\
\text { been helpful in your work (i.e. other community agencies) }\end{array}$ & 1 & 2 & 3 & 4 & 5 & 0 & \\
\hline $\begin{array}{l}\text { 39. Provide therapy to a client whose diagnosis is outside your area of } \\
\text { competence }\end{array}$ & 1 & 2 & 3 & 4 & 5 & 0 & \\
\hline 40. Find it difficult to keep a clear boundary between home and work life & 1 & 2 & 3 & 4 & 5 & 0 & \\
\hline 41. Consult with specialists within the field of psychology & 1 & 2 & 3 & 4 & 5 & 0 & \\
\hline 42. Discuss a client with a physician without informed consent & 1 & 2 & 3 & 4 & 5 & 0 & \\
\hline $\begin{array}{l}\text { 43. Take continuing education classes on areas of psychology that are of } \\
\text { interest to you }\end{array}$ & 1 & 2 & 3 & 4 & 5 & 0 & \\
\hline $\begin{array}{l}\text { 44. Observe other therapists provide services outside their area of } \\
\text { competence }\end{array}$ & 1 & 2 & 3 & 4 & 5 & 0 & \\
\hline 45. Discuss theory and the practice of psychology with colleagues & 1 & 2 & 3 & 4 & 5 & 0 & \\
\hline
\end{tabular}




\begin{tabular}{|c|c|c|c|c|c|c|c|}
\hline & Never & Rarely & $\begin{array}{l}\text { Some } \\
\text { Times }\end{array}$ & $\begin{array}{l}\text { Fairly } \\
\text { Often }\end{array}$ & Often & N/A & $\begin{array}{l}\sqrt{\text { if a }} \\
\text { concern } \\
\end{array}$ \\
\hline 46. Run into your clients in the community & 1 & 2 & 3 & 4 & 5 & 0 & \\
\hline $\begin{array}{l}\text { 47. Discuss a client with other non-mental health professionals without } \\
\text { informed consent }\end{array}$ & 1 & 2 & 3 & 4 & 5 & 0 & \\
\hline 48. Socialize with a client after terminating therapy & 1 & 2 & 3 & 4 & 5 & 0 & \\
\hline 49. Work on the same committee with a former client & 1 & 2 & 3 & 4 & 5 & 0 & \\
\hline 50. Receive emotional support from colleagues & 1 & 2 & 3 & 4 & 5 & 0 & \\
\hline 51. Provide regularly scheduled clinical services via the telephone & 1 & 2 & 3 & 4 & 5 & 0 & \\
\hline $\begin{array}{l}\text { 52. Not be able to refer clients because of a lack of psychological referral } \\
\text { services }\end{array}$ & 1 & 2 & 3 & 4 & 5 & 0 & \\
\hline 53. Refer clients after finding that the client is not making any progress & 1 & 2 & 3 & 4 & 5 & 0 & \\
\hline 54. Become social friends with a former client & 1 & 2 & 3 & 4 & 5 & 0 & \\
\hline $\begin{array}{l}\text { 55. Find that your ethical beliefs and practices conflict with those of } \\
\text { other professionals with whom you work }\end{array}$ & 1 & 2 & 3 & 4 & 5 & 0 & \\
\hline 56. Have time to devote to professional development & 1 & 2 & 3 & 4 & 5 & 0 & \\
\hline 57. Provide therapy to a friend of an employee & 1 & 2 & 3 & 4 & 5 & 0 & \\
\hline $\begin{array}{l}\text { 58. Obtain regular training and supervision on new techniques and clinical } \\
\text { skills }\end{array}$ & 1 & 2 & 3 & 4 & 5 & 0 & \\
\hline $\begin{array}{l}\text { 59. Have the opportunity to discuss problems in the work environment } \\
\text { with peers }\end{array}$ & 1 & 2 & 3 & 4 & 5 & 0 & \\
\hline $\begin{array}{l}\text { 60. Consult colleagues on special cases that may be beyond your scope of } \\
\text { competence }\end{array}$ & 1 & 2 & 3 & 4 & 5 & 0 & \\
\hline 61. Receive constructive feedback from supervisors & 1 & 2 & 3 & 4 & 5 & 0 & \\
\hline 62. Receive constructive feedback from colleagues or coworkers & 1 & 2 & 3 & 4 & 5 & 0 & \\
\hline 63. Confer with another non-psychology professional on a difficult case & 1 & 2 & 3 & 4 & 5 & 0 & \\
\hline 64. Know colleagues who practice beyond their scope of training & 1 & 2 & 3 & 4 & 5 & 0 & \\
\hline 65. Receive technical support from supervisors or coworkers & 1 & 2 & 3 & 4 & 5 & 0 & \\
\hline 66. Doubt your abilities as a therapist & 1 & 2 & 3 & 4 & 5 & 0 & \\
\hline 67. Unintentionally disclose confidential client information & 1 & 2 & 3 & 4 & 5 & 0 & \\
\hline $\begin{array}{l}\text { 68. Feel frustrated with the lack of alternative resources to help your } \\
\text { clients }\end{array}$ & 1 & 2 & 3 & 4 & 5 & 0 & \\
\hline
\end{tabular}




\begin{tabular}{|c|c|c|c|c|c|c|c|c|}
\hline & & Never & Rarely & $\begin{array}{l}\text { Some } \\
\text { times }\end{array}$ & $\begin{array}{l}\text { Fairly } \\
\text { Often }\end{array}$ & Often & N/A & $\begin{array}{l}\sqrt{\text { if a }} \\
\text { concern } \\
\end{array}$ \\
\hline & $\begin{array}{l}\text { Have to treat populations (children, ethnic groups) for which you do not } \\
\text { feel you have adequate training }\end{array}$ & 1 & 2 & 3 & 4 & 5 & 0 & \\
\hline & Feel supported in your work environment & 1 & 2 & 3 & 4 & 5 & 0 & \\
\hline & $\begin{array}{l}\text { Provide therapy to a client whom you know of from being in the same } \\
\text { social sphere }\end{array}$ & 1 & 2 & 3 & 4 & 5 & 0 & \\
\hline & Socialize with your own friends outside of your work sphere & 1 & 2 & 3 & 4 & 5 & 0 & \\
\hline & Work when too distressed to be effective & 1 & 2 & 3 & 4 & 5 & 0 & \\
\hline & Disclose details of a current personal stressor to a client & 1 & 2 & 3 & 4 & 5 & 0 & \\
\hline & Feel you have control over the types of clients you see & 1 & 2 & 3 & 4 & 5 & 0 & \\
\hline & Discuss the ethics of practice with colleagues & 1 & 2 & 3 & 4 & 5 & 0 & \\
\hline & Find your work to be personally satisfying & 1 & 2 & 3 & 4 & 5 & 0 & \\
\hline & Have a current or former client become employed in your agency & 1 & 2 & 3 & 4 & 5 & 0 & \\
\hline & Find your work to be professionally satisfying & 1 & 2 & 3 & 4 & 5 & 0 & \\
\hline & Take work home with you to complete & 1 & 2 & 3 & 4 & 5 & 0 & \\
\hline & Emotionally, or mentally, take your work home with you & 1 & 2 & 3 & 4 & 5 & 0 & \\
\hline & Find yourself feeling responsible for your client’s well-being & 1 & 2 & 3 & 4 & 5 & 0 & \\
\hline & Provide therapy to a friend of a current client & 1 & 2 & 3 & 4 & 5 & 0 & \\
\hline & Feel you have control over what you do during your work day & 1 & 2 & 3 & 4 & 5 & 0 & \\
\hline 85. & Receive emotional support from coworkers & 1 & 2 & 3 & 4 & 5 & 0 & \\
\hline 86. & Go into business with a former client & 1 & 2 & 3 & 4 & 5 & 0 & \\
\hline & $\begin{array}{l}\text { Find yourself working with a client who discusses problems with a } \\
\text { person who is also your client }\end{array}$ & 1 & 2 & 3 & 4 & 5 & 0 & \\
\hline 88. & Purchase goods or services from a client & 1 & 2 & 3 & 4 & 5 & 0 & \\
\hline 89. & Feel that you are working harder for change than your clients & 1 & 2 & 3 & 4 & 5 & 0 & \\
\hline & Receive emotional support from family and friends & 1 & 2 & 3 & 4 & 5 & 0 & \\
\hline & Do not seek counseling for yourself due to a lack of time & 1 & 2 & 3 & 4 & 5 & 0 & \\
\hline & Establish clear boundaries between your work and personal life & 1 & 2 & 3 & 4 & 5 & 0 & \\
\hline 93. & Accept a client's invitation to a party & 1 & 2 & 3 & 4 & 5 & 0 & \\
\hline
\end{tabular}




\begin{tabular}{|c|c|c|c|c|c|c|c|}
\hline & Never & Rarely & $\begin{array}{l}\text { Some } \\
\text { times }\end{array}$ & $\begin{array}{l}\text { Fairly } \\
\text { Often }\end{array}$ & Often & N/A & $\begin{array}{l}\sqrt{ } \text { if a } \\
\text { concern } \\
\end{array}$ \\
\hline $\begin{array}{l}\text { 94. Do not seek counseling because you feel too well-known by all of } \\
\text { the therapists near your home and work }\end{array}$ & 1 & 2 & 3 & 4 & 5 & 0 & \\
\hline 95. Seek informal support such as from a pastor or minister & 1 & 2 & 3 & 4 & 5 & 0 & \\
\hline 96. Seek counseling from another therapist & 1 & 2 & 3 & 4 & 5 & 0 & \\
\hline 97. Prepare clients for chance encounters in the community & 1 & 2 & 3 & 4 & 5 & 0 & \\
\hline 98. Support staff you work with receive training in confidentiality issues & 1 & 2 & 3 & 4 & 5 & 0 & \\
\hline 99. Attend workshops on ethics & 1 & 2 & 3 & 4 & 5 & 0 & \\
\hline 100. Discuss clients with friends, using client names & 1 & 2 & 3 & 4 & 5 & 0 & \\
\hline 101. Feel unprepared for the work you do with clients & 1 & 2 & 3 & 4 & 5 & 0 & \\
\hline $\begin{array}{l}\text { 102. Discuss clients with referring agencies, or the person who referred the } \\
\text { client, without informed consent }\end{array}$ & 1 & 2 & 3 & 4 & 5 & 0 & \\
\hline $\begin{array}{l}\text { 103. Have processed, during therapy, a chance encounter you have had with } \\
\text { a client }\end{array}$ & 1 & 2 & 3 & 4 & 5 & 0 & \\
\hline $\begin{array}{l}\text { 104. Have to use treatment approaches for which you have not had adequate } \\
\text { training or experience }\end{array}$ & 1 & 2 & 3 & 4 & 5 & 0 & \\
\hline $\begin{array}{l}\text { 105. Discuss a client with other mental health professionals without } \\
\text { informed consent }\end{array}$ & 1 & 2 & 3 & 4 & 5 & 0 & \\
\hline 106. Dine with a client after a session & 1 & 2 & 3 & 4 & 5 & 0 & \\
\hline $\begin{array}{l}\text { 107. Discuss with clients how to deal with a situation where you may run } \\
\text { into each other in public }\end{array}$ & 1 & 2 & 3 & 4 & 5 & 0 & \\
\hline 108. Hesitate to break confidentiality because families are known to you & 1 & 2 & 3 & 4 & 5 & 0 & \\
\hline $\begin{array}{l}\text { 109. Felt uncomfortable acknowledging a client when seeing them in } \\
\text { the community }\end{array}$ & 1 & 2 & 3 & 4 & 5 & 0 & \\
\hline $\begin{array}{l}\text { 110. Unintentionally learn information about a client from other resources } \\
\text { or people in the community (i.e. social conversations with others) }\end{array}$ & 1 & 2 & 3 & 4 & 5 & 0 & \\
\hline 111. Feel that you are a therapist 24 hours a day & 1 & 2 & 3 & 4 & 5 & 0 & \\
\hline 112. Discuss specific ethical dilemmas with colleagues & 1 & 2 & 3 & 4 & 5 & 0 & \\
\hline 113. Attend the same church as a client & 1 & 2 & 3 & 4 & 5 & 0 & \\
\hline 114. See your clients in restaurants & 1 & 2 & 3 & 4 & 5 & 0 & \\
\hline
\end{tabular}


Rural Ethics 188

\begin{tabular}{|c|c|c|c|c|c|c|c|}
\hline & Never & Rarely & $\begin{array}{l}\text { Some } \\
\text { Times }\end{array}$ & $\begin{array}{l}\text { Fairly } \\
\text { Often }\end{array}$ & Often & N/A & $\frac{\sqrt{ } \text { if a }}{\text { concern }}$ \\
\hline 115. Have accepted an offer of a handshake from a client & 1 & 2 & 3 & 4 & 5 & 0 & \\
\hline $\begin{array}{l}\text { 116. Have clients who know more about your personal life than you would } \\
\text { prefer they knew }\end{array}$ & 1 & 2 & 3 & 4 & 5 & 0 & \\
\hline $\begin{array}{l}\text { 117. Belong to or join the same club or community organization as a } \\
\text { former client (i.e. political, religious, social, athletic) }\end{array}$ & 1 & 2 & 3 & 4 & 5 & 0 & \\
\hline $\begin{array}{l}\text { 118. Participate in the same neighborhood activity as a client (i.e. } \\
\text { fundraiser, community project) }\end{array}$ & 1 & 2 & 3 & 4 & 5 & 0 & \\
\hline 119. Receive support from a supervisory or mentoring relationship & 1 & 2 & 3 & 4 & 5 & 0 & \\
\hline $\begin{array}{l}\text { 120. Have a client become aware of a personal stressor in your life from a } \\
\text { source other than yourself }\end{array}$ & 1 & 2 & 3 & 4 & 5 & 0 & \\
\hline
\end{tabular}

121. Please use this space to comment on any experiences you have had related to the content of this survey. You may also use this space to make clarifications on any of the above questions. Thank you very much for taking the time to complete this survey, any comments will be greatly appreciated. 